\title{
Nano-enhanced biolubricant in sustainable manufacturing: From processability to mechanisms
}

\author{
Yanbin ZHANG ${ }^{1, \uparrow}$, Hao Nan $\mathrm{LI}^{2, \dagger}$, Changhe $\mathrm{LI}^{1,{ }^{*}}$, Chuanzhen HUANG ${ }^{3}$, Hafiz Muhammad ALI ${ }^{4}$, Xuefeng $\mathrm{XU}^{5}$, \\ Cong MAO ${ }^{6}$, Wenfeng DING ${ }^{7}$, Xin CUI ${ }^{1}$, Min YANG ${ }^{1}$, Tianbiao YU $^{8}$, Muhammad JAMIL $^{9}$, Munish Kumar GUPTA ${ }^{10}$, \\ Dongzhou JIA ${ }^{11}$, Zafar SAID ${ }^{12 *}$ \\ ${ }^{I}$ School of Mechanical and Automotive Engineering, Qingdao University of Technology, Qingdao 266520, China \\ ${ }^{2}$ School of Aerospace, University of Nottingham Ningbo China, Ningbo 315100, China \\ ${ }^{3}$ School of Mechanical Engineering, Yanshan University, Qinhuangdao 066004, China \\ ${ }^{4}$ Mechanical Engineering Department, King Fahd University of Petroleum and Minerals, Dhahran 31261, Saudi Arabia \\ ${ }^{5}$ Key Laboratory of Special Purpose Equipment and Advanced Processing Technology, Ministry of Education \& Zhejiang Province, \\ Zhejiang University of Technology, Hangzhou 310032, China \\ ${ }^{6}$ College of Automotive and Mechanical Engineering, Changsha University of Science and Technology, Changsha 410114, China \\ ${ }^{7}$ College of Mechanical and Electrical Engineering, Nanjing University of Aeronautics and Astronautics, Nanjing 210016, China \\ ${ }^{8}$ School of Mechanical Engineering \& Automation, Northeastern University, Shenyang 110006, China \\ ${ }^{9}$ Industrial Engineering Department, University of Engineering and Technology Taxila, Taxila 47080, Pakistan \\ ${ }^{10}$ School of Mechanical Engineering, Shandong University, Jinan 250061, China \\ ${ }^{11}$ College of Mechanical Engineering and Automation, Liaoning University of Technology, Jinzhou 121001, China \\ ${ }^{12}$ College of Engineering, University of Sharjah, Sharjah 27272, United Arab Emirates \\ Received: 18 February 2021 / Revised: 22 April 2021 / Accepted: 11 June 2021 \\ (C) The author(s) 2021.
}

\begin{abstract}
To eliminate the negative effect of traditional metal-working fluids and achieve sustainable manufacturing, the usage of nano-enhanced biolubricant (NEBL) is widely researched in minimum quantify lubrication (MQL) machining. It's improved tool wear and surface integrity have been preliminarily verified by experimental studies. The previous review papers also concluded the major influencing factors of processability including nano-enhancer and lubricant types, NEBL concentration, micro droplet size, and so on. Nevertheless, the complex action of NEBL, from preparation, atomization, infiltration to heat transfer and anti-friction, is indistinct which limits preparation of process specifications and popularity in factories. Especially in the complex machining process, in-depth understanding is difficult and meaningful. To fill this gap, this paper concentrates on the comprehensive quantitative assessment of processability based on tribological, thermal, and machined surface quality aspects for NEBL application in turning, milling, and grinding. Then it attempts to answer mechanisms systematically considering multi-factor influence of molecular structure, physicochemical properties, concentration, and dispersion. Firstly, this paper reveals advanced lubrication and heat transfer mechanisms of NEBL by quantitative comparison with biolubricant-based MQL machining. Secondly, the distinctive filmformation, atomization, and infiltration mechanisms of NEBL, as distinguished from metal-working fluid, are clarified combining with its unique molecular structure and physical properties. Furtherly, the process optimization strategy is concluded based on the synergistic relationship analysis among process variables, physicochemical properties, machining mechanisms, and performance of NEBL. Finally, the future development directions are put forward aiming at current performance limitations of NEBL, which requires improvement on preparation and jet methods respects. This paper will help scientists deeply understand effective mechanism, formulate process specifications, and find future development trend of this technology.
\end{abstract}

Keywords: nano-enhanced biolubricant (NEBL); sustainable manufacturing; minimum quantity lubrication (MQL); tribological properties; machining mechanisms

$\uparrow$ Yanbin ZHANG and Hao Nan LI contributed equally to this work.

* Corresponding authors: Changhe LI, E-mail: sy_lichanghe@163.com; Zafar SAID, E-mail: zsaid@sharjah.ac.ae 


\begin{tabular}{|c|c|c|c|}
\hline \multicolumn{4}{|c|}{ Nomenclature } \\
\hline NEBL & Nano-enhanced biolubricant & BMQL & Biolubricant-based minimum quantify \\
\hline MQL & Minimum quantify lubrication & & lubrication \\
\hline GHG & Greenhouse gas & SDGs & Sustainability development goals \\
\hline PCD & Polycrystalline diamond & $\mathrm{HBN}$ & Hexagonal boron nitride \\
\hline CNTs & Carbon nanotubes & GR & Graphene \\
\hline $\mathrm{RS}_{\mathrm{m}}$ & Average width of the profile $(\mu \mathrm{m})$ & $\mathrm{R}_{\mathrm{a}}$ & Arithmetical mean deviation of the profile $(\mu \mathrm{m})$ \\
\hline $\mathrm{CoF}$ & Coefficient of friction & $\mathrm{R}_{\mathrm{z}}$ & Maximum height of the profile $(\mu \mathrm{m})$ \\
\hline MWFs & Metal-working fluids & $\mathrm{C}=\mathrm{C}$ & Carbon-carbon double bond \\
\hline VB & Flank wear $(\mu \mathrm{m})$ & PBLC & Performance between lubrication and cooling \\
\hline SEM & Scanning electron microscope & APE-10 & Alkylphenol polyoxyethylene ether 10 \\
\hline EDS & Energy dispersive spectrometer & SDS & Sodium dodecyl sulfate \\
\hline$-\mathrm{OH}$ & Hydroxyl group & $-\mathrm{COOH}$ & Carboxyl group \\
\hline
\end{tabular}

\section{Introduction}

\subsection{Background}

Limited nature resources and severe environmental issues human beings are facing with at the moment inherently drive the need of sustainable manufacturing in nearly all the industries, from aerospace, marine, automobile engineering, via energy, to optics and electronics. This can not only be clearly evidenced by the emphasized from national strategy of manufacturing industry (e.g., SDGs, Germany Industry 4.0 and Made in China 2025) [1], but also be enforced by carbon emission standards (e.g., ISO 14064 and GHG Protocol).
Manufacturers therefore must adapt to existing policies and laws by minimization of machining-induced environmental contamination.

Traditional metal-working fluids (MWFs), which are prepared by non-renewable minerals and scarce water, are necessity in manufacturing industry for hundreds of years [2]. However, it's also the core of machining-induced contamination due to the following environmental, health, and economic issues (Fig. 1): (i) The usage and disposal of non-degradable MWFs would lead to environmental pollution [3], the death of freshwater organisms, and eutrophication of water resources; (ii) compared to with natural environment, more than 150 times concentration of micro particles

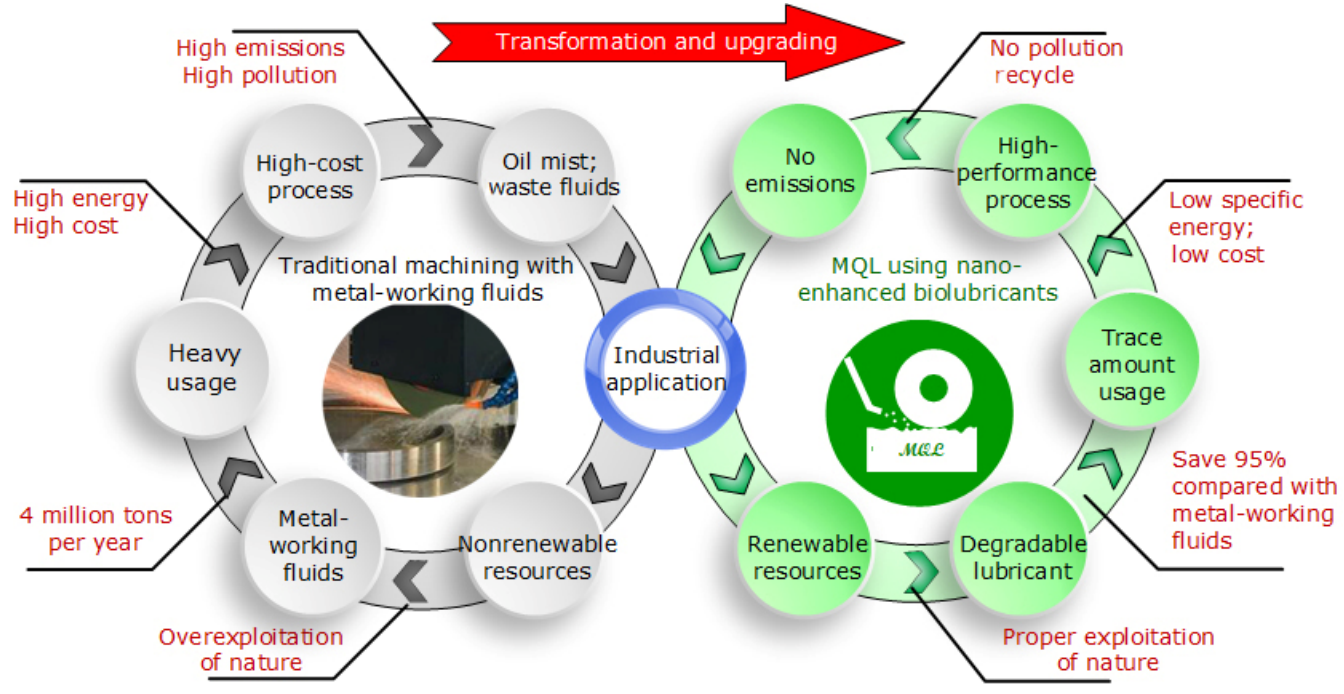

Fig. 1 Impact of traditional MWFs and NEBL on industrial application. 
will generate and cause various respiratory diseases [4]; (iii) high cost of traditional MWFs, which is about 2.5 times of the cutter cost, caused by expensive mineral fluid components, inefficient/heavy supply method, and strict requirement of the wastewater disposal. It's urgent to find a renewable and biodegradable lubricants as substitute for traditional MWFs for sustainable transformation and upgrading of traditional manufacturing industry.

Biolubricant, which is typically produced from raw plant oils and animal fats for industrial application, has already gained importance as alternatives to conventional mineral-based lubricants in various applications, especially the automotive industry [5]. It is undeniable that vegetable oils or animal fats are good alternative lipid sources due to their environmentally friendly, nontoxic, and readily degradable nature. Inspired by the above, scholars have made attempts by using biolubricant in minimum quantity lubrication (MQL) for sustainable manufacturing. Triglycerols of fatty acids are the main ingredients of vegetable oils and animal fats, which usually has poor extreme pressure properties [6]. Especially, biolubricant couldn't meet anti-friction and heat-transfer requirements of machining, in which working zone characterized by high-temperature and high-pressure. This shortcoming is caused by poor lubrication/cooling performance of biolubricant and can be addressed by introducing nano-enhancer in plant oil to prepare NEBL. NEBL could realize the low cost and sustainable development of industry while realizing the machining performance. By employing only tiny amount of NEBL with the flow rate of $10-100 \mathrm{~mL} / \mathrm{h}[7,8]$, MQL can provide similar cooling and lubricating effects in comparison with traditional flood machining processes but with the unique advantages in terms of cost (because of a very small amount of coolant usage and large disposal saving), environmental protection (because plant oils are degradable), and human safety [9].

The employment of NEBL supplying by MQL system has four basic functions of lubrication, cooling, rust prevention, and chip removal, so it is hopeful to replace traditional MWFs: (i) Due to blocking effect of air boundary layer around a rotating tool (especially the grinding wheel) [10], the 'useful' flow rate, which is the volume ratio of flow into the cutting zone to total flow, is only $5 \%-40 \%$ [11]. Extra flow rate is wasted. The distribution of airflow field in milling and grinding has been researched by scholars. They found that the airflow field will play a drag role on the entry of micro droplets at a high jet velocity when micro droplets are injected along the 'entry flow' in the airflow field (avoiding the 'return flow'). Iskandar et al. [12] found that the jet velocity researches at $35 \mathrm{~m} / \mathrm{s}$ when air flow rate is set as $31 \mathrm{~L} / \mathrm{min}$. Therefore, although dosage of NEBL is lower than traditional MWFs, the 'useful' flow rate is higher thanks to bigger jet speed of NEBL droplets with the help of high pressure gas. Even in high speed machining, NEBL droplets could be fed through air boundary layer into the cutting zone easily; (ii) thanks to favorable physical properties of base oil and high thermal conductivity of nano-enhancers, the usage of NEBL presents better lubrication and cooling performance than traditional MWFs. Moreover, using NEBL to instead water-soluble MWFs is more conducive to the rust prevention of the workpiece; (iii) better than traditional MWFs, the chips will be washing off from cutting zone and maintain cleanliness around cutting zone with combined efforts of lubricants and high pressure gas. Especially for slot parts machining of aerospace structural components, the chips might stay at slot and paly an interference role due to MWFs filling the slot. MQL could solve this problem.

Although substantial efforts have been paid to NEBL application in sustainable machining, the scientific knowledge and understanding in this technology seems still unclear, such as how or why NEBL atomizes, infiltrates, formats film, lubricates and cooling in machining with influence of various molecular structures and physical properties. The present processing couldn't guide the production practice due to lack of process specifications, such as how to prepare NEBL with suitable plant oil, nano-enhancer, and concentration for multiple processing conditions. In order to fill this literature gap and provide scientific foundation, this paper aims to present a comprehensive review and provide a periodic critical assessment of the existing understandings.

\subsection{Paper structure}

Figure 2 shows the paper flow. By employing the theoretical and technical bottlenecks of NEBL for 
(Section 1) Introduction: the background and propose of NEBL based MQL
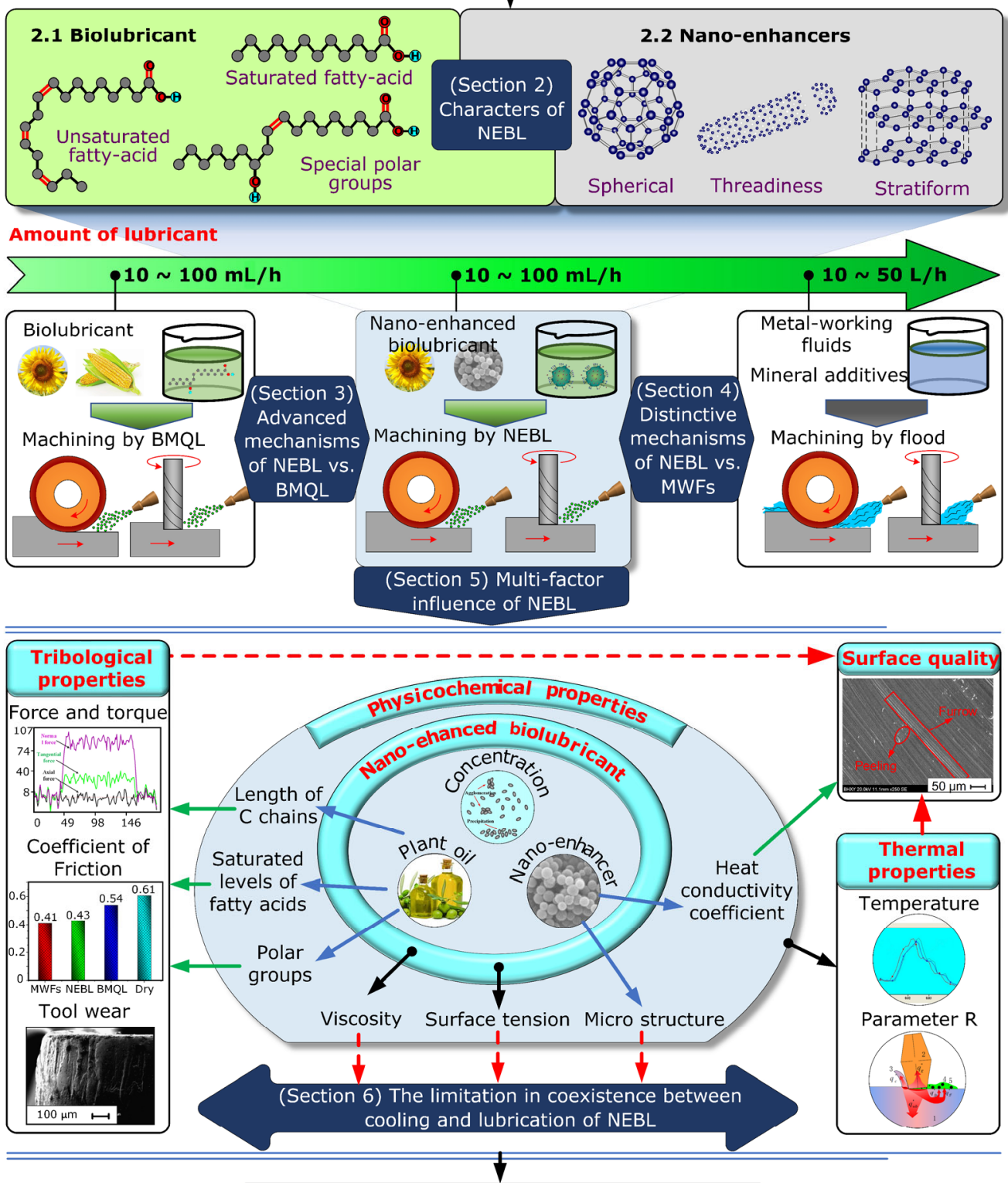

(Section 7) Conclusions and future challenges

Fig. 2 Paper structure.

industrial application as the storyline, this review starts with introduction of components of NEBL used in sustainable manufacturing (Section 2), followed by feasibility demonstration of NEBL comparing with biolubricant in MQL application and unique lubrication/cooling mechanisms are revealed in Section 3. Feasibility demonstration is also set furtherly in Section 4 of NEBL comparing with traditional MWFs, in which advanced film-formation, atomization, and infiltration mechanisms are clarified combining with its unique molecular structure and physical properties. The process optimization strategy is concluded based on the synergistic relationship analysis among process variables, physicochemical properties, machining mechanisms, and performance of NEBL (Section 5). Section 6 discusses the contradictory relationship in the coexistence of cooling and lubrication performances of NEBL and proposes the possible solutions. The paper ends with the conclusion and future challenges of sustainable machining processes in Section 7. 


\section{Characters of nano-enhanced biolubricant}

\subsection{Biolubricant}

Toxic and hazardous contaminants included in mineral oils convey adverse health and environmental effect and heavily influence for the global sustainability. The significant properties of readily biodegradable, low toxicity, and environmental friendliness have attracted manufacturing industries to use plant oils as base oil of NEBL, which could satisfy the higher industrial demand on sustainable lubricants. More significant, plant oil is a renewable resource. Its application in machining avoids overexploitation of nature, which is also an important direction of sustainable development. It's worth noting that biolubricant from animal fats are anther main kinds, however, no reference of animal oil application in MQL was published at present. Therefore, the biolubricant as mentioned below in this paper are those derived from vegetable oils.

Natural plant oil is composition of various kinds of saturated and unsaturated fatty acids, and can be classified into several types based on carbon chain length (usually varies from 16 to 22 ), $\mathrm{C}=\mathrm{C}$ number (usually varies from 0 to 3 ), and polar group $(-\mathrm{OH}$, $-\mathrm{COOH}$, etc.) (Fig. 3).

\subsubsection{Oils with high-content unsaturated fatty-acid}

The majority of plant oils has a high content of unsaturated fatty-acid (typical types in Fig. 4(a)). These oils were the most extensively investigated due to the large number of their varieties. These oils have proper viscosity and surface tension, and therefore presents a good balance between cooling and lubrication. However, the problems come from their limited strength and their film instability due to easy-to-oxidise nature of $\mathrm{C}=\mathrm{C}$ bonds.

\subsubsection{Oils with high-content saturated fatty-acid}

In comparison, more and more attentions are paid to oils with a high content of saturated fatty-acid (typical types in Fig. 4(b)). These oils have higher viscosity and therefore better lubrication performance. More importantly, these oils have no $\mathrm{C}=\mathrm{C}$ bonds and molecular chains have straight-line backbones, which are beneficial to lubricating film strength.

\subsubsection{Oils with special polar groups}

Most oils reviewed above have both $-\mathrm{COOH}$ and -COOR polar groups at one carbon chain end. However, there are also some exceptions such as castor oil having $-\mathrm{OH}$ at the chain end. The $-\mathrm{OH}$ group has

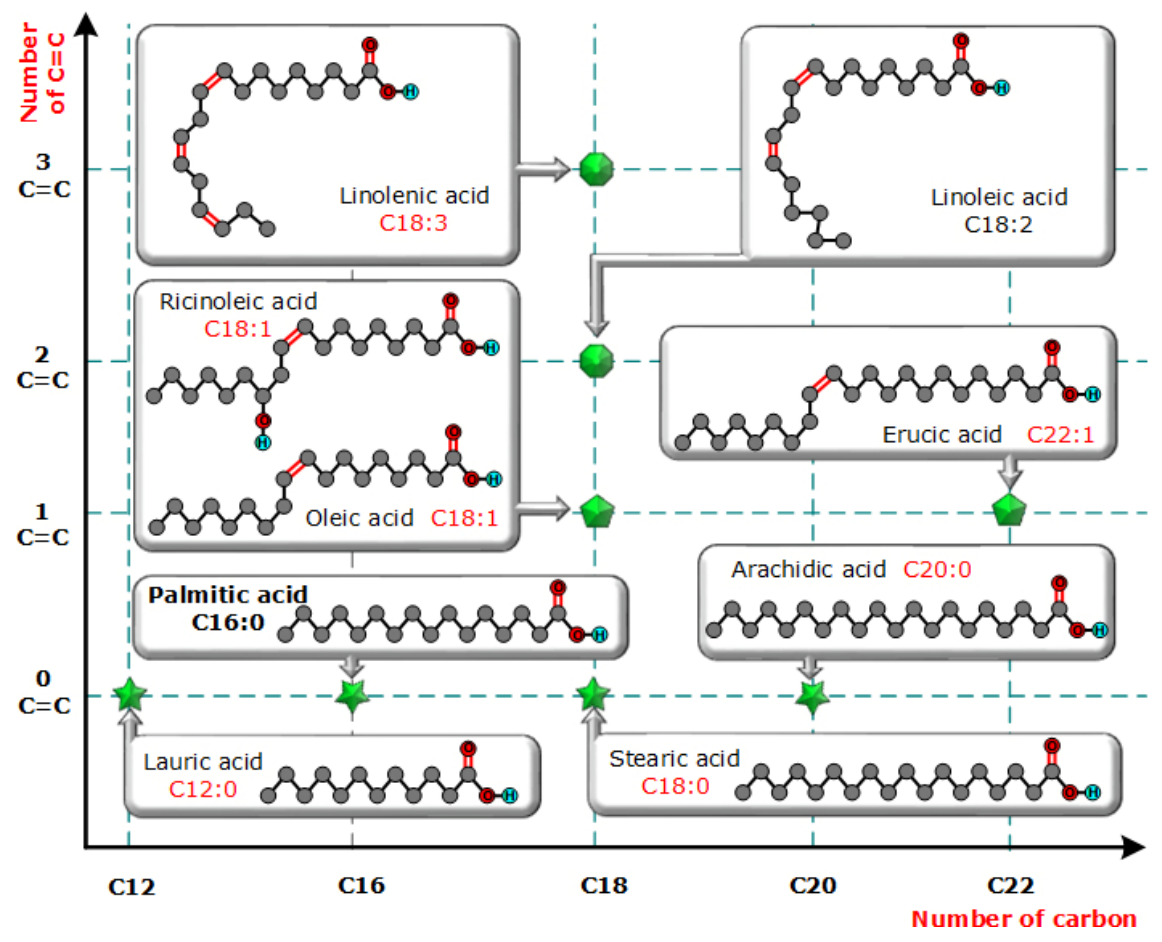

Fig. 3 Classification of common fatty acids existed in plant oils. 


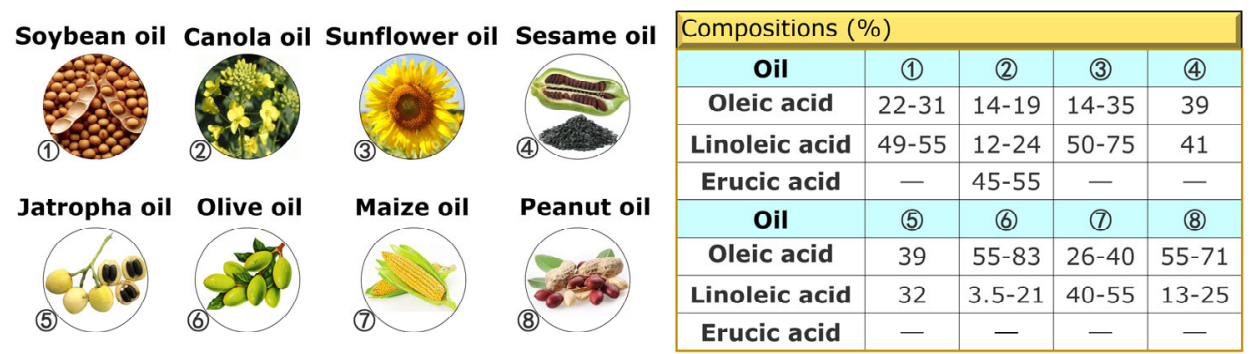

(a)

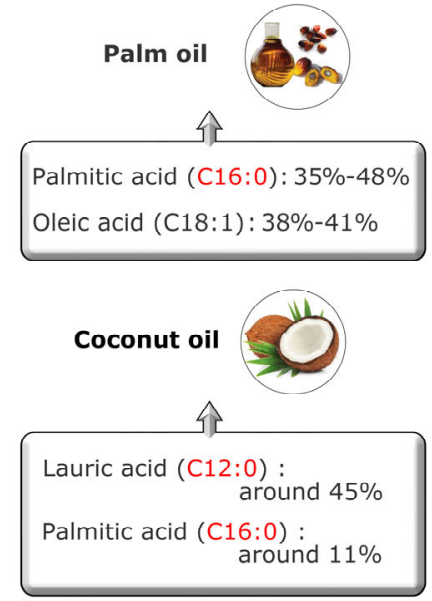

(b)

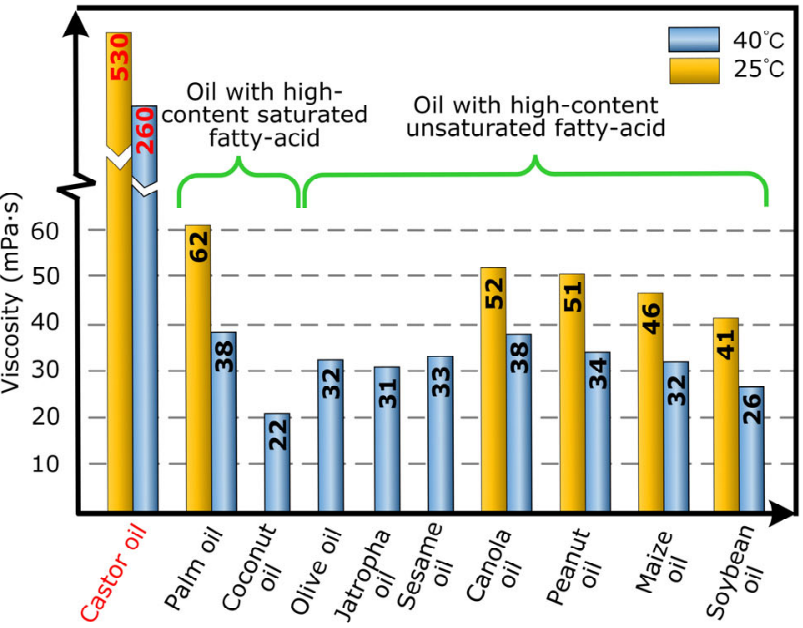

(c)

Fig. 4 Compositions of (a) oils with high-content unsaturated fatty-acid; (b) oils with high-content saturated fatty-acid; and (c) viscosity of different plant oils.

a very strong adsorption to metallic surface, and therefore provides easy lubricating film formation and desired film properties. However, the existence of $-\mathrm{OH}$ increases the viscosity by one order of magnitude (Fig. 4(c)), which degrades the heat exchange performance of NEBL. With this, one big research stream at present is mainly focusing on the optimisation of oils with special polar groups so that the good balance between cooling and lubricating performances can be achieved.

\subsection{Nano-enhancers}

The purpose of adding nano-enhancer to plant oil aims to further improve the application range of plant oil, which could adapt to high-temperature or high-pressure processing conditions. Thanks to ultra-large specific surface area and various available physicochemical properties of nano-enhancer, NEBL can significantly improve thermal conductivity and tribology behaviors at the tool-workpiece interfaces where intensive friction, high temperature and pressure, and high relative velocity simultaneously exist [13].

\subsubsection{Spherical nano-enhancers}

There is no surprise that if spherical nano-enhancer can be introduced into NEBL they can act like 'ball rollers in the bearings' at nanoscale, significantly reducing friction so as to improve tool life, temperature, and force.

Spherical nano-enhancer (or zero-dimensional nanoenhancer) used in NEBL mainly include $\mathrm{Al}_{2} \mathrm{O}_{3}, \mathrm{SiO}_{2}$, $\mathrm{ZrO}_{2}, \mathrm{SiC}$, and nano diamond (ND) (Fig. 5(a)), where $\mathrm{ND}$ and $\mathrm{Al}_{2} \mathrm{O}_{3}$ are widely used due to high strength, hardness, and heat resistance. $\mathrm{SiO}_{2}$ nano-enhancer is popular as well due to the three-dimensional reticulated structure containing more unsaturated suspension bonds and therefore high surface activity. The low heat transfer coefficient seems to be the key problem for these nano-enhancer, and therefore many efforts for the moment focused on this field to improve the cooling performances of these particles [14].

\subsubsection{Threadiness nano-enhancers}

Threadiness nano-enhancers (or one-dimensional nano-enhancers) are also widely used in NEBL. 

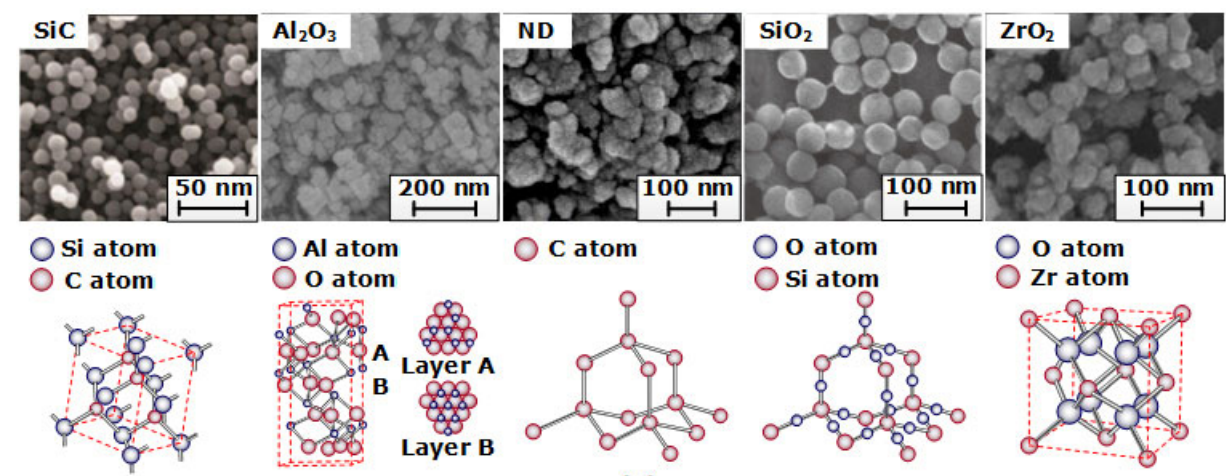

(a)
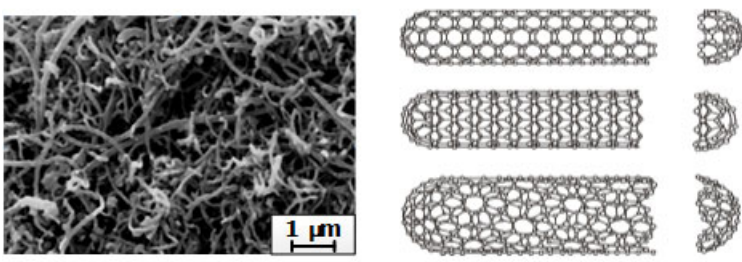

Single-walled carbon nanotubes

Double-walled carbon nanotubes

Multi-walled carbon nanotubes

(b)
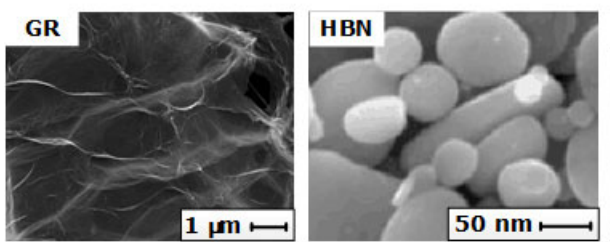

O C atom

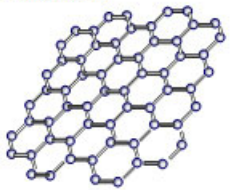

$\bigcirc \mathrm{N}$ atom $\bigcirc \mathrm{B}$ atom
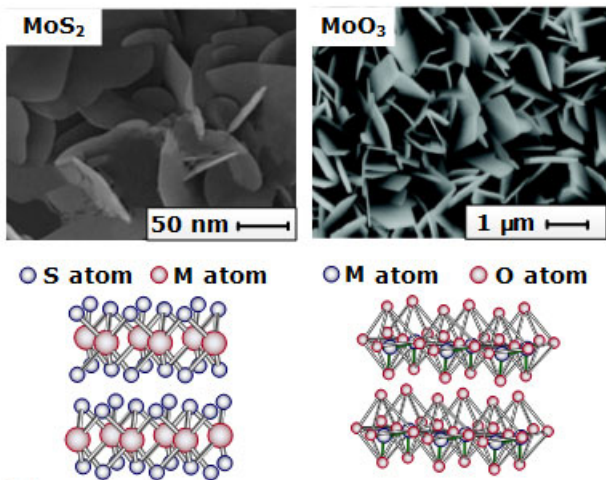

OS atom $O M$ atom
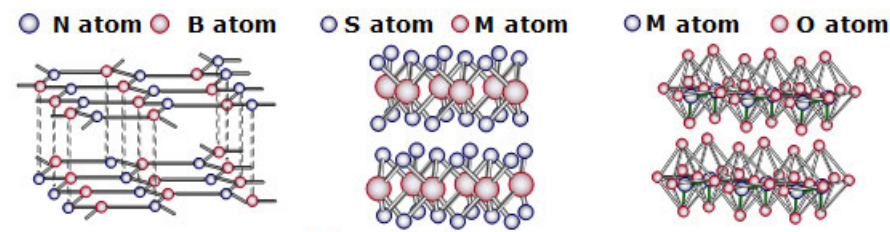

(c)

Fig. 5 SEM and microstructure of (a) spherical nano-enhancer; (b) carbon nanotubes (CNTs); and (c) stratiform nano-enhancer.

These nano-enhancers have excellent heat conductivity coefficient, and therefore can largely reduce machining temperature. These nano-enhancers mainly include $\mathrm{CuO}_{2}, \mathrm{MnO}_{2}, \mathrm{TiO}_{2}, \mathrm{ZnO}$, and CNTs (Fig. 5(b)). However, the unwanted aggregation resulted in high modulus and strength, deteriorating the tribological performances of these nano-enhancer at the cutting/ grinding zone [15].

\subsubsection{Stratiform nano-enhancers}

Stratiform nano-enhancers in NEBL (or twodimensional nano-enhancer) act like sliders at nanoscale thanks to the weak shearing strength between neighboring layers. With this, machined surface quality, process force, and temperature can be improved. In comparison with typical stratiform nano-enhancers such as $\mathrm{CBN}, \mathrm{MoO}_{3}, \mathrm{HBN}$, and $\mathrm{MoS}_{2}$
(Fig. 5(c)), graphene (GR) is the most popular material because of the good combination of excellent heat conductivity coefficient $\left(5,300\left(\mathrm{~W} \cdot \mathrm{m}^{-1} \cdot \mathrm{K}^{-1}\right)\right)$, high strength, and large Young's modulus. GR is also the only type stratiform particle whose heat transfer is better than that of CNTs, making GR the most promising materials in terms of both cooling and lubrication. The limitation of GR for wider applications for the moment is the high price.

\subsubsection{Composite nano-enhancers}

The composite nano-enhancers used in NEBL, which could also be named as mix or hybrid nano-enhancers, are very popular in recent years. The NEBL prepared by composite nano-enhancers may present better lubrication or cooling performance than mono nanoenhancers. Compared with mono nano-enhancers, 
composite nano-enhancers have more formulation options, which brings more possibilities for the development of NEBL. This method was first proposed in 2015 by Zhang et al. [15], and then a series of scholars conducted relevant studies. Hemmat et al. [16] and Khan et al. [17] summarized the common tested kinds of composite nano-enhancers in different machining processes. The excellent antifriction mechanisms of composite nano-enhancers have been confirmed in oil film lubrication in tribological tests and strips hot rolling experiment [18]. Du et al. [19] assessed the tribological performance of graphene oxide/ $/ \mathrm{TiO}_{2}$ composite nano-enhancers. The superior lubricating properties of graphene oxide/ $/ \mathrm{TiO}_{2}$ nanocomposites were attributed to the excellent dispersion stability and the formation of absorption films, carbonaceous protective films, and transfer films. Nevertheless, previous studies did not apply to high temperature, pressure, and speed interface between tool and workpiece, which necessitates in-depth understanding.

\section{Advanced mechanisms of NEBL vs. BMQL}

The machining performance comparison with BMQL is the most intuitive way to reveal the advanced and unique cooling and lubrication mechanisms of NEBL. Therefore, the feasibility demonstration of NEBL vs. BMQL is naturally the first topic. It should be noted that, the performance evaluation experiments of BMQL or NEBL are carried out with dry machining in the current researches. Therefore, as a comparable method, dry machining is set as common reference of BMQL or NEBL in the evaluation of performance data below.

\subsection{Tribological aspect}

Force and torque: Comparing with dry grinding, the large force reduction (Fig. 6(a)) of 52\% in normal and $46 \%-51 \%$ in tangential directions was observed in BMQL for AISI 4140 [20] and 1045 [21-23]. The introduction of nano-enhancer in NEBL further reduced forces, achieving $58 \%-62 \%$ force reduction for AISI 1045 [21-23] and 9\%-35\% for AISI 52100 [24] in tangential direction. Apart from grinding, the force reduction of $27 \%$ in aluminum silicon alloy (AlSi5)
[25] and $10 \%$ in $42 \mathrm{CrMo} 4 \mathrm{BMQL}$ turning [26] were observed in comparison with dry cutting. Except for cutting forces, the torque and thrust force were also reduced by separately $42 \%$ and $18 \%$ was also obtained in both BMQL drilling of ACP 5080 [27] and BMQL turning of AISI 1040 [28]. However, the negative example obtained by BMQL was the force rise of $20 \%$ at the high cutting speed of $800 \mathrm{~mm} / \mathrm{min}$ in turning of AlSI5 [25], which might be due to the cutting instability caused by the intermittent liquid supply and cooling of MQL (chilling effect) under the heavy machining loads.

CoF: CoF is the evaluator of lubrication at the tool-workpiece interface and can be calculated based on measured normal and tangential forces. The CoF reduction was observed including $11 \%-36 \%$ in $\mathrm{BMQL}$ grinding of AISI 1045 [21-23], 29\%-49\% using NEBL in grinding of AISI 1045 [21-23], and AISI 52100 [24], and $17 \%$ and $38 \%$ using BMQL and NEBL in milling of AISI 1045, respectively [31]. These results can be a good indicator of the better lubrication performance induced by NEBL [32].

Tool wear: In comparison with dry machining, obviously improved tool wear at the flank surface was observed in BMQL turning of AISI 9310 (Fig. 6(c)) [29], AISI 1060 [33], 39NiCrMo3 alloy steel [34], and AISI 420B [35], where VB values (referring to the principal flank wear, Fig. 6(b)) were separately decreased by $65 \%$ [29] and $20 \%$ [33]. The tool wear mode was changed from severe adhesive or even corrosive wear in dry machining to abrasive wear in BMQL [36]. The NEBL further extended the tool service life and reduced the $\mathrm{VB}$ value by $51 \%$ in comparison with $\mathrm{BMQL}$ milling and turning of AISI 1045 [37], Ti-6Al-4V [30] (Fig. 6(d)), and alloy 718 [38]. It's worth noting that the hybrid using of cryogenic and BMQL presents lager VB than BMQL, as shown in Fig. 6(d). The composite usage of cryogenic and BMQL might cause a significant increase in viscosity. Therefore the wetting property and cooling property decreased sharply. Park et al. [30] concluded that tool wear was substantially smaller at the early stage of machining process due to effective cooling action. However, both cutting force and tool wear (adhesion and chipping) increased significantly as the $\mathrm{Ti}$ alloy hardens with the application of the liquid nitrogen during the cutting. 


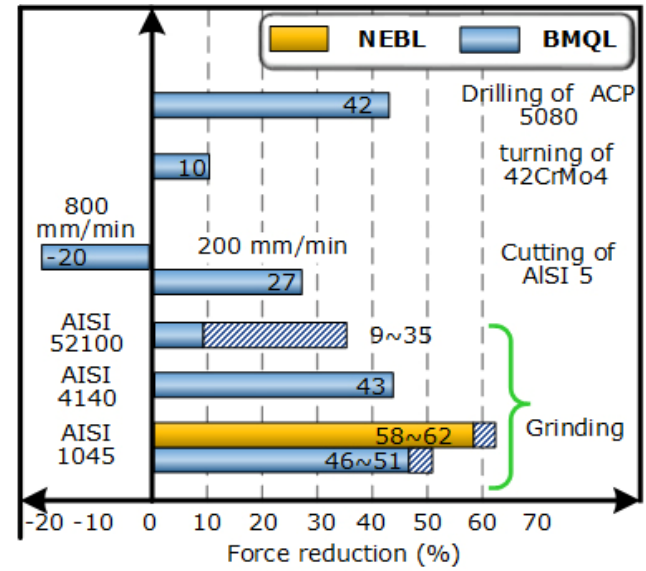

(a)

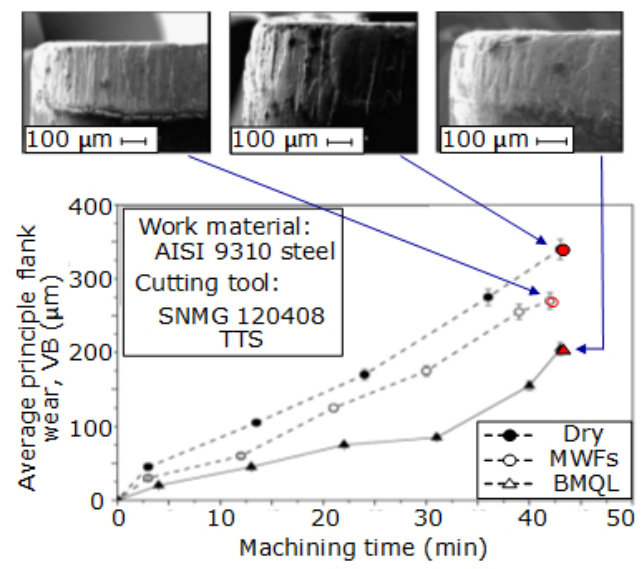

(c)

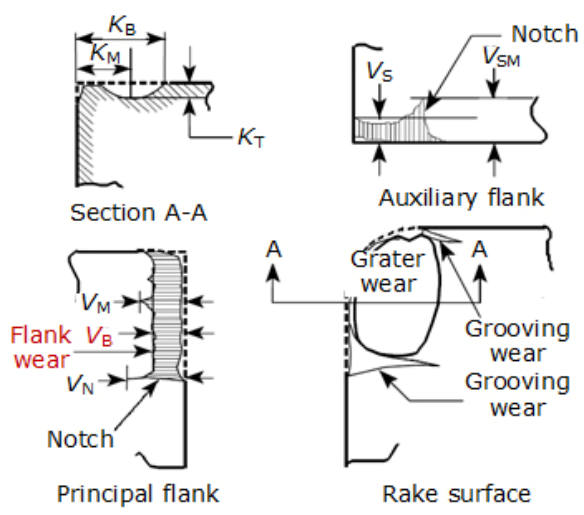

(b)

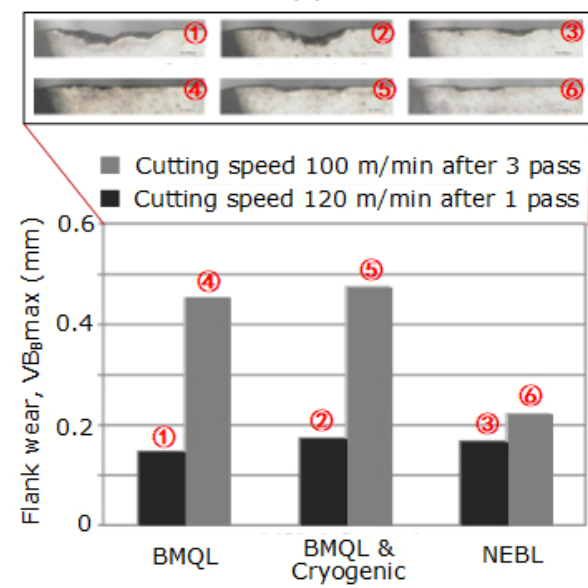

(d)

Fig. 6 Tribological parameters of BMQL and NEBL compared to dry machining. (a) Force and torque reductions; (b) geometry of wear of turning tool; and (c) SEM and VB for AISI 9310 turning. Reproduced with permission from Ref. [29]. C) Elsevier, 2009. (d) SEM and VB for Ti-6Al-4V turning. Reproduced with permission from Ref. [30]. C KSPE and Springer, 2017.

\subsection{General lubrication mechanism of NEBL}

The above improved tribological performance can be explained by the general lubrication mechanism of NEBL. In BMQL machining, micro craters on the workpiece surface and micro pores in grinding wheels acted like 'capillary tubes', and were filled with micro plant oil droplet by capillary forces, generating lubricating films at the workpiece-tool interface and improving the tribological behaviors. However, the film locations, sizes, and thicknesses were found random (called boundary lubrication in hydrodynamics [39]), and in most cases resulted in low film strength and instable film performances. This is the drawback of plant oils which limits its application in cleaner processing.

The introduction of nano-enhancer in NEBL stabilized these instable performances [40]. After nano-enhancer were transported into grinding/cutting zone based on capillary forces, these nano-enhancer showed three key functions based on SEM and Energy dispersive spectrometer (EDS) observation [41] (Fig. 7): (i) Nanoenhancer was distributed in the oil film and played a ball-saddle role, which protected oil films from damage due to the high particle strength; (ii) the interactions between the flat facets of abrasive crystals and the workpiece transformed themselves into solid lubricants as the composite tribofilm; and (iii) the composite tribofilms were helpful to avoid not only the bonding between the abrasives and the cutting edges but also the adhesive wear [32].

\subsection{Thermal aspect}

Temperature: In comparison with dry machining, the employment of BMQL resulted in the temperature 


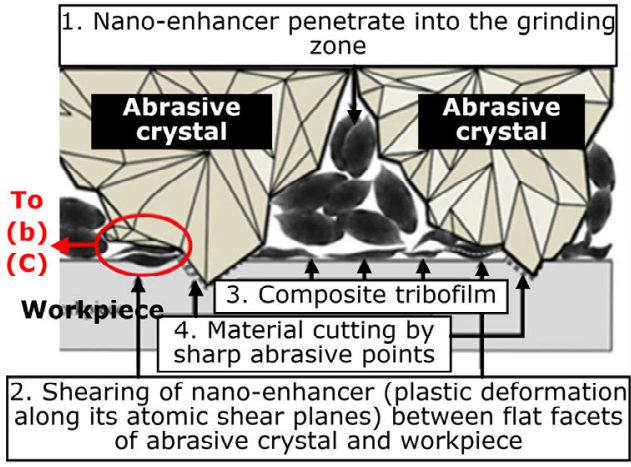

(a)

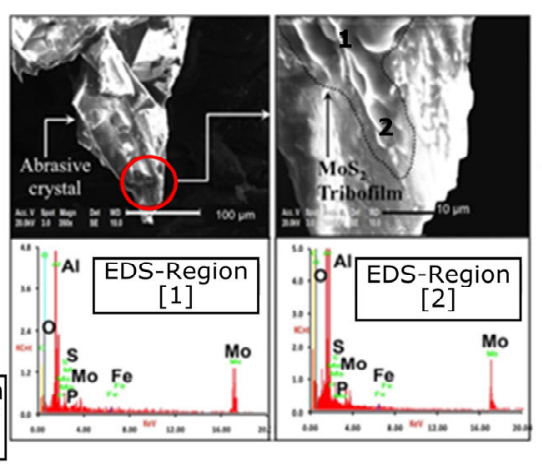

(b)

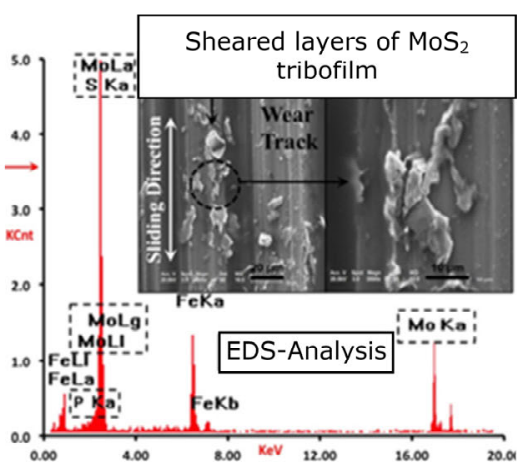

(c)

Fig. 7 General lubrication mechanism of NEBL. (a) Tribofilm formation mechanism of nano-enhancer; SEM and EDS spectra of the surface of (b) an abrasive grain and (c) workpiece. Reproduced with permission from Ref. [41]. (C) Elsevier, 2012.

reduction of $14 \%-52 \%$ in AISI 1045 grinding [39, 42, 43], $34 \%$ in ductile iron grinding [44], and $18 \%$ in AISI 1045 milling [45] (Fig. 8(a)). Even more obvious temperature reduction was achieved by utilizing NEBL, and the examples include: the temperature reduction of 33\% 62\% in AISI 1045 grinding [39, 42, 43], 22\% in AISI 52100 grinding [24], 7\% in AISI 1045 turning [46], $13 \%$ in AISI 9310 turning [29], $9 \%-12 \%$ in $42 \mathrm{CrMo} 4$ steel turning [26], 15\% in AISI 1040 turning [28], and 31\% in AISI 1045 milling (Fig. 8(b)) [45].

Parameter $R$ : Parameter $R$ (the ratio of the energy that transfers into the workpiece to the total energy generated due to the abrasive-workpiece interactions) is a classic thermal evaluator in grinding [39, 47]. Comparing with high-pressure gas where $R$ value was $68 \%$, the smaller $R$ values were obtained, including $54 \%$ and $53.5 \%$ separately using BMQL and NEBL in grinding of ductile irons [48], and $50 \%$ and $41 \%$ in using plant oil and NEBL in grinding of AISI $1045[39,42]$.

\subsection{General heat transfer mechanism of nano- enhanced biolubricant}

The above thermal improvement can be explained by general heat transfer mechanism of NEBL. In terms of thermal properties, the heat transfer ability and the specific heat of plant oil were much better and higher than those of flowing gases in dry machining [49], and therefore the increased proportion of machining-generated heat can be transferred away from the cutting or grinding zone. The introduction of nano-enhancer into plant oil further enhanced the thermal conductivity and convective heat transfer capacity of NEBL because solid matters in general have

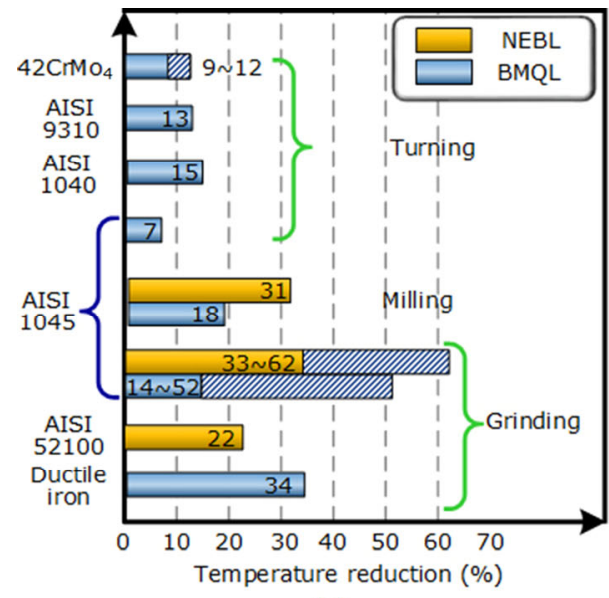

(a)

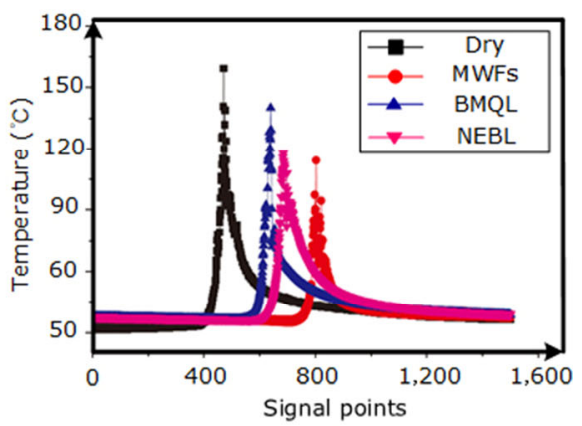

(b)

Fig. 8 Thermal parameters of plant oil and NEBL compared to high-pressure gas. (a) Temperature reductions and (b) temperature curve in AISI 1045 milling. Reproduced with permission from Ref. [45]. C China Academic Journal Electronic Publishing House, 2018. 
even better cooling performances than liquids [50].

In terms of heat behaviors, Brownian motion forced nano-enhancer to impact on workpiece and therefore heat would be transferred from workpiece to nanoenhancer (Fig. 9(a)) [51]. Nano-enhancer attracted liquid

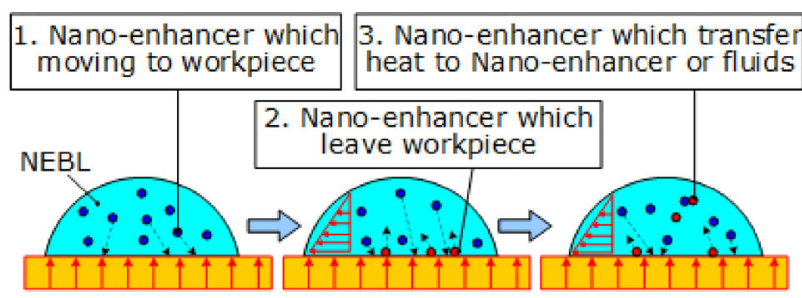

(a)

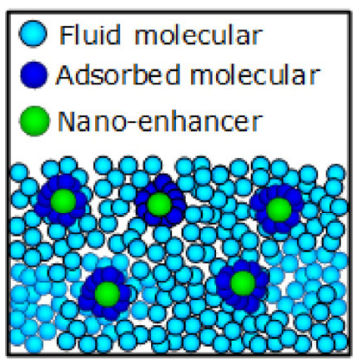

(b)

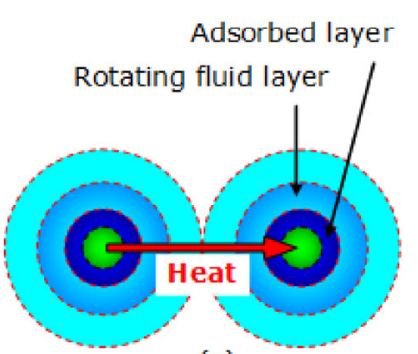

(c)
Fig. 9 General heat transfer mechanism of NEBL. (a) Heat transfer motion of nano-enhancer; (b) nano-enhancer and adsorption layer around them; and (c) heat transfer channels. Reproduced with permission from Ref. [51]. (C) The Author, 2019. molecules of plant oil fluids due to high surface energy and formed the adsorption layers on the external surface of nano-enhancer (Fig. 9(b)) [51]. When these layers contacted with each other, heat transfer channels were formed, via which excessive heat was effectively transferred far away from cutting and grinding zone (Fig. 9(c)) [52].

\subsection{Machined surface integrity}

Machined surface integrity, the most important indicator of the availability of machining, can be considered as the compound result of the above tribological (Section 3.1) and thermal performances (Section 3.3).

In comparison with dry grinding, surface burns were completely avoided by using BMQL and NBEL grinding of AISI 4140 [41], AISI 1045 [21], Ti-6Al-4V [53], and Inconel 600 [54], while the machined surface roughness $R_{a}$ was reduced by $5 \%$ and $11 \%$ separately by using BMQL and NBEL grinding of AISI 1045 [23] (Figs. 10(a) and 10(b)). Except for grinding, NBEL milling of AISI 1045 obtained 13\% reduction compared with BMQL [31]. The smoother chip back surfaces and better workpiece surfaces were also observed in NEBL machining (Fig. 10(c)) [55, 56].

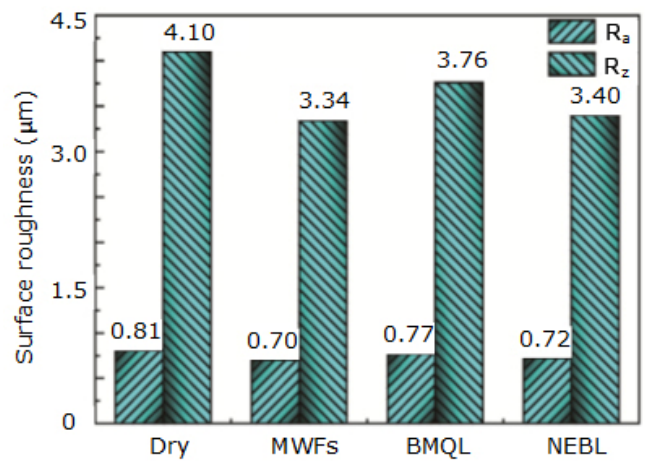

(a)
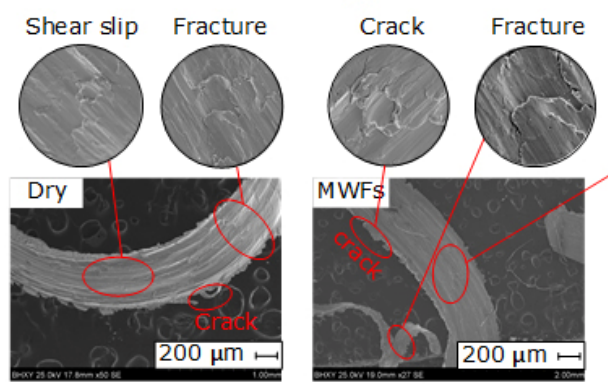

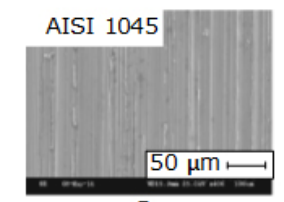

Dry

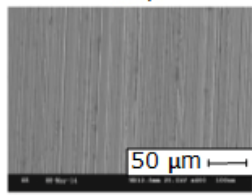

BMQL

(b)

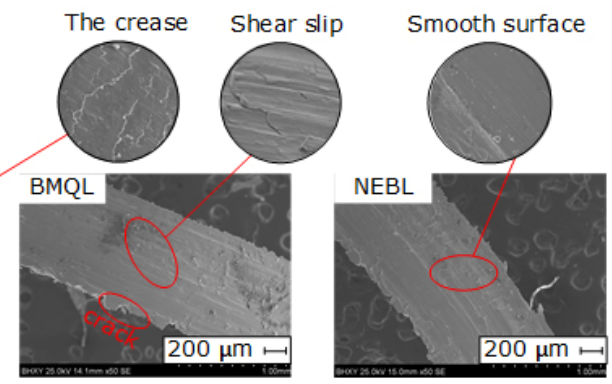

(c)

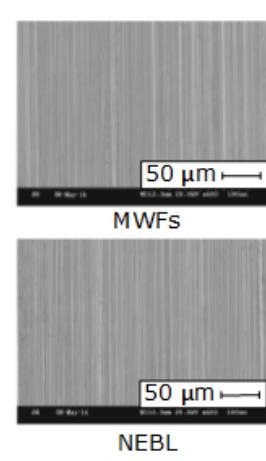

Fig. 10 Machined surface integrity of BMQL and NEBL compared to dry condition. (a) $R_{a}$ in AISI 1045 grinding and (b) SEM images of workpiece surface in AISI 1045 grinding. Reproduced with permission from Ref. [23]. (C) The Authors, 2015. (c) SEM images of chips surfaces in AISI 1045 milling. Reproduced with permission from Ref. [31]. C Springer Nature, 2018. 
To summarize this section, it might be concluded that NEBL is the better lubricant, which have improved tribological and thermal properties and extended application scope compared with BMQL. The application of NEBL in MQL shows highly improved performances including force reduction of $9 \%-62 \%$ and temperature reduction of $14 \%-62 \%$, comparing with dry machining. The application of NEBL also shows machined surface roughness improvement of $5 \%-13 \%$ compared with BMQL. The addition of nano-enhancers changes lubrication performance at tool/workpiece interface by its unique anti-friction and anti-wear behavior due to formation of solid tribofilm. Furthermore, the enhanced heat transfer performance due to Brownian motion of nano-enhancers also significantly reduces the temperature in cutting zone. Because of the above benefits, the machining of difficult-to-cutting materials (e.g. titanium alloy and nickel-based alloy) could be well done, which is a technical bottleneck for BMQL. From the green transformation of the whole industry, therefore, NEBL shows great promise.

\section{Distinctive mechanisms of NEBL vs. traditional MWFs}

The usage of NEBL meets requirement of sustainable manufacturing from resource sources aspect. Further, no oil mist and waste liquids generation meet requirement of sustainable manufacturing from environmental protection aspect. Therefore, the only question is whether NEBL could provide the same (or better) machining performance compared with heavy usage of traditional MWFs. It might be more interesting to perform the between-group comparison between NEBL and conventional flood machining.

\subsection{Tribological aspect}

Force and CoF: Comparing with traditional MWFs, the large force reduction was recognised, including $67 \%$ in tangential and $43 \%$ in normal direction in BMQL grinding of AISI 4140 [20], and 7\% in NEBL milling of $\mathrm{Ti}-6 \mathrm{Al}-4 \mathrm{~V}$ [30]. However, the increased force was also observed in BMQL grinding of AISI 1045 [23]. Similar contradictory results were observed as well regarding CoF. The reduction of $38 \%$ and $17 \%$ were separately found in BMQL grinding of cast iron (Fig. 11(a)) and EN24 steel [41] while the increase of 24\% was reported in BMQL grinding of AISI 1045 (Fig. 11(b)) [21]. The general conclusion can be that NEBL can provide either better or worse tribological performances than conventional machining depending on the employed process conditions. Especially in the grinding process with high heat generated and complex geometric interface, the employment of NEBL presents slightly higher CoF than traditional MWFs. Oxidation of plant oil at high temperature is might the reason due to low flash point, therefore their cooling/ lubrication properties are lost. This indicates that the preparation method and raw materials of NEBL need to be further optimized before it can completely replace the traditional MWFs in performance.

Tool wear: Compared with traditional MWFs, the VB values of the tool flank surface were largely reduced via BMQL and NEBL turning, including 33\% for $39 \mathrm{NiCrMo} 3$ alloy steel [34], 55\% for AISI 1045 [58], $67 \%$ for AISI 9310 [29], and 4.3\% for Inconel 625 [59]. The G-ratio of grinding wheels was increased by $41.9 \%$ for YG8 hard alloy [60]. The flank wear of tool was reduced by $27.1 \%$ for high-speed drilling of Ti-6Al-4V [57]. Furthermore, thermal cracking, adhesion, attrition, and abrasion of tool were fully avoided (Fig. 11(c)) [57].

\subsection{Formation mechanism of lubricating film of plant oil}

Although the NEBL amount used in MQL is very small comparison with flood machining, improved tribological performances also obtained thanks to excellent film-formation performance of green coolant, which significantly influenced by polar groups, molecular cohesion, and viscosity of NEBL. Mineral oils don't have these excellent properties.

(i) Polar groups: Lubricating films were resulted from the co-existence of both physical and chemical absorptions between NEBL and workpiece surface in the cutting/grinding zone [61]. In comparison with traditional MWFs used in flood machining, NEBL can generate much stronger physical absorptions due to the polar atoms or groups such $-\mathrm{COOH},-\mathrm{COOR}$, and $-\mathrm{OH}$ (Fig. 12(a)) with the large van der Waals forces. NEBL was also easy to form chemical absorption 


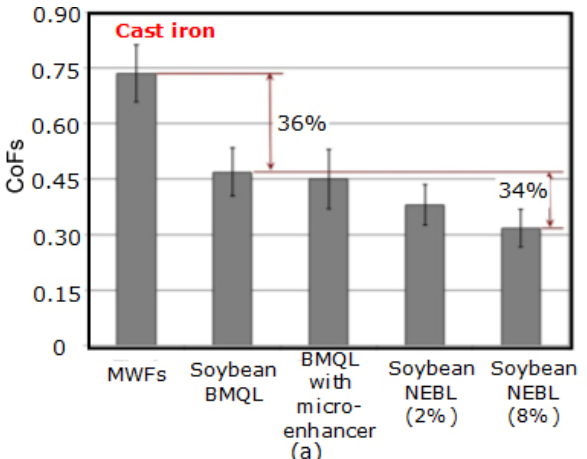

(a)

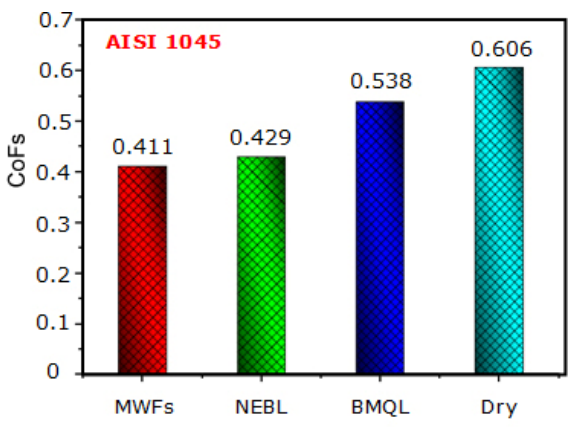

(b)

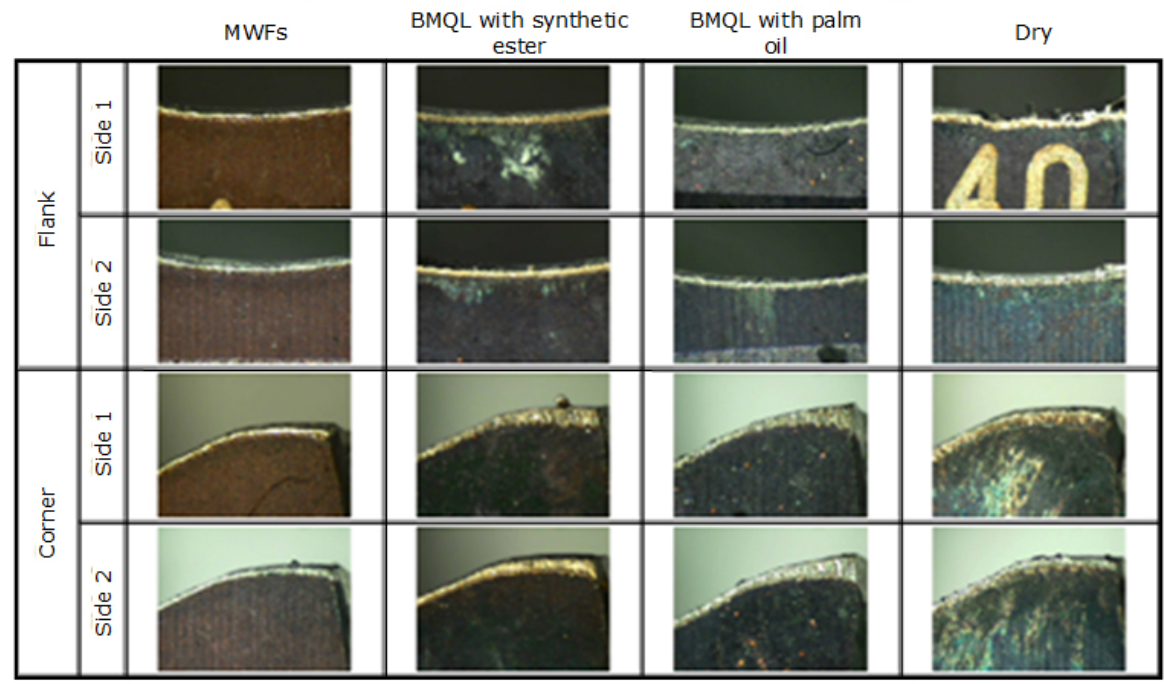

(c)

Fig. 11 Tribological parameters of BMQL and NEBL compared to traditional MWFs. (a) CoFs in cast iron grinding. Reproduced with permission from Ref. [41]. (c) Elsevier, 2012. (b) CoFs in AISI 1045 grinding. Reproduced with permission from Ref. [21]. (C) Springer, 2014. (c) Tool failure modes in Ti-6Al-4V high speed drilling. Reproduced with permission from Ref. [57]. (C) Elsevier, 2010.

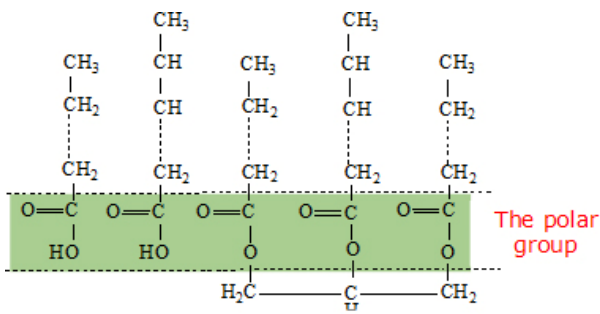

(a)

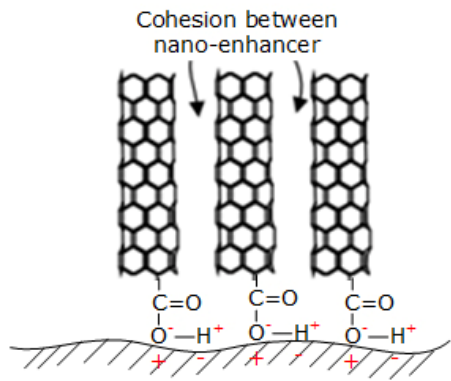

(c)

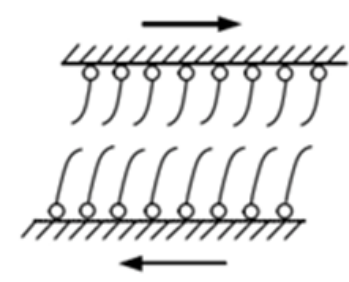

(b)

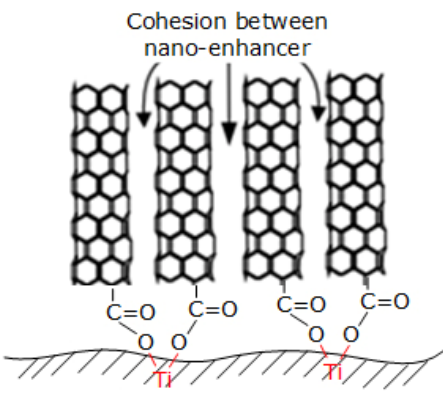

(d)

Fig. 12 Schematic diagrams of formation mechanism of NEBL. (a) Polar groups in molecule of NEBL. Reproduced with permission from Ref. [61]. (O Elsevier, 2016. (b) Slide of lubrication film; (c) lubrication film on tool surface (PCD); and (d) lubrication film on workpiece surface (titanium alloy). Reproduced with permission from Ref. [64]. () The Author, 2018. 
based on the metal saponification effect thanks to - $\mathrm{COOH}$ [22].

(ii) Molecular cohesion: NEBL resulted in not only easy formation of lubricating films but also the improvement of lubricating film properties. Fatty acid molecules have the long-chain structure (usually 12-14 carbon atoms), resulting in strong cohesive force within and between NEBL molecules [62]. This cohesive force was much larger than the internal force within traditional MWFs molecules in flood machining, leading the much higher film strength in MQL. Except for cohesion within NEBL molecules, the cohesion between oil molecules and nano-enhancer was also enhanced [63]. Nano-enhancer such as CNTs or $\mathrm{SiO}_{2}$ can either physically or chemically react with fitty acid molecules and become a new part of fatty acid chain, further increasing the film strength (Figs. 12(b)-12(d)) [64].

(iii) Viscosity: The polar atoms or groups (such as $-\mathrm{COOH},-\mathrm{COOR}$, and -OH) in fatty acid molecules can increase the viscosity and therefore plant oil viscosity was much higher than that of traditional MWFs [65]. These viscous NEBL would result in good tribological performances thanks to the strong colloidal force and Brown force in lubricants [66]. This explanation can be experimentally supported by tribological tests [67-70], grinding trials [24, 71, 72], and cutting experiments [73-75].

\subsection{Thermal aspect}

Temperature and $R$ : In comparison with traditional MWFs, BMQL can effectively lower machining temperature, including the reduction of $10 \%$ in AISI 9310 turning [29] and 35\% in AISI 1045 milling, while NEBL achieved the temperature reduction of $43 \%$ in AISI 1045 milling (Fig. 13) [76]. However, in comparison with traditional MWFs, grinding with NEBL might also generate higher temperature such as temperature increase of $190{ }^{\circ} \mathrm{C}$ for ductile iron [44], $100{ }^{\circ} \mathrm{C}$ for AISI 1045 [42], and $30^{\circ} \mathrm{C}$ for AISI 1045 [42]. Few studies also reported the slightly improved $R$ value of $5.6 \%$ in AISI 1045 grinding [39, 42].

\subsection{Atomization and infiltration mechanisms of plant oil}

In comparison with traditional MWFs, the above thermal improvements can be explained by the excellent atomization and infiltration performances of NEBL [77-79].

(i) Atomization: In MQL, NEBL were mixed with gas and then the mixture was atomized and transformed into either symmetrical or asymmetric waves modes (Fig. 14(a)). This mixture can be smoothly delivered into the cutting/grinding zone by negative pressure via capillary structures [80]. This provided two difference in comparison with traditional MWFs: (i) Atomized coolants delivered with high pressure had a higher passing rate when obstructing air barriers around fast rotating tools; and (ii) atomized coolants enable the generation of fog droplets with much smaller sizes (Fig. 14(b)) [39].

(ii) Infiltration: The above atomization mechanism can result in very fast infiltration (Figs. 14(c) and 14(d)). On the contrary, traditional MWFs in flood machining would experience two stages before they reach cutting/ grinding zone: (i) Atomization at high cutting temperature; and (ii) flow into capillary structures.

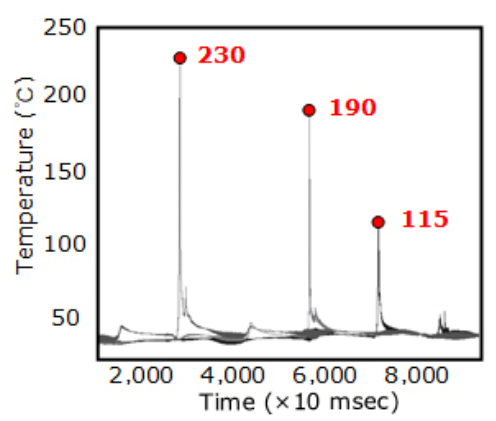

(a)

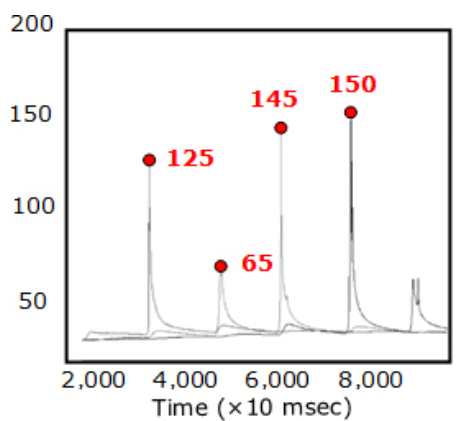

(b)

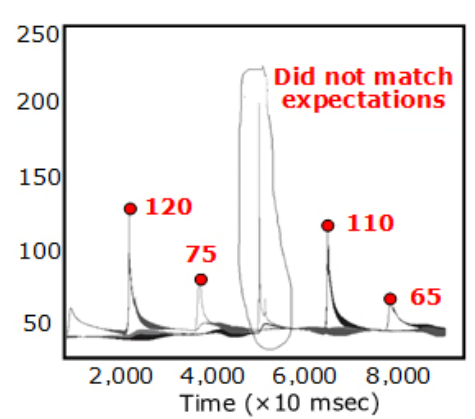

(c)

Fig. 13 Milling temperature of AISI 1045 under (a) traditional MWFs; (b) BMQL; and (c) NEBL. Reproduced with permission from Ref. [76]. C The Authors, 2018. 


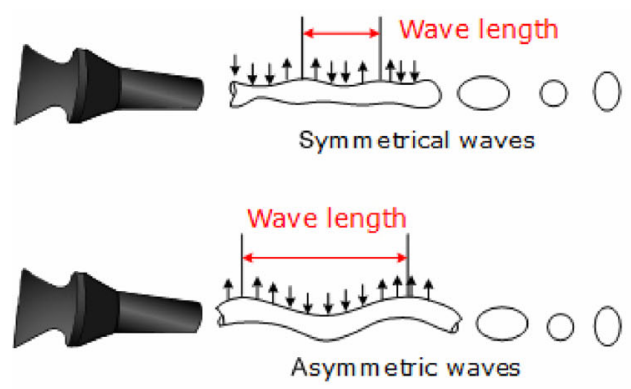

(a)

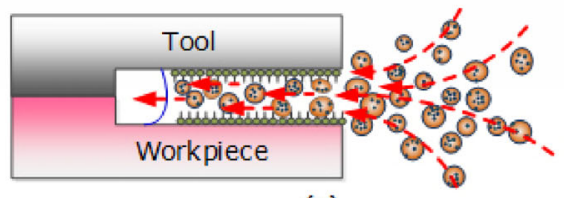

(c)

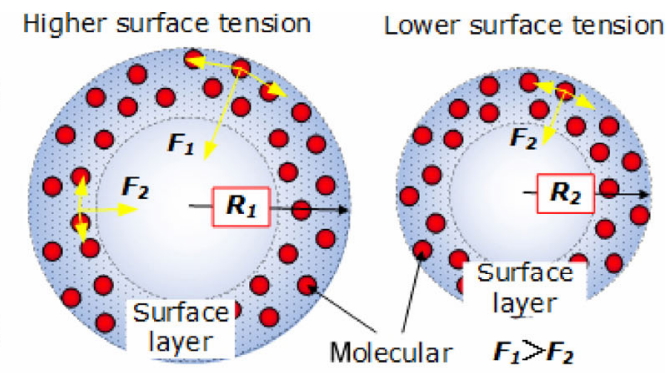

(b)

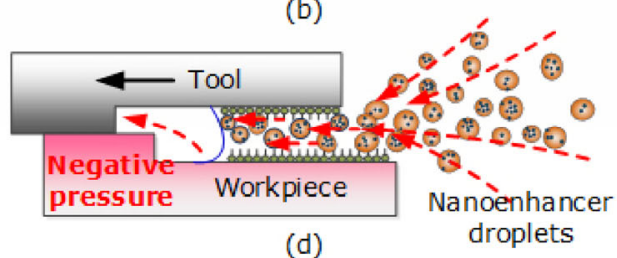

Fig. 14 Schematic diagrams of atomization and infiltration mechanism of NEBL. (a) Atomized of coolant in symmetrical or asymmetric waves. (b) Broplet size influenced by surface tension of NEBL. Reproduced with permission from Ref. [39]. C Elsevier, 2016. Infiltration in (c) static capillary and (d) dynamic capillary.

Therefore, infiltration in flood machining was often slow, providing insufficient cooling performances.

\subsection{Machined surface integrity}

Based on the above tribological and thermal improvement, machined surface integrities were improved by BMQL and NEBL. Compared with traditional MWFs, the $\mathrm{R}_{\mathrm{a}}$ was reduced by $37 \%$ for $\mathrm{Ti}-6 \mathrm{Al}-4 \mathrm{~V}$ [81], 31.2\% for Inconel 718 [82], and by $48 \%$ for AISI 9310 [29]. Better surface quality with lower depth of wear scars on the ground surface of AISI 1045 was observed (Fig. 15(a)). The introduction of nano-enhancer in NEBL further optimized plastic flows (Fig. 15(b)) [32], which indicated NEBL produced better surface quality. However, in one exceptional case the increased $\mathrm{R}_{\mathrm{a}}$ by $25 \%$ was also observed in NEBL in grinding of AISI 4140 [20].

Except for grinding, the employment of BMQL and NEBL in turning reduced the $\mathrm{R}_{\mathrm{a}}$ value by $50 \%$ for $39 \mathrm{NiCrMo} 3$ alloy steel [34], 6.7\% for M2 steel [83], $23 \%$ for AISI 1045 [76], and 5.2\% for Inconel 625 [59] in comparison with traditional MWFs.

Based on above, an encouraging conclusion could be obtained that NEBL is the ideal replacement of traditional MWFs. The application of NEBL in MQL shows highly improved performances including force reduction of $7 \%-67 \%$, temperature reduction of $5.6 \%-43 \%$, and surface roughness improvement of $5.2 \%-48 \%$, comparing with traditional MWFs.

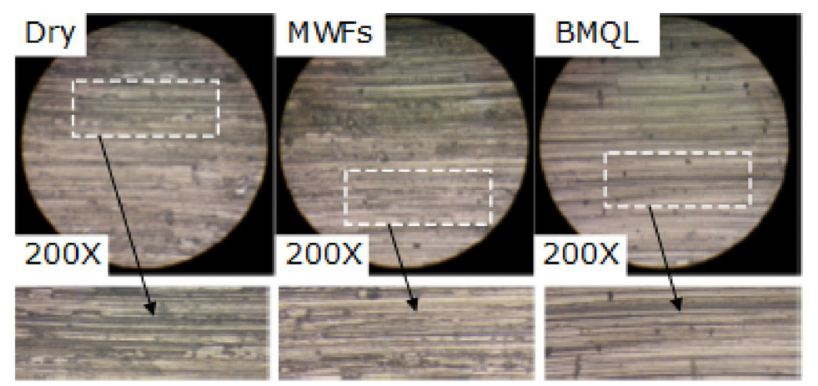

(a)

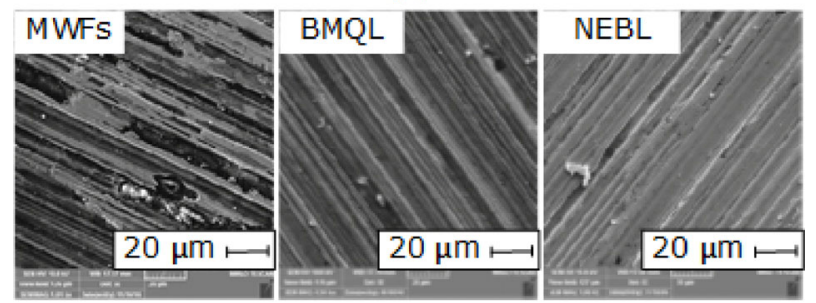

(b)

Fig. 15 Machined surface integrity of NEBL compared to traditional MWFs. (a) Wear scars of ground surfaces in AISI 1045 grinding and (b) SEM images of ground surface under in AISI 1045 grinding. Reproduced with permission from Ref. [32]. (C) Springer-Verlag London, 2017.

The usage of a small amount of NEBL could obtain comparable processing performance compared with Massive using of traditional MWFs. On one hand, the physicochemical properties of NEBL are more conducive to cooling and lubrication than that of traditional MWFs. On the other hand, the jet supply method of NEBL to cutting zone with help of high-pressure gas results in a higher utilization rate of the trace amount 
of lubricant. And unique film-formation, atomization, and infiltration mechanisms of this technology also conducive to better cleaner manufacturing performance. Therefore, both environmental and processing performance could be achieved with employment of NEBL.

\section{Multi-factor influence with considering various components and concentrations of NEBL}

In order to improve performance stability of current process application and provide a theoretical guidance for sustainable machining of unexplored processing/ materials in future, it's important to understand how to obtain the best machining performance and establish optimization strategy of NEBL. It is closely related both base oils (plant oils) and nano-enhancer in terms of not only types but also volume/mass proportions. With this, this section focuses on understanding the mechanisms and optimization strategy in terms of different (i) base oils, (ii) nano-enhancer, and (iii) concentration of NEBL.

\subsection{Processability and mechanisms using different base oils}

In application of sustainable manufacturing, many kinds of plant oils are generally used as base oil of NEBL. It's more important to make clear the influence rule and mechanism of different base oil molecules on the lubrication/cooling performance, which is the theory basis for plant oil application in cleaner machining.

\subsubsection{Tribological aspect}

Force and CoFs: Based on the NEBL grinding trials of AISI 1045 [39] and Inconel 718 [72], the CoF by using sunflower, maize, and palm oils only showed a slight difference. They believe that the molecular structure of different vegetable oils is responsible for the differences. The application of castor oil in NEBL generated the largest CoF reduction of $50 \%$ (Fig. 16), which might be because of the high viscosity and the $-\mathrm{OH}$ group contained in fatty acids. In the drilling of Inconel 718 [74] and Ti-6Al-4V [57], the palm oil also outperformed synthetic ester in terms of cutting force,

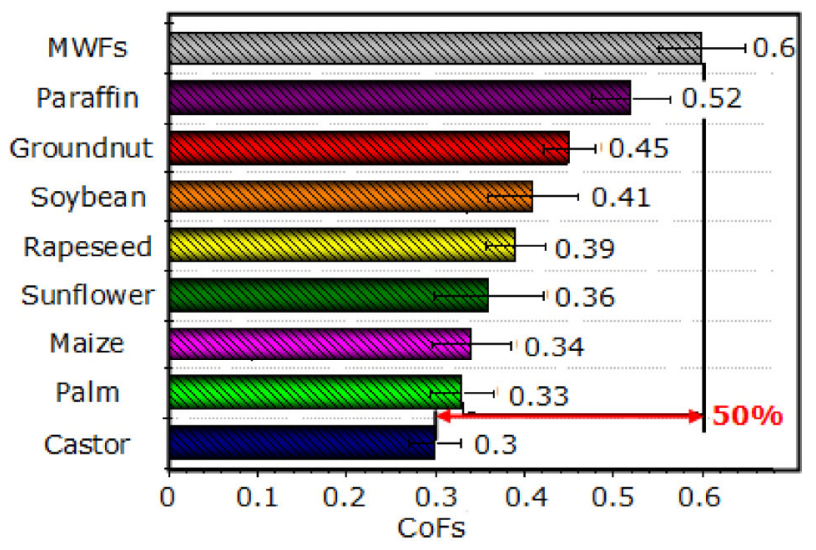

Fig. $16 \mathrm{CoFs}$ in Inconel 718 grinding with employment of different plant oils. Reproduced with permission from Ref. [72]. (C) Elsevier, 2016.

power, and specific cutting energy thanks to higher viscosity and high content of saturated fatty acids.

Tool wear: Tool wear and service life were also varied by using different kinds of plant oils. In NEBL milling of AISI 1045 [84, 85], the obvious tool wear was observed when using canola oil (better lubricity) and cottonseed oil (better cooling ability) (Fig. 17). Moreover, adhesion or attrition (stick-slip phenomenon) was recognised as the dominant wear mechanism for these two oil types. This is due to the different vegetable oils in the tool workpiece interface have relatively large differences in friction reduction and wear resistance.

Based on above experimental results analysis, it could be found that the tribological performance of different base oils are different and certain rules. This is closely related to the composition and molecular structure of the base oil, which will be discussed in-depth in Section 5.1.2.

\subsubsection{Varied lubrication performances due to micro- structures of base oils}

The above varied tribological performances in NEBL can attribute to different microstructures of plant oils in terms of (i) special polar groups, (ii) saturated levels of fatty acids, and (iii) molecular chain length.

(i) Special polar groups: For oils with special polar groups (such as $-\mathrm{OH}$ in castor oil [86]), they showed better lubrication performances than other oils because these polar groups significantly improved the formation ability (by stronger adhesion) and strength (by higher viscosity) of lubricating films. Therefore, this kind of oils can achieve much stronger adhesion between the 


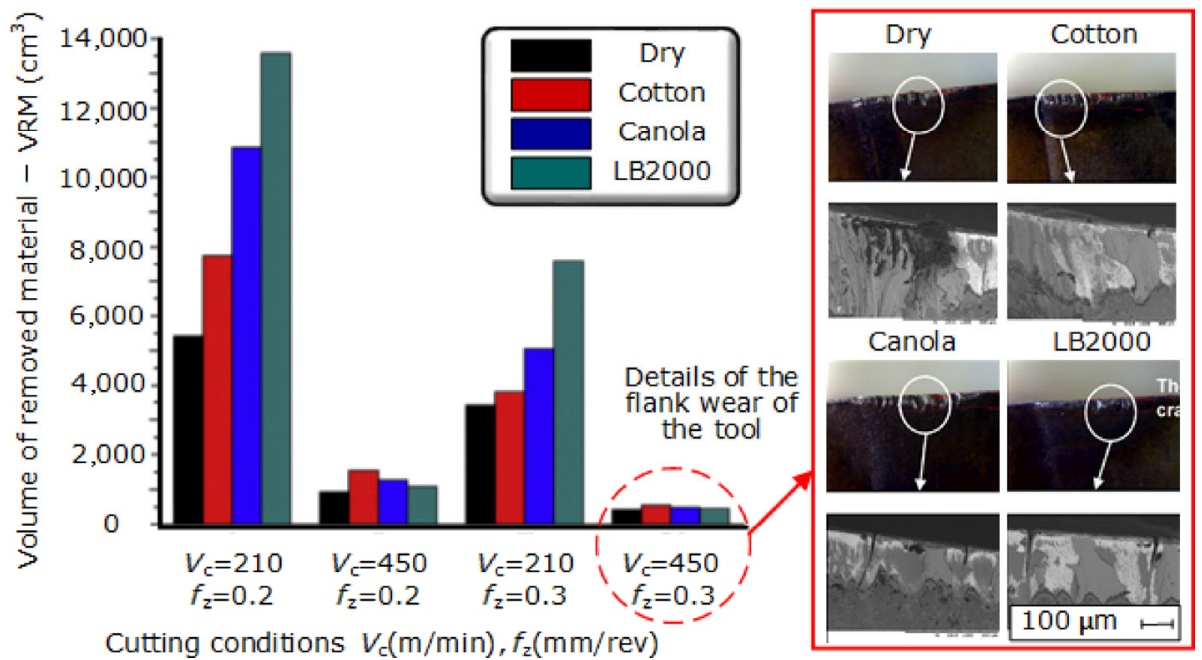

Fig. 17 The flank wear and tool life in milling of AISI 1045. Reproduced with permission from Ref. [85]. C Elsevier, 2017.

formed lubricating film and cutting edge/workpiece surfaces [22]. At the meantime, the high viscosity of these oils also enabled the good film strength. However, the excessively high viscosity resulted in poor heat transfer [87].

(ii) Saturated levels of fatty acids: Oils with high saturated levels of fatty acids (i.e. a small number of $\mathrm{C}=\mathrm{C}$ bonds on molecular chains) have better lubrication performance. This was because (i) no $\mathrm{C}=\mathrm{C}$ bonds existed and therefore the molecule can align itself as a slim and straight chain $[88,89]$, which improved the inter-molecular interactions due to the strong packing effect [70, 90] (Fig. 18); and (ii) $\mathrm{C}=\mathrm{C}$ bonds can be easily oxidized resulting in poor thermal stability of plant oils and consequently physical film failure [73].

(iii) Molecular chain length: Oils with longer molecular chain (i.e. a large number of carbon atoms) had better lubrication performances because absorption capability presented a rise trend with increasing carbon atom number [91, 92]. However, the largest improvement can be reached when carbon atom number was 16 [62].

In fact, lubrication property of plant oils is the comprehensive result of special polar groups, saturated levels of fatty acids, and molecular chain length. The weighted relationship between lubricating properties and molecular structures of plant oils (Fig. 19) can be:

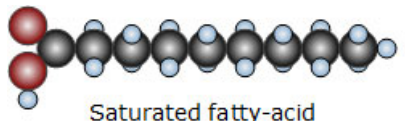

Saturated fatty-acid

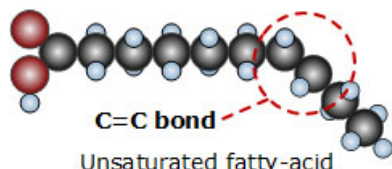

(a)

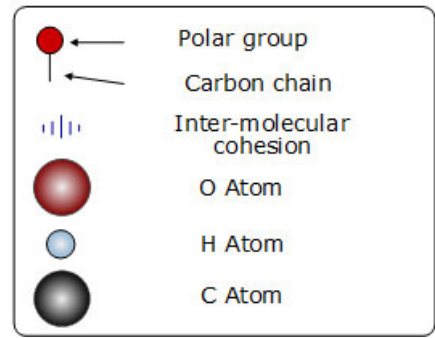

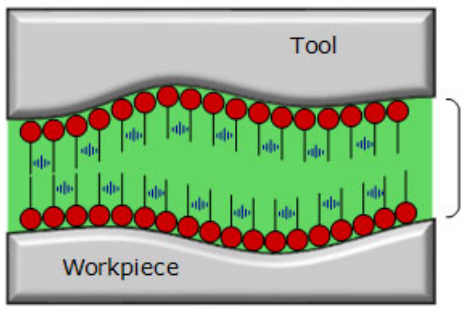

(b)

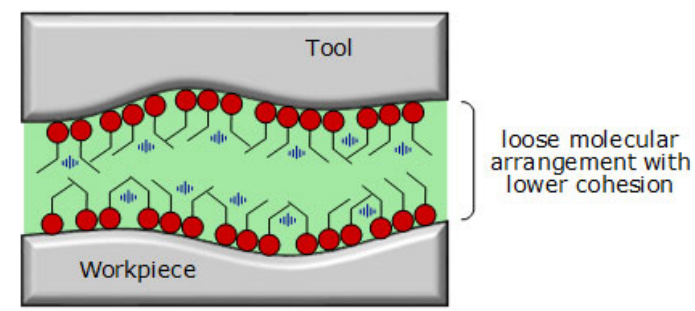
(c)

Tight molecular arrangement with higher cohesion

ose molecular ment with

Workpiece

Fig. 18 Schematic diagrams of lubrication mechanism in NEBL. (a) 3D structure of fatty acid; (b) lubricate with saturated fatty-acid; and (c) lubricate with unsaturated fatty-acid. 


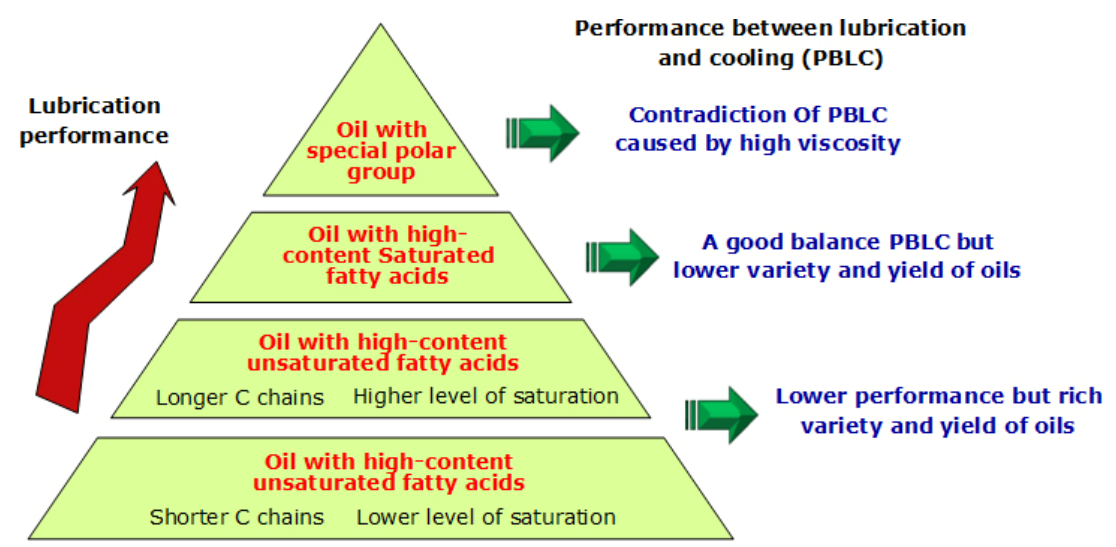

Fig. 19 The relationship between lubricating performance and molecular structure.

(i) plant oils with special polar groups presented the best lubrication performances; (ii) oils with the high content of saturated fatty acids had the second best lubrication performances; (iii) oils with the high content of unsaturated fatty acids had the third best performances because of the long carbon chains and the high-level saturation; and (iv) oils with short carbon chains had the worst lubrication due to the low-level saturation.

Please note superior plant oils in NEBL might require both good cooling and lubrication performances, and these two performances have the opposite relationships with oil viscosity. Although oils with special polar groups had the best lubrication performance, they presented the worst cooling performance.

\subsubsection{Thermal aspect}

Temperature: In comparison with other oils, castor oil resulted in the higher grinding temperature of $176^{\circ} \mathrm{C}$ and the larger $R$ value of $69.3 \%$ in grinding of Inconel 718 [72, 93]. On the contrary, palm oil based NEBL grinding generated the lowest grinding temperature of $119.6{ }^{\circ} \mathrm{C}$ and the smallest $R$ value of $52.3 \%$ (Figs. 20(a) and 20(b)). Cottonseed oil and canola oil also resulted in the low temperature and the good convective heat transfer in NEBL milling of AISI 1045 (Figs. 20(c) and 20(d)) due to its good spreadability proved by wettability tests [85]. Surprisingly, the rules obtained for heat transfer performance are different from those obtained for tribological aspect in Section 5.1.1. Castor oil has better tribological performance with lower cutting forces and CoFs, but it is not ideal in thermal aspect. It can be predicted that the viscosity and surface tension of base oil have different influence laws on the heat transfer performance, which belongs to the theory of boundary layer heat transfer.

\subsubsection{Heat transfer mechanism of boundary layer}

The above varied thermal performances of different plant oils can be explained by the heat transfer mechanism of boundary layer, which was affected by both viscosity and surface tension of NEBL [94].

For viscosity, oils with a lower viscosity can provide better cooling performance. This was because (i) droplets with a lower viscosity generated thinner viscous flows in thermal boundary layer at the toolworkpiece interface (Fig. 21(b)) [39]. The thermal boundary layer contained turbulence and viscous flows [95]. The former transferred more heat than the latter, and therefore the thickness reduction of viscous flows improved the heat transfer efficiency, and (ii) high viscosity in most cases referred to the large intramolecular friction, inactive Brownian movement, and consequently ineffective heat transfer behaviors. Therefore, oils with high viscosity generated small $R$ values.

For surface tension, oils with a lower surface tension can provide better cooling performance. This was because (i) droplets with lower surface tension were small in size but with a high specific surface area $[70,96]$, covering a large area by a unit volume of lubricant and therefore improving cooling performance [97-100] (Fig. 21(a)); (ii) the thermal boundary layer would be expanded when the surface tension was low (Fig. 21(c)), and improved the cooling efficiency by using a unit volume of lubricant because the thermal 


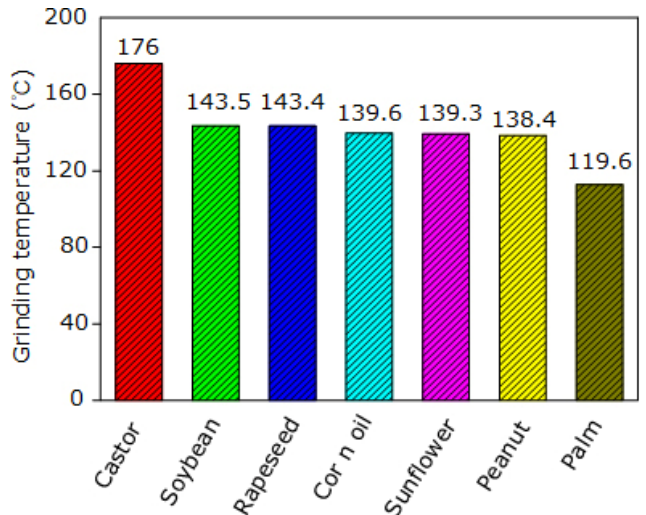

(a)

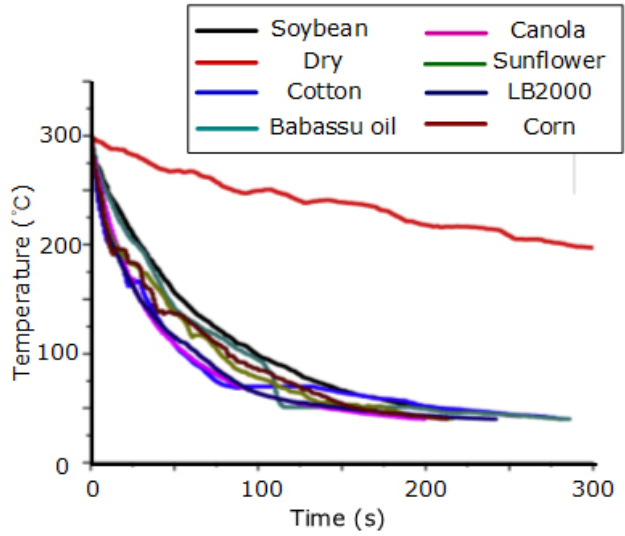

(c)

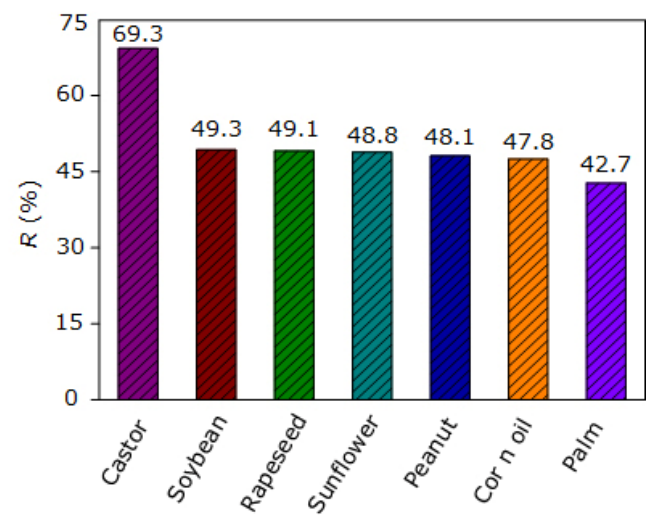

(b)

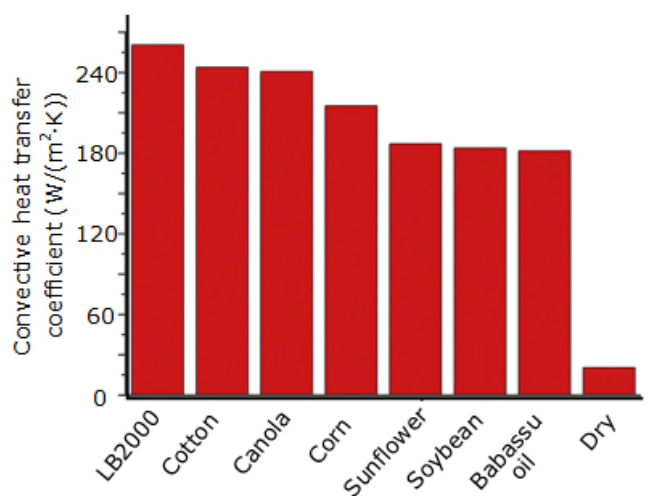

(d)

Fig. 20 Thermal parameters of different plant oils. (a) Temperature in Inconel 718 grinding and (b) $R$ in Inconel 718 grinding. Reproduced with permission from Ref. [93]. C) The Authors, 2015. (c) Temperature curve in V-AISI 1045 milling and (d) Convection heat transfer coefficient of different plant oil. Reproduced with permission from Ref. [85]. C) Elsevier, 2017.

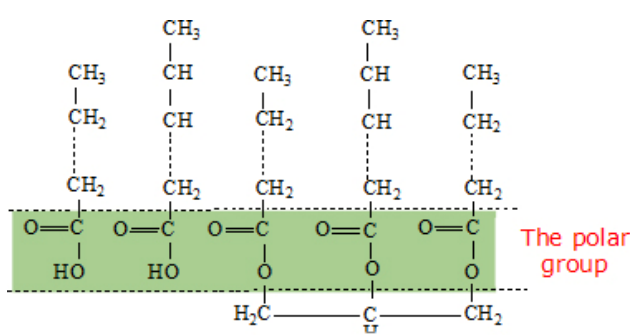

(a)

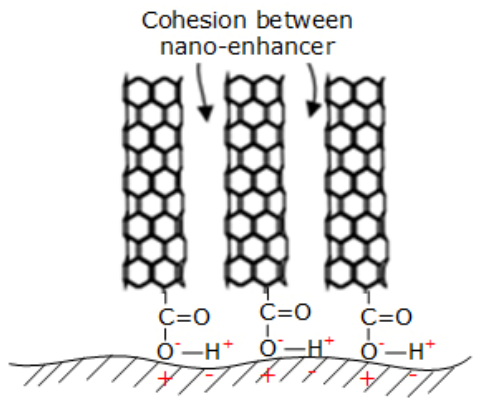

(c)

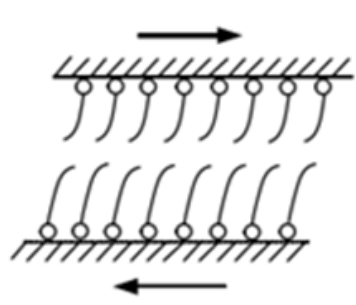

(b)

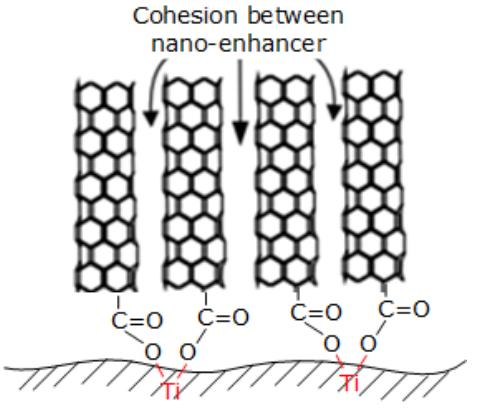

(d)

Fig. 21 Schematic diagrams of heat transfer mechanism in NEBL. (a) Oval spray boundary in grinding zone; (b) heat transfer mechanism of thermal boundary layer; and (c) influence mechanism of surface tension on cooling performance. Reproduced with permission from Ref. [39]. (C) Elsevier, 2016. 
boundary layer played the leading role due to the high speed in cutting zone; and (iii) fog droplets with a lower surface tension (i.e., small contact angle) spreaded out more quickly than those with a large surface tension.

\subsubsection{Machined surface integrity}

In comparison with other plant oils, the employment of castor oil in NEBL grinding of Inconel 718 [72] resulted in good machined surface morphology and small roughness value $\left(R_{a}\right.$ of $0.366 \mu \mathrm{m}$ and $R S_{m}$ of $32.4 \mu \mathrm{m}$ ) (Fig. 22(a)). The similar result was also obtained in grinding of $\mathrm{H} 13$ hot die steel using castor oil [101]. The average thickness of the deformed layer, which was related to the sticking friction due to elevated temperature [102], was in the range from 122 to $167 \mathrm{~mm}$ [74] (Fig. 22(b)).

In the BMQL drilling of AISI 316 using palm oil, olive oil, and sesame oil, however, adhesion was found which indicated the increased friction and flank wear in tool/workpiece interface due to low thermal conductivity of lubricants [103]. Further, the least

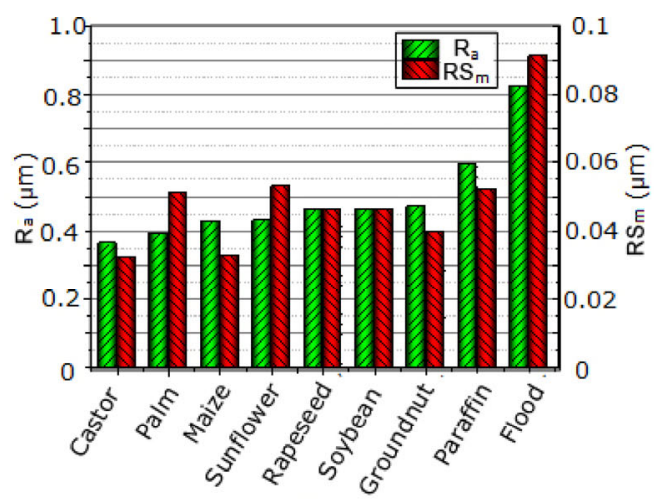

(a)
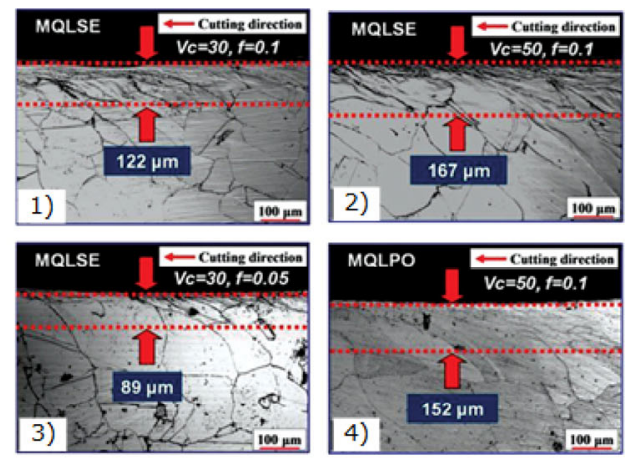

(b)

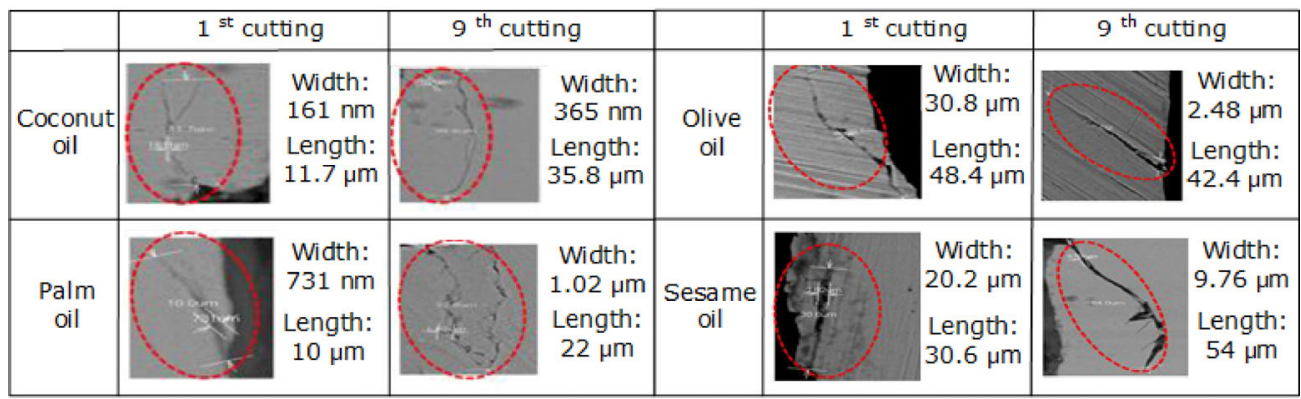

(c)

Fig. 22 Machined surface integrity of NEBL with employment of different plant oil. (a) $R_{a}$ in Inconel718 grinding. Reproduced with permission from Ref. [72]. (C) Elsevier, 2016. (b) Plastically deformed layer below the machined surface in inconel 718 drilling. Reproduced with permission from Ref. [74]. (C) Taylor \& Francis Group, LLC, 2011. (c) Surface texture and micro cracks In AISI 316 drilling. Reproduced with permission from Ref. [103]. @ AENSI, 2014.

amount of micro-cracks for coconut oil (lowest viscosity) and the largest amount of micro-cracks for sesame oil (biggest viscosity) were observed (Fig. 22(c)).

It could be obtained that different plant oils have different machining performances, and the varied molecular structure and physicochemical properties (viscosity and surface tension) are the key reason. Higher viscosity of biolubricant benefits lubrication performance, while lower surface tension benefits heat transfer performance. Unfortunately, high viscosity and low surface tension couldn't co-exist in natural plant oils. This contradiction will be discussed detailly in Section 6.

\subsection{Processability and mechanisms using different nano-enhancers}

The use of different nano-enhancer are expanding options of plant oil for various processing and materials in cleaner machining system. It's necessary to understand the effects of micromorphology and physical properties of nano-enhancer on cooling and lubrication performance, which is key reference

政 
for cleaner process design based on machining and economic performances.

\subsubsection{Tribological aspect}

Force and CoF: Two or three kinds of nano-enhancers such as $\mathrm{Al}_{2} \mathrm{O}_{3}, \mathrm{MoS}_{2}$, and CNTs [21, 23, 24, 42] were often used in NEBL grinding and different force and $\mathrm{CoF}$ were observed. The $\mathrm{CoFs}$ for $\mathrm{MoS}_{2}, \mathrm{Al}_{2} \mathrm{O}_{3}$, and $\mathrm{SiO}_{2}$ NEBL were decreased separately by $31.4 \%$, $35.3 \%$, and $34.8 \%$ when using traditional MWFs as the reference (Fig. 23(a)) [104], which might be because nano-enhancer (with either spherical and stratiform molecular structure) played a lubricating role in grinding zone. Further, the composite nano-enhancers present better lubrication performance than mono one. In NMQL grinding research of Inconel 718, the $\mathrm{CoF}$ for composite $\mathrm{MoS}_{2} / \mathrm{CNT}$ NEBL was decreased separately by $8.8 \%$ and $15.3 \%$ comparing with mono $\mathrm{MoS}_{2}$ and CNT [15]. The tangential force reduction of $20.9 \%$ and $35.0 \%$ were obtained by $\mathrm{Al}_{2} \mathrm{O}_{3} / \mathrm{SiC}$ comparing with mono $\mathrm{Al}_{2} \mathrm{O}_{3}$ and $\mathrm{SiC}[105,106]$, respectively. The results of CoFs and specific grinding

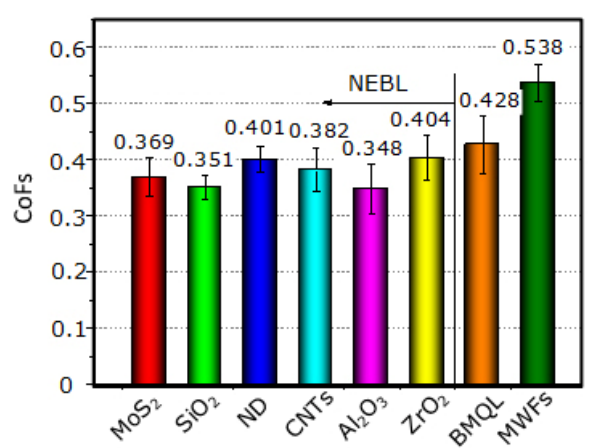

(a)

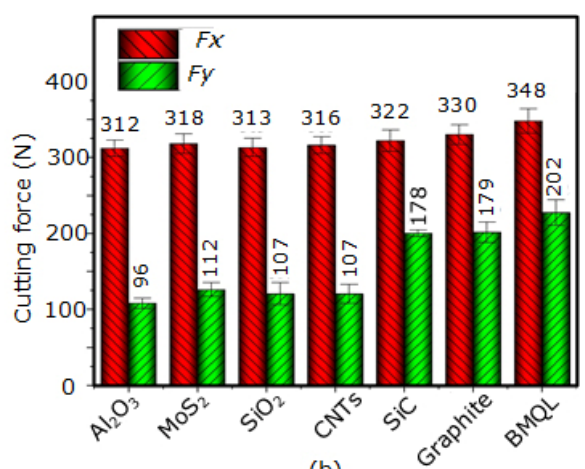

(b)

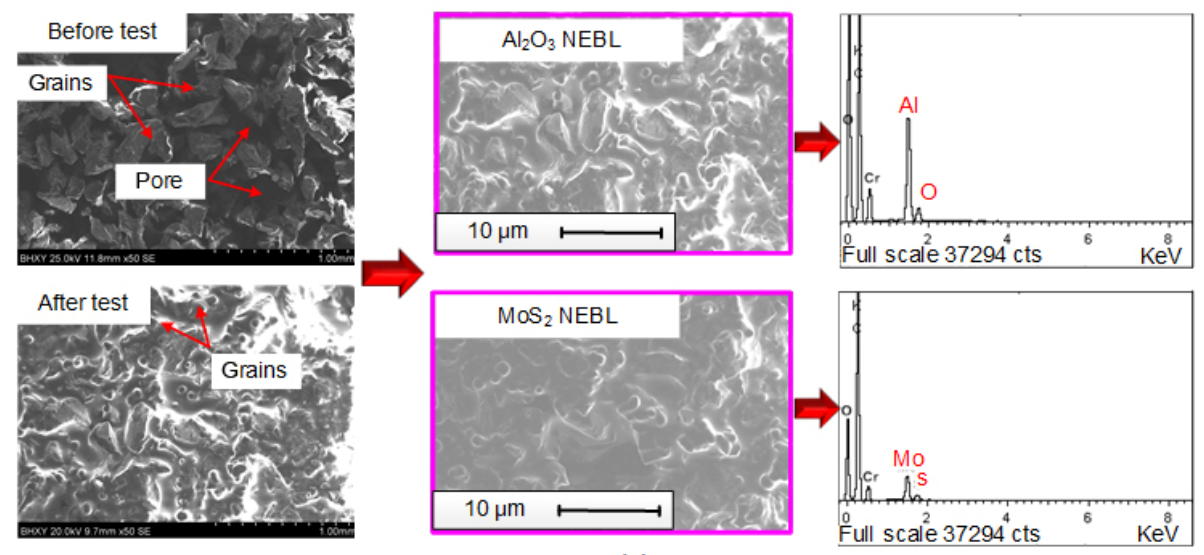

(c)

\begin{tabular}{|l|c|c|}
\hline $\begin{array}{c}\text { Machining } \\
\text { conditions }\end{array}$ & Alumina nanofluid & Alumina/MWCNT hybrid nanofluid \\
\hline $\begin{array}{l}v=120 \mathrm{mmin}, \\
f=0.12 \mathrm{~mm} / \mathrm{rev}, \\
d=0.9 \mathrm{~mm}, \\
n p=0.25 \%\end{array}$ & High flank wear & \\
& Wois flank wear \\
& Worn out cutting edge $200 \mu \mathrm{m}$ & \\
\hline
\end{tabular}

(d)

Fig. 23 Tribological parameters in NEBL machining with employment of different nano-enhancers. (a) CoFs in Inconel 718 grinding. Reproduced with permission from Ref. [104]. C Elsevier, 2016. (b) Cutting force in Ti-6Al-4V milling. Reproduced with permission from Ref. [107]. (C) Springer Nature, 2018. (c) SEM and EDS of the wheel block surface before and after grinding. Reproduced with permission from Ref. [61]. C Elsevier, 2017. (d) Microscopic photographs of tool flank wear with alumina and alumina/MWCNT based NEBL. Reproduced with permission from Ref. [111]. (C) The author(s), 2018. 
energy present similar trend. They attribute the improved performance to 'physical synergistic effect' of composite nano-enhancers. In further research [106], they found that a composite of large particle size $\mathrm{Al}_{2} \mathrm{O}_{3}$ and small particle size $\mathrm{SiC}$ can increase the grinding efficiency furtherly. It maybe due to the 'physical coating' phenomenon of the $\mathrm{Al}_{2} \mathrm{O}_{3} / \mathrm{SiC}$ with different particle sizes.

Except for grinding, cutting forces and $\mathrm{CoF}$ in NEBL milling of Ti-6Al-4V presented the similar results, where $\mathrm{Al}_{2} \mathrm{O}_{3}$ NEBL achieved the minimum milling force and CoF compared with another five kinds of nano-enhancers (Fig. 23(b)) [107]. Cutting forces and CoF in NEBL turning of AISI 4340 obtained the lowest value, where $\mathrm{CuO}$ NEBL achieved the minimum milling force and $\mathrm{CoF}$ compared with $\mathrm{Fe}_{2} \mathrm{O}_{3}$ and $\mathrm{Al}_{2} \mathrm{O}_{3}$ nano-enhancers $[108,109]$.

Tool wear: The G-ratio for $\mathrm{MoS}_{2}$ and $\mathrm{Al}_{2} \mathrm{O}_{3}, \mathrm{SiO}_{2}$ NEBL were increased separately by $66.1 \%$ and $82.9 \%$ compared to traditional MWFs for Inconel 718 [104]. Further observation of the grinding wheel surface showed that oil film existed on the abrasive surface and contained nano-enhancer elements by SEM and EDS analysis (Fig. 23(c)) [61]. It can be inferred that nano-enhancers can form lubricating oil film on the surface of abrasive particles, thus reducing friction coefficient and improving wear resistance of grinding wheel. The average flank wear of AISI 1045 turning also obtained similar results [110].

Compared with mono $\mathrm{Al}_{2} \mathrm{O}_{3}$, the value $\mathrm{VB}$ was reduced by $11 \%$ with employment of $\mathrm{Al}_{2} \mathrm{O}_{3} / \mathrm{CNT}$ in NEBL turning trials of AISI 304 stainless steel [111]. The worn out cutting edge observed in $\mathrm{Al}_{2} \mathrm{O}_{3}$ NEBL turning was significant less by composite nanoenhancers (Fig. 23(d)). They ascribe it to 'synergic effect' of $\mathrm{Al}_{2} \mathrm{O}_{3} / \mathrm{CNT}$ during relative motion between the sliding surfaces. The usage of $\mathrm{GO} / \mathrm{SiO}_{2}$ also obtained improved tool wear than mono one in NMQL milling, severe chipping and fracture was avoided [112]. In addition, Ali et al. [113] found that the size of nanoenhancer plays a significant role in NMQL turning. The usage of $\mathrm{Al}_{2} \mathrm{O}_{3}$ with $50 \mathrm{~nm}$ particle size in NMQL nanolubricant reduced tool wear by $62.5 \%$ compared to that of $\mathrm{Al}_{2} \mathrm{O}_{3}$ with $600 \mathrm{~nm}$ particle size.

Based on above researches, it could be concluded that the geometries and hybrid use of nano-enhancers are the main factor for tribological aspect. Although particle size also plays a role, it is only mentioned as the influencing factor in references of application of composite nano-enhancers. It's difficlt to find a universal law for different kinds of hybrid nano-enhancers. Therefore, the various anti-friction mechanisms due to geometries and combination modes of nano-enhancer will be discussed detailly in Section 5.2.2.

\subsubsection{Various anti-friction mechanisms due to geometries} and combination modes of nano-enhancers

(i) Effect of nano-enhancers shape on lubrication performance. The above varied tribological performances in NEBL are related with anti-friction mechanism of nanoenhancers thanks to spherical, threadiness, and stratiform nano-enhancers geometries.

Spherical nano-enhancer with high hardness and strength (such as $\mathrm{Al}_{2} \mathrm{O}_{3}$ and $\mathrm{SiO}_{2}$ ) showed remarkable diffusivity and lubrication property in cutting zone. They changed the friction condition from sliding to rolling friction. The lubricating behaviors can be featured by rolling (Fig. 24(a)), protective film forming (Fig. 24(b)), wear restoration (Fig. 24(c)), and polishing (Fig. 24(d)) [114, 115] so that tool life, temperature, and force can be largely improved.

Threadiness nano-enhancer showed good lubrication performance but the performance was limited by nano-enhancer concentration in NEBL. When threadiness nano-enhancer with a low concentration was introduced in cutting zone, threadiness nano-enhancer can act as 'cylindrical bearing' therefore significantly reduce friction. However, when threadiness nano-enhancer with a high concentration was introduced in cutting zone, the formation of cluster would lead to poor friction lubricating performance [15].

Stratiform nano-enhancer can act as a good solid lubricant in tool/workpiece interface (Figs. 24(e) and 24(f)) [116]. The low shearing strength between neighboring layers in nano-enhancer microstructure allowed the smooth sliding at the interface [118]. Different stratiform nano-enhancer presented different lubrication performances due to varied intermolecular force, and in most cases the performance was positively related with relative molecular mass [116].

(ii) Performance gain of composite nano-enhancers. It has been verified by above researches that composite 


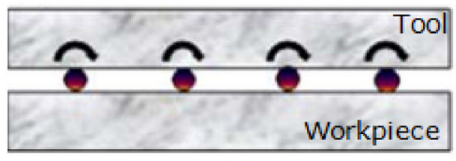

(a)

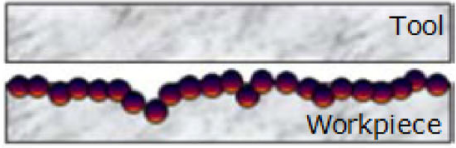

(b)

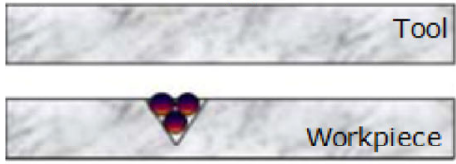

(c)

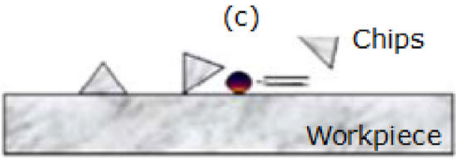

(d)

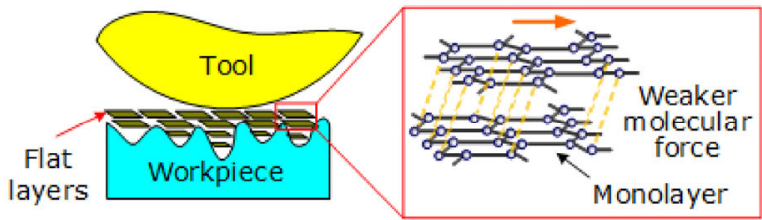

(e)

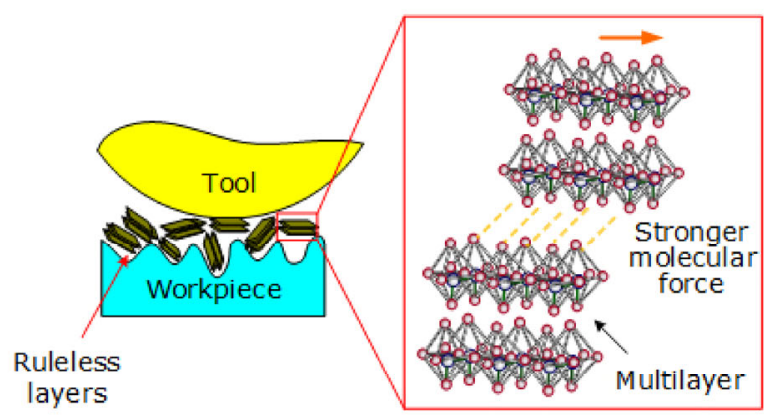

(f)

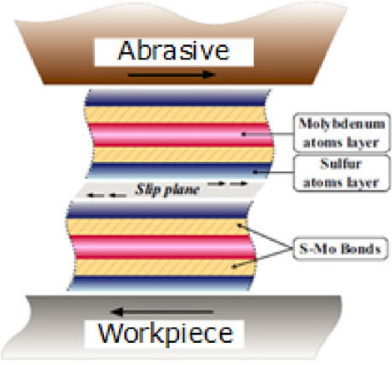

(g)

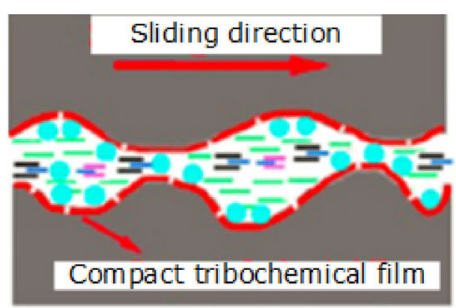

(h)

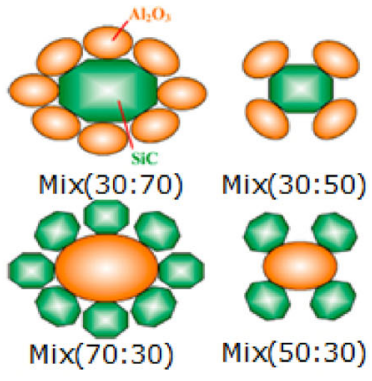

(i)

Fig. 24 Schematic diagrams of anti-friction mechanisms in NEBL machining. (a) Rolling effect of spherical nano-enhancer; (b) protective effect of spherical nano-enhancer; (c) mending effect of spherical nano-enhancer; and (d) polishing effect of spherical nano-enhancer. Reproduced with permission from Ref. [114]. C Springer Science + Business Media, LLC, 2009. (e) Lubrication effect of graphene nano-enhancer; and (f) lubrication effect of other stratiform nano-enhancer. Reproduced with permission from Ref. [116]. (C) Springer Nature, 2019. (g) Physical synergistic effect of $\mathrm{MoS}_{2} / \mathrm{CNT}$. Reproduced with permission from Ref. [15]. C Elsevier, 2015. (h) Synergistic effect of $\mathrm{SiO}_{2} / \mathrm{MoS}_{2}$ hybrid nano-enhancers. Reproduced with permission from Ref. [117]. (C) The Author(s), 2016. (i) 'Physical coating' phenomenon of the $\mathrm{Al}_{2} \mathrm{O}_{3} / \mathrm{SiC}$ with different particle sizes. Reproduced with permission from Ref. [106]. (C) Elsevier, 2016.

nano-enhancers present better tribological property than mono nano-enhancers, especially in the uneven tool workpiece interface. This effect was named as 'physical synergistic effect' by researches. The essence of this phenomenon is that the hybrid use of nanoenhancer with different shapes could change the anti-friction behavior of NEBL.

As seen in Figs. 24(g) and 24(h), stratiform nanoenhancer are distributed in parallel in the interface of the tool workpiece, which divides the uneven lubrication zone into regular shear-sliding interface. On this basis, the spherical or tubular nano-enhancers play a rolling role in reducing friction between the shear interfaces, and play a filling role on the surface of the workpiece and the tool. There are the following advantages: on the one hand, this mode of composite use increases the bearing capacity of NEBL at the high pressure interface, avoiding congestion and interference of nanoparticles between each other caused by the use of single shape nano-enhancers, thus significantly reducing the coefficient of friction. On the other hand, the stratiform nano-enhancer with excellent lubrication performance and the tubular/spherical nanoparticles with high thermal conductivity could act at the same time, which is expected to improve the lubrication performance and increase the thermal conductivity. As seen in Fig. 24(i), the particle size is also the main factor of 'physical coating' phenomenon of the $\mathrm{Al}_{2} \mathrm{O}_{3} / \mathrm{SiC}$.

In addition, Xiong et al. [119] reported that the better lubrication performance mainly attributed to 
composite nano-enhancers increases the viscosity of nanofluids and the oil film to avoid the direct contact tribopair during hot rolling, thus reducing the friction coefficient and roll wear.

\subsubsection{Thermal aspect}

Temperature and $R$ : Based on the NEBL grinding trials of Inconel718, the application of CNTs NEBL obtained the lowest grinding temperature of $110.7{ }^{\circ} \mathrm{C}$ and $R$ value of $40.1 \%$ compared to other five typical kinds of nano-enhancers (Fig. 25) [120]. In another research of turning, $\mathrm{MoS}_{2}$ based NEBL showed thermal conductivity, specific heat, and viscosity than $\mathrm{CaF}_{2}$ based NEBL [79].

Based on the NEBL turning trials of AISI 304 stainless steel [111], the application of $\mathrm{Al}_{2} \mathrm{O}_{3} / \mathrm{CNT}$ improved thermal conductivity of $2.6 \%$ compared with mono NEBL. A significant reduction of $27.36 \%$ in the nodal temperature was achieved for $\mathrm{Al}_{2} \mathrm{O}_{3} / \mathrm{CNT}$ hybrid nano-enhancer compared to $\mathrm{Al}_{2} \mathrm{O}_{3}$. There were $16.6 \%$ and $10.25 \%$ decrease in cutting temperature when turning of EN-24 steel under $\mathrm{Al}_{2} \mathrm{O}_{3} / \mathrm{CuO}$ NEBL as compared to $\mathrm{Al}_{2} \mathrm{O}_{3}$ and $\mathrm{CuO}$ NEBL [121]. They suggesting that the mixing of $\mathrm{CNT}$ with $\mathrm{Al}_{2} \mathrm{O}_{3}$ improves the spreadability, thanks to its smallest contact angle. In another researches, although lubrication performance was improved by composite of $\mathrm{MoS}_{2} /$ $\mathrm{Al}_{2} \mathrm{O}_{3}$ [122], $\mathrm{CNT} / \mathrm{Al}_{2} \mathrm{O}_{3}$ [123] and graphene $/ \mathrm{Al}_{2} \mathrm{O}_{3}$ [124-126], they found that it also affects the thermal conductivity negatively. This phenomenon maybe caused by increased viscosity of composite NEBL compared with mono NEBL, which weakens cooling performance.

It could be concluded that the heat conductivity coefficient, shape, and particle size of nano-enhancers are the main influence factors for thermal aspect, which will be discussed in Section 5.2.4.

\subsubsection{Various heat transfer mechanisms of different nano- enhancers}

The above varied cooling performances in NEBL are related with heat transfer mechanism of nanoenhancers, which could be understood from three aspects.

(i) Heat conductivity coefficient of nano-enhancer: The introduction of nano-enhancer significantly improved heat transfer ability of NEBL because the heat conductivity coefficient of nano-enhancer is much higher than that of plant oils (Table 1) [127]. This explained why CNTs NEBL presented the best cooling performance.

(ii) Effect of nano-enhancers shape on heat transfer: Except for Brownian motion, self-rotational of nanoenhancer was another key heat transfer behavior between nano-enhancers and plant oil. Nonspherical nano-enhancer had a higher rotational speed than spherical ones in NEBL, and therefore generated a larger disturbance region. Hence, the local micro-

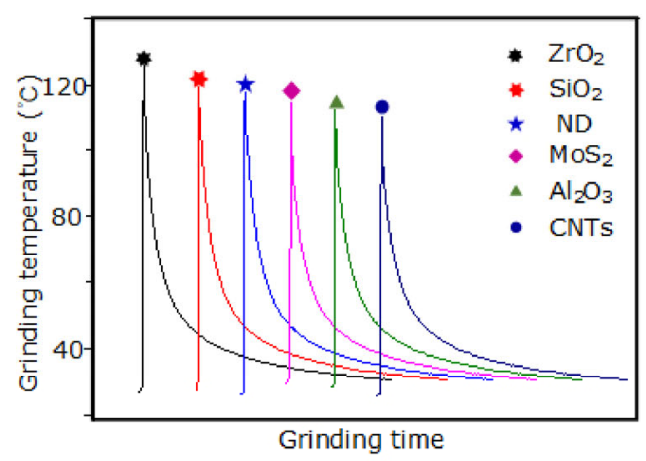

(a)

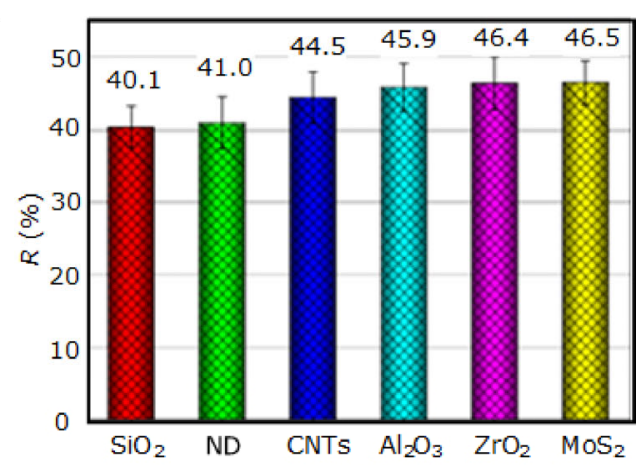

(b)

Fig. 25 Thermal parameters in Inconel718 NEBL grinding with employment of different nano-enhancers. (a) Temperatures and (b) $R$. Reproduced with permission from Ref. [120]. C Elsevier, 2017.

Table 1 Heat conductivity coefficient of different nano-enhancers.

\begin{tabular}{cccccccccc}
\hline Nano-enhancers & $\mathrm{ZrO}_{2}$ & $\mathrm{SiO}_{2}$ & $\mathrm{HBN}$ & $\mathrm{Al}_{2} \mathrm{O}_{3}$ & $\mathrm{MoS}_{2}$ & $\mathrm{ND}$ & $\mathrm{CNT}$ & $\mathrm{GR}$ \\
\hline Heat conductivity coefficient $\left(\mathrm{W} \cdot \mathrm{m}^{-1} \cdot \mathrm{K}^{-1}\right)$ & $<2$ & 7.6 & 33 & 40 & 138 & 2300 & 3000 & 5300 \\
\hline
\end{tabular}


convection and energy transmission can be enhanced between the nano-enhancer surface and the liquid (Fig. 26) [47].

(iii) Effect of particle size of nano-enhancers on heat transfer: Particle size of nano-enhancers play an important role in increasing thermal conductivity of NEBL. On the one hand, the thermal conductivity will be increased by smaller size of nano-enhancers, due to the active Brownian motion. This can also be verified by classical equation of thermal conductivity of nanofluids, as studied in Ref. [128]. On the other hand, at the same dosage, smaller particles have larger specific surface area, which is more conducive to improving the heat transfer efficiency of nanoparticles in the base oil.

\subsubsection{Machined surface quality}

In comparison with other kinds of nano-enhancer, the employment of $\mathrm{Al}_{2} \mathrm{O}_{3}$ in NEBL grinding of Inconel718 resulted in good machined surface morphology with neither obvious ductile plowing nor adhesion phenomena [104]. The $R_{a}$ was reduced to $0.30 \mu \mathrm{m}$ while $\mathrm{RS}_{\mathrm{m}}$ was reduced to $38 \mu \mathrm{m}$ (Fig. 27(a)). In

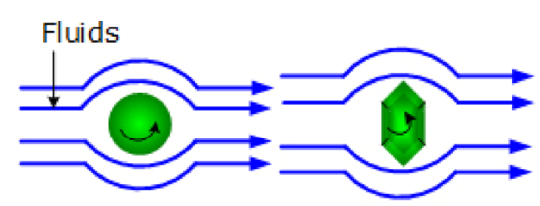

(a) (b)

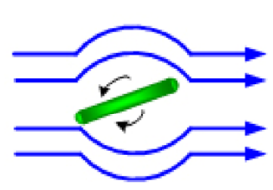

(c)
Fig. 26 Schematic diagrams of self-rotational motion of nanoenhancer. (a) Spherical nano-enhancer; (b) irregular nano-enhancer; and (c) tubular nano-enhancer. Reproduced with permission from Ref. [47]. (C) Taylor \& Francis, 2017. comparison with mono nano-enhancer, the employment of $\mathrm{MoS}_{2} / \mathrm{CNT}$ in NEBL grinding of Inconel 718 resulted in good machined surface morphology with no workpiece burns phenomena [15]. When the mix ratio of $\mathrm{MoS}_{2}$ and CNT is 2:1, the $\mathrm{R}_{\mathrm{a}}$ was reduced to $0.294 \mu \mathrm{m}, 13 \%$ and $38.9 \%$ lower than that of mono $\mathrm{MoS}_{2}$ and CNT, respectively. Compared with mono $\mathrm{MoS}_{2}$ in NMQL grinding, subsurface damage layer of $\mathrm{Si}_{3} \mathrm{~N}_{4}$ was significantly reduced with employment of $\mathrm{MoS}_{2} / \mathrm{WS}_{2}$ [129].

Similar result was obtained in NEBL milling of Ti-6Al-4V (Figs. 27(b)-27(e)) [107] . Spherical $\mathrm{Al}_{2} \mathrm{O}_{3}$ achieved the minimum roughness value $\left(R_{a}\right.$ of $0.633 \mu \mathrm{m}$ and $\mathrm{RS}_{\mathrm{m}}$ of $\left.95 \mu \mathrm{m}\right)$. Good machined surface morphology and higher $\mathrm{Al}$ atom content were also observed on workpiece surface by SEM and EDS. Spherical $\mathrm{SiO}_{2}$ nano-enhancer also had good machined surface topographies and morphologies containing the biggest profile supporting length rate $\left(\mathrm{R}_{\mathrm{mr}}\right)$ of workpiece, and shallow scratches. In addition, the usage of $\mathrm{Al}_{2} \mathrm{O}_{3} / \mathrm{CuO}$ obtained lower $\mathrm{R}_{\mathrm{a}}$ than mono $\mathrm{Al}_{2} \mathrm{O}_{3}$ in turning of EN-24 steel [121].

Based on above, it might be concluded that different nano-enhancers have different machining performances, and the varied microstructure and heat conductivity coefficient are the key reason. Threadiness CNTs presents better cooling performance, however, its lubrication performance is worse than stratiform and spherical nano-enhancers. This contradiction might be solved by composite using of different kinds of nano-enhancers. Because there are many more

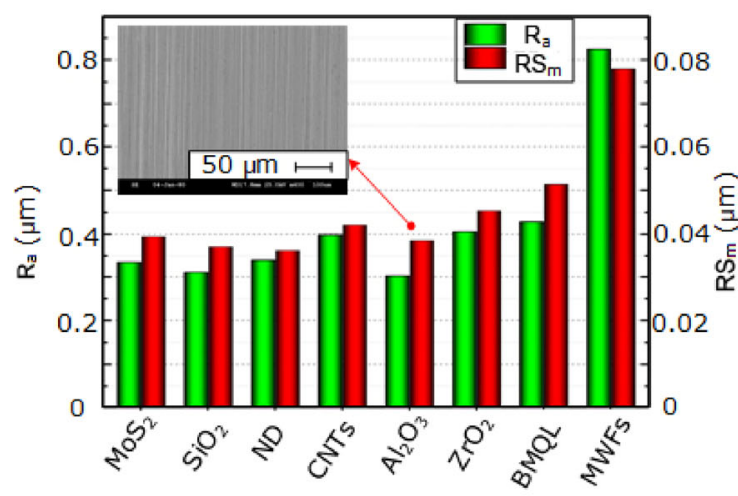

(a)

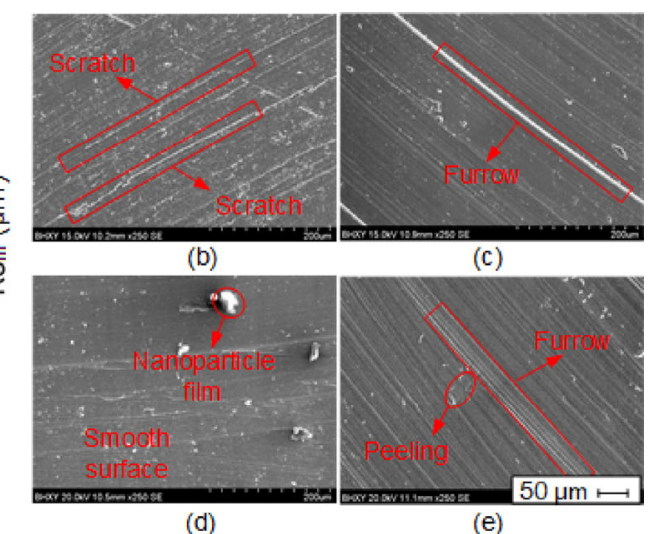

(d) (e)

Fig. 27 Machined surface integrity of NEBL with employment of different nano-enhancer. (a) $\mathrm{R}_{\mathrm{a}}$ in Inconel718 grinding. Reproduced with permission from Ref. [104]. (C) Elsevier, 2016. SEM images in Ti-6Al-4V milling with employment of (b) $\mathrm{Al}_{2} \mathrm{O}_{3}$; $\left(\right.$ c) $\mathrm{MoS}_{2}$; (d) $\mathrm{SiO}_{2}$; and (e) CNTs. Reproduced with permission from Ref. [107]. C) Springer Nature, 2018. 
possibilities for composite nano-enhancers, it is hard to predict a best mixing scheme from the limited literature.

\subsection{Processability and mechanisms using different concentration of NEBL}

It's no doubt that increasing the concentration of NEBL could improve the processing performance. However, it's also one of the most important contents that obtained appropriate concentration to not only realize machining performance but also avoid waste after excessive use. Therefore, the mechanism understanding of concentration on tribological and thermal performance is the major content in sustainable machining.

In the early studies, pioneers employed two or three concentration values for NEBL in research such as $\mathrm{MoS}_{2}-$ Soybean oil (5 $\mathrm{wt} \%, 20 \mathrm{wt} \%$ ) [130], EP additive-coconut oil $(8 \%, 12 \%)$ [131], diamond NEBL (1 vol\%, 2 vol\%) [132], $\mathrm{MoS}_{2}$-Soybean oil (2 wt \%, $8 \mathrm{wt} \%$ ) [41], exfoliated graphite NEBL (0.1 vol\%, $1 \mathrm{vol} \%)$ [37], and $\mathrm{Al} / \mathrm{MoS}_{2}$ NEBL (0.25 vol\%, $0.75 \mathrm{vol} \%$, and
$1.25 \mathrm{vol} \%$ ) [122]. However, few studies discussed the accurate relation between machining performances and concentration.

\subsubsection{Tribological aspect}

Force and CoF: Based on the comprehensive NEBL grinding trials of Inconel718 [133], the employment of $1.5 \mathrm{vol} \% \mathrm{Al}_{2} \mathrm{O}_{3}$-palm oil NEBL obtained the larger CoF reduction of $29.7 \%$ (Fig. 28(a)) and the larger specific grinding energy reduction of $34.4 \%$ compared to palm oil. With the concentration increasing from 0 to $4.0 \mathrm{vol} \%, \mathrm{CoF}$ and specific grinding energy presented first falling and then rising trend, which might be due to aggregation effect of nano-enhancer. The similar result was obtained for Ti-6Al-4V-ELI. The employment of concentration $1.5 \mathrm{wt} \%$ graphene NEBL obtained the larger CoF reduction of $17.3 \%$ and the larger force reduction of $25 \%$ compared to BMQL [134].

Except for grinding, NEBL milling force of TC4 [135] and Inconel 690 [136] presented the similar results.

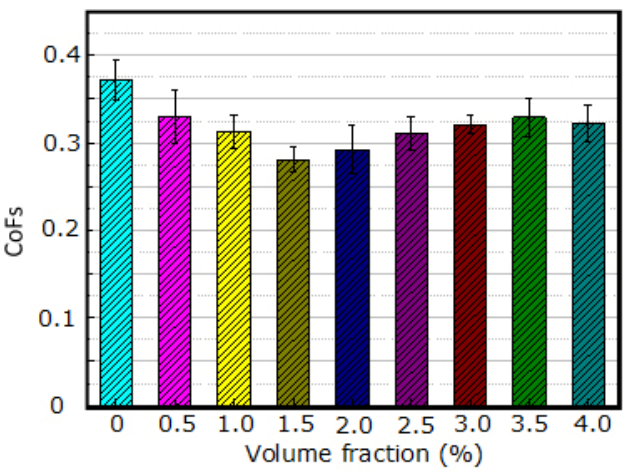

(a)

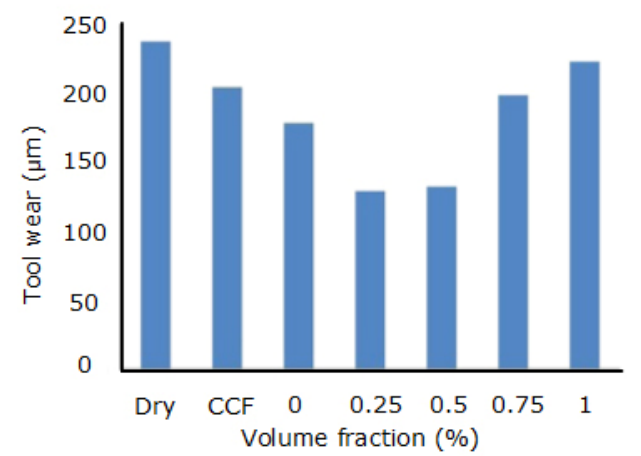

(c)

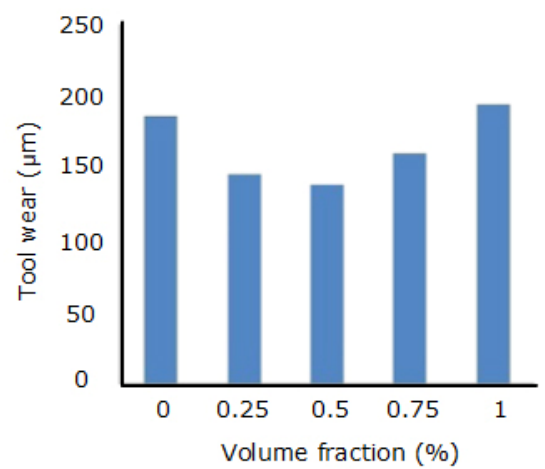

(b)

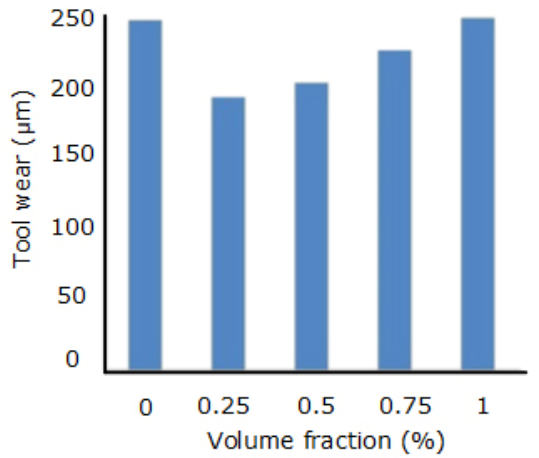

(d)

Fig. 28 Tribological parameters in machining with employment of different concentrations of NEBL. (a) CoFs in Inconel718 grinding of with employment of $\mathrm{Al}_{2} \mathrm{O}_{3}$-palm oil NEBL. Reproduced with permission from Ref. [133]. C Elsevier, 2017. Tool wear in AISI 1040 turning with employment of (b) $\mathrm{MoS}_{2}$-sesame oil NEBL; (c) $\mathrm{MoS}_{2}$-coconut oil NEBL; and (d) MoS 2 -canola oil NEBL. Reproduced with permission from Ref. [137]. C) Elsevier, 2016. 
The employment of concentration $0.1 \mathrm{wt} \%$ graphene NEBL obtained the larger CoF reduction of $26.3 \%$ and the larger force reduction of $42.7 \%$ compared to BMQL [135].

Tool wear: Tool wear was also varied by using different concentration of NEBL. Based on the comprehensive NEBL grinding trials of Inconel718 [133], the employment of $2.5 \mathrm{vol} \% \quad \mathrm{Al}_{2} \mathrm{O}_{3}$-palm NEBL obtained the larger G-ratio increase of $50 \%$ compared to palm oil based BMQL. In NEBL turning of AISI 1040 [137], the smallest tool wear was respectively observed when using $0.5 \mathrm{vol} \%$ for $\mathrm{MoS}_{2}$-sesame oil NEBL (Fig. 28(b)), 0.25 vol\% for $\mathrm{MoS}_{2}$-coconut oil (Fig. 28(c)), and $\mathrm{MoS}_{2}$-canola oil NEBL (Fig. 28(d)). The curve of tool wear also showed a change trend of first falling and then rising.

\subsubsection{Thermal aspect}

Temperature and $R$ : Temperature presented a similar variation trend with the increasing concentration of CNTs-palm oil NEBL in grinding of Inconel718 [138]. The employment of concentration 2 vol\% NEBL obtained the lowest grinding temperature of $108.9^{\circ} \mathrm{C}$ and $R$ value of $42.7 \%$. The thermal conductivity of different concentration NEBL presented the increasing trend as concentration rising because the increasing amount of nano-enhancer improved heat transfer ability. However, the growth curve of thermal conductivity presented a sharp increasing first and then a slow increasing due to 'aggregation effect', which is explained in Section 5.3.3 (Fig. 29).

Except for grinding, temperature of NEBL turning presented the similar results [131]. In turning of AISI $1040[137,139]$, thermal conductivity presented a rising trend and obtained the highest value for NEBL with $1 \mathrm{vol} \%$ concentration due to the increased effective number and specific area of nano-enhancer [140, 141].

\subsubsection{Aggregation mechanism optimum concentration of} $N E B L$

The above varied tribological and thermal performances in NEBL are related with aggregation mechanism of nano-enhancer.

When an excessive particle number of nano-enhancer were introduced into NEBL, the inter-molecular forces would lead to the formation of micro clusters and reduce nano-enhancer dispersibility (Fig. 30) [142, 143].

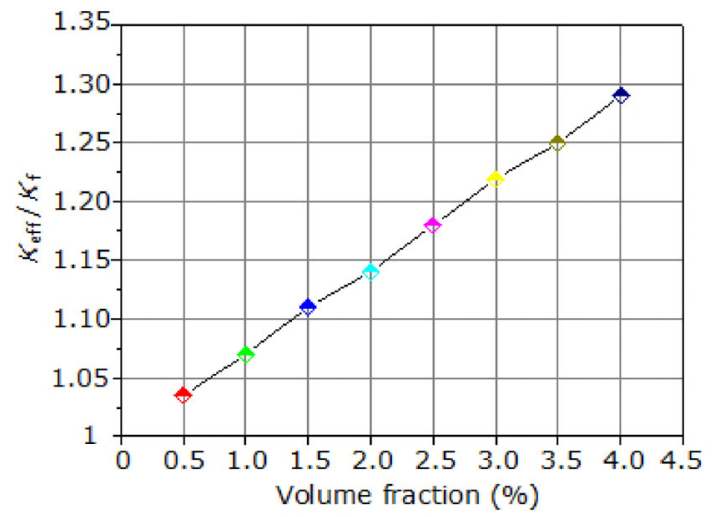

(a)

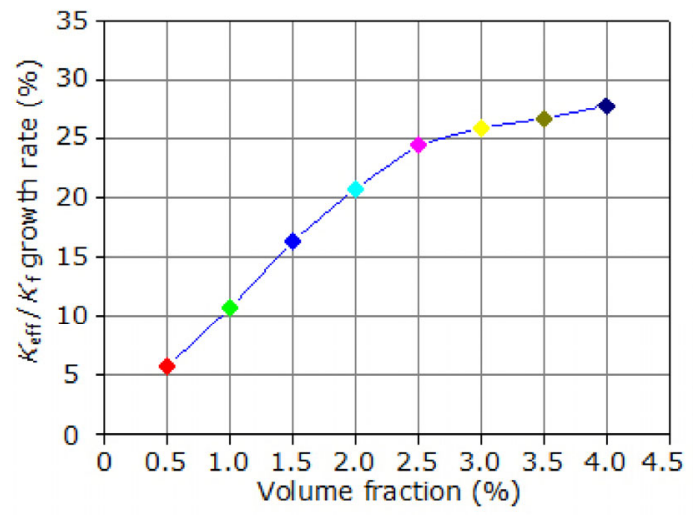

(b)

Fig. 29 Cooling-performance parameters of NEBL with different concentrations. (a) Thermal conductivity and (b) growth rate of thermal conductivity. Reproduced with permission from Ref. [138]. (c) Springer Nature, 2017.

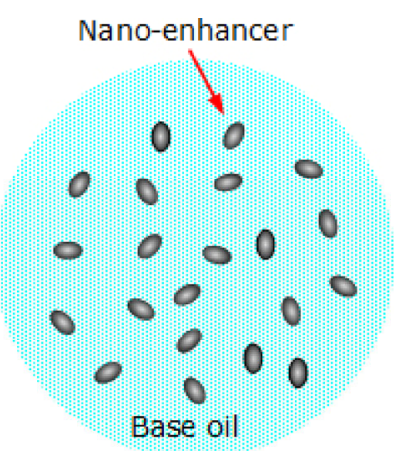

(a)

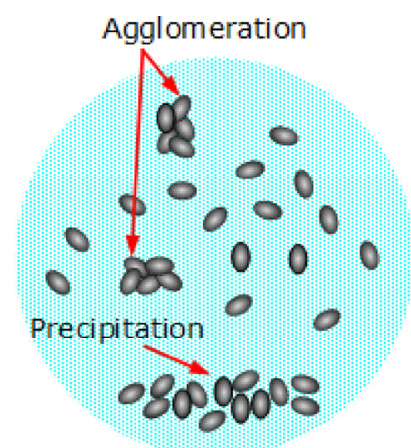

(b)
Fig. 30 Schematic diagrams of aggregation mechanism of nanoenhancer. (a) Good dispersibility with proper concentration and (b) bad dispersibility with exorbitant concentration. Reproduced with permission from Ref. [43]. (c) Elsevier, 2016.

Based on the measurement test of NEBL with different concentrations, viscosity presented the increasing trend with the reduced increasing rate (Figs. 31(a) and 31(b)). The curve of contact angle first fell and then rose (Figs. 31(c) and 31(d)) [65, 144, 145]. 


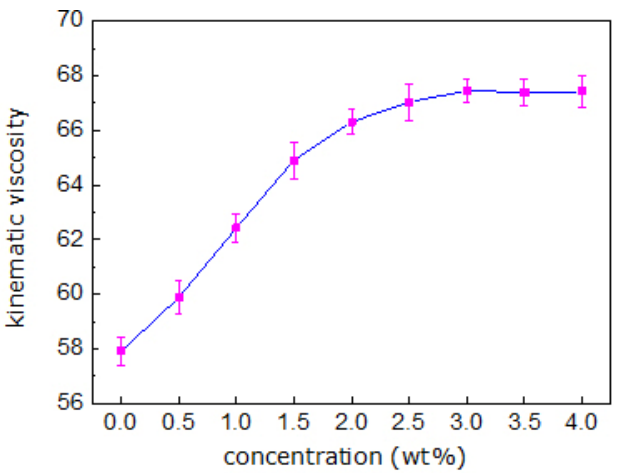

(a)

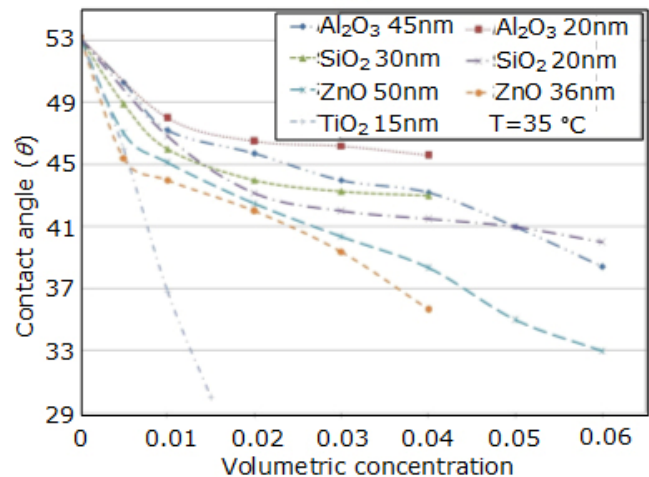

(c)

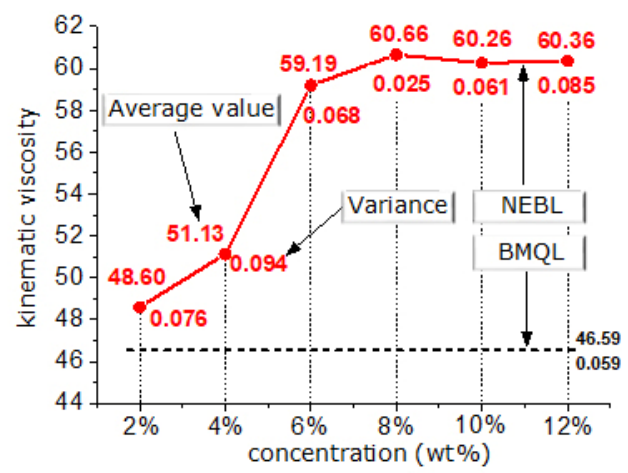

(b)

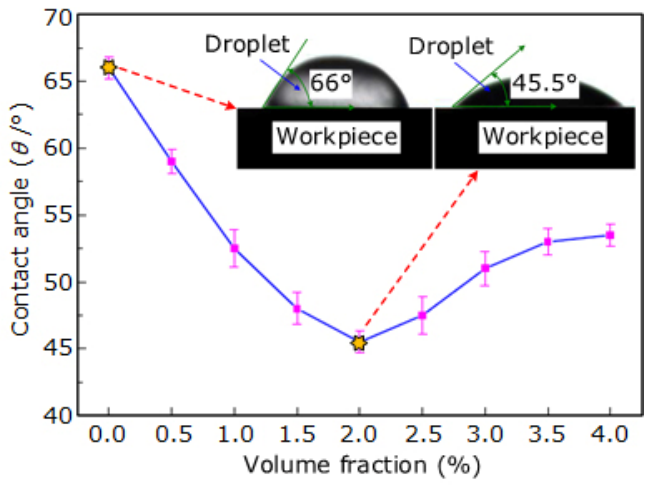

(d)

Fig. 31 Physical properties of NEBL with different concentrations. (a) Viscosity of $\mathrm{Al}_{2} \mathrm{O}_{3}-$ palm oil NEBL. Reproduced with permission from Ref. [133]. (C) Elsevier, 2017. (b) Viscosity of $\mathrm{MoS}_{2}$-soybean oil NEBL. Reproduced with permission from Ref. [43]. (C) Elsevier, 2016. (c) Contact angle of seven kinds of NEBL. Reproduced with permission from Ref. [146]. (C) Elsevier, 2014. (d) Contact angle of $\mathrm{Al}_{2} \mathrm{O}_{3}$-palm oil NEBL. Reproduced with permission from Ref. [133]. C) Elsevier, 2017.

The machining performances reached top at the inflection points for curves of viscosity and contact angle.

\subsubsection{Machined surface quality}

In comparison with other concentration values, the employment of $2.0 \%$ NEBL in NEBL grinding of Inconel718 resulted in good machined surface morphology with the small roughness value $R_{a}$ of $0.301 \mu \mathrm{m}$ (Figs. 32(a)-32(d)) [133]. The excessively high or low concentrations led to poor lubrication performances (Figs. 32(e) and 32(f)). The concentration of $8 \mathrm{wt} \%$ was confirmed as the best for $\mathrm{MoS}_{2}-\mathrm{CNTs}$ NEBL [43].

Except for grinding, $\mathrm{R}_{\mathrm{a}}$ showed a change trend of first falling and then rising in turning of AISI 1040 [137]. The employment of concentration $0.5 \mathrm{vol} \% \mathrm{MoS}_{2}-$ coconut NEBL obtained the most obvious reduction of surface roughness when compared with other NEBL with varied concentrations.

Although the machining performance could be improved obviously by increasing concentration of NEBL, there is an inflection point for concentration value. Before the inflection point, the heat transfer coefficient, viscosity, and surface tension of NEBL will change in a favorable direction. Instead, after the inflection point, the physical and chemical properties will get worse due to aggregation effect of nanoenhancers. It might become a puzzle for processing occasions with higher requirements of cooling and lubrication. This contradiction will be discussed detailly in Section 6.

\section{The limitation in coexistence between cooling and lubrication of NEBL}

Most of the current researches are focused on the application of natural plant oil and individual nano-enhancer, which exists limitation in coexistence between cooling and lubrication. Therefore, in order to improve application range for industrial application, the contradiction between good cooling and effective 

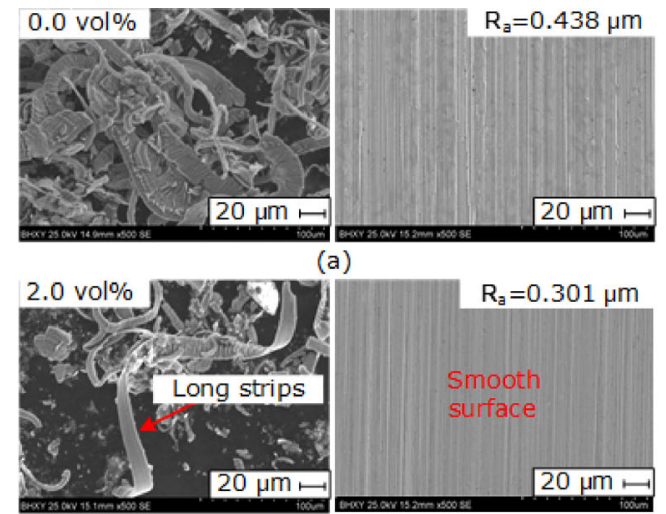

(c)

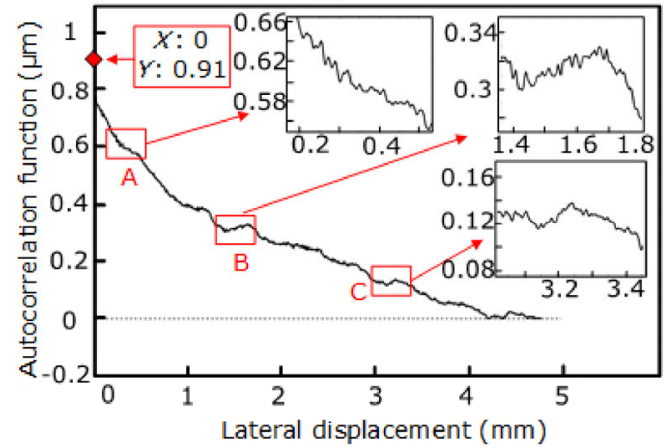

(e)

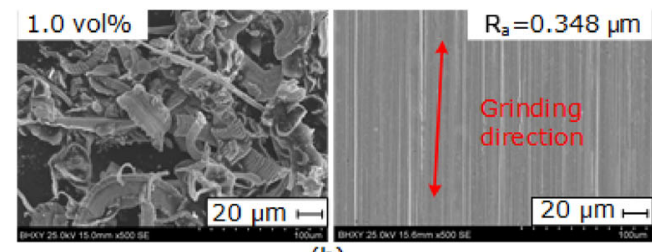

(b)

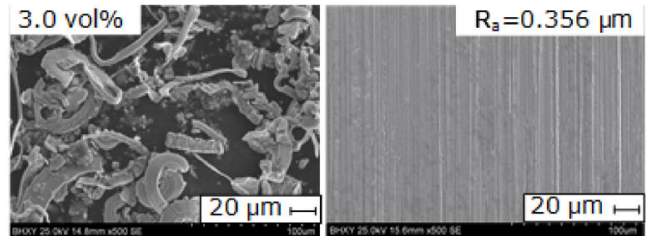

(d)

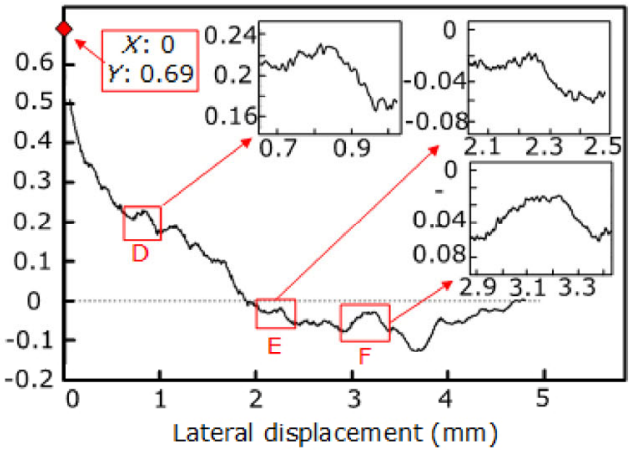

(f)

Fig. 32 SEM of debris; workpiece; and $R_{a}$ in Inconel718 NEBL grinding with employment of different concentrations of (a) 0.0 vol\%; (b) $1.0 \mathrm{vol} \%$; (c) $2.0 \mathrm{vol} \%$; and (d) $3.0 \mathrm{vol} \%$. Reproduced with permission from Ref. [133]. (C) Elsevier, 2017. Autocorrelation curve of workpiece surface profile under (e) $2 \mathrm{wt} \%$ and (f) $8 \mathrm{wt} \%$. Reproduced with permission from Ref. [43]. C Elsevier, 2016.

lubrication should be analyzed in-depth and possible solutions should be put forward by changing oil viscosity, nano-enhancer types, and nano-enhancer concentration.

\subsection{From base oil aspect}

The oils with a high viscosity have a strong absorption between molecules, and therefore the generated oil film has a high strength and good lubrication performance. However, the excessive molecule absorption would lead to less active Brownian motion, showing a reduced cooling performance.

Temperature can be considered as the compound result of both cooling and lubrication performance, because the cutting/grinding zone temperature is determined by the difference between the total generated heat and the heat cooled by NEBL. If the oil with a high viscosity is used, the lubrication performance would be enhanced and therefore less heat is generated. However, the cooling performance would be weakened as well. Therefore, there should be an optimum viscosity value to achieve a balance between cooling and lubrication performance. Especially for aerospace difficult-to-cutting materials, which requires high surface quality and no thermal damage at the same time, the coexistence between cooling and lubrication caused by viscosity must be solved in the future.

For nature plant oil, higher viscosity value is usually caused by polar groups (e.g., -OH). There is no doubt that the existence of polar groups is beneficial to film formation and lubrication behavior. In order to avoid lower heat transfer performance due to high viscosity, with this, oils with a high viscosity was mixed with oils with a low viscosity so that not only the cooling can be improved but also the special polar groups can guarantee the good lubrication performance $[147,148]$. Besides, chemical modification was also suggested to improve the viscosity [149-151].

\subsection{From nano-enhancer aspect}

The shape and thermal conductivity of nano-enhancers 
are the main factors affecting the processing performance. Spherical or stratiform geometries of nano-enhancer can provide good lubrication, thanks to regular shape and stable lubrication behavior. In contrast, the lubrication performance of tubular nanoenhancers (e.g., CNTs) is fluctuating due to the shape of CNTs is not the standard linear, which feature causes the CNTs to stumble on each other when act as a roller. Even so, CNTs have promising applications because of their thermal conductivity, which is much higher than that of other nano-enhancers.

Therefore, there is a contradiction between cooling and lubrication performance in selection of nanoenhancer. The following are several potential solutions that may become future research directions.

i) If we want to choose a single nano-enhancers with excellent cooling and lubrication properties, the stratiform graphene is the ideal choice. Layer structure of graphene is good for lubrication, while the higher thermal conductivity (higher than CNTs) is conducive to heat transfer. There have been attempts to study graphene based NEBL application in MQL and better processing property is also obtained [152]. However, its price is too high to apply in real industries [153]. Perhaps in the future, when the preparation process of graphene is improved and the production cost is significantly reduced, the application of graphene in NEBL will be broadened.

ii) The composite usage of different kind of nanoenhancers is a more economical and effective way at present. It seems like a compromise when this method was proposed, cooling and lubrication performance could be maintained at a certain level simultaneously, but not the best. What is exciting is that the lubrication mechanism has changed significantly after the mixed using and the improvement of machining performance was far greater than expected [154]. However, because there are many more possibilities for composite nanoenhancers, it is hard to predict a best mixing scheme from the limited literature.

\subsection{From concentration of NEBL aspect}

As the concentration increases, a large nano-enhancer number will participate in lubrication and cooling process therefore improves the tribological and thermal properties. However, the dispersity of nano-enhancer in plant oils is a limitation. Excessive nano-enhancer would lead to a largely increased number of nanoparticle collision during the Brownian motion, leading to cluster. Some nanoparticles deposit at surface of workpiece or tool due to cluster. Although these deposited nano-enhancer can have the lubrication function, the nano-enhancer in the base oil would be reduced. Therefore the cooling performance is weakened. With this, there should be an optimum concentration for a certain type of nano-enhancers and base oils.

Compared with the selection of base oil and the type of nano-enhancers, increasing the concentration of NEBL to improve the heat transfer performance is a more effective method. Therefore, how to improve the optimum concentration value is the focus of current and future research. To solve this, increasing the concentration and simultaneously improving the cooling performance via adding dispersants is the solution. Regarding this, alkylphenol polyoxyethylene ether 10 (APE-10) (Fig. 34) and sodium dodecyl sulfate (SDS) were found as good dispersants for CNT-based NEBL, while oleic acid is a good dispersant for $\mathrm{ZnO}$ and $\mathrm{WS}_{2}$ mixed NEBL [155-157]. More efforts are needed to find best dispersants for other NEBL.

\section{Conclusions and future challenges}

This paper comprehensively reviewed the advances of minimum quantify lubrication (MQL) technologies using nano-enhanced biolubricant (NEBL). The biodegradability of NEBL, harmlessness to nature, and more than $95 \%$ of coolant consumption save establish itself as a promising sustainable manufacturing solution with largely reduced cost and specific energy.

The key findings and possible future research can be identified as follows:

(i) The application of NEBL in MQL is an effective cleaner machining technology, showing highly improved performances including force reduction of $9 \%-62 \%$, temperature reduction of $7 \%-62 \%$, and machined surface roughness improvement of $5 \%-50 \%$, comparing with dry machining. Based on the comprehensive summaries given in this paper, this improved performances can be explained by two theories: (a) the introduction of nano-enhancer to biolubricant 
completely changed the friction state of tool-workpiece interface based on general lubrication mechanism, and (b) the Brownian motion and heat transfer channels of nano-enhancers greatly improved heat transfer performance based on general heat transfer mechanism.

However, the future research might focus on: (a) By understanding of MQL mechanism using NEBL in basic machining processing, this sustainable method could be promoted wider application to other industries such as automobile, aerospace, and ship building industries; (b) the MQL equipment relies on high pressure gas to supply micro droplets of NEBL, which may be scattered floated into the air. The cleanliness of this method is not optimal at present due to the appearance of a certain amount of oil mist in processing environment and the impact on environment and human health of nano-enhancer with small size is still a possible threat, which must be solved to realize cleaner machining. Electrostatic atomization assisted MQL maybe the possible solution in the near future, in which way oil mist dispersion may be reduced under the constraint of electric field force.

(ii) Compared with traditional metal-working fluids, NEBL can provide equal machining performance and pronouce environmental protection because the employed NBEL amount is only $1 \%-5 \%$ thanks to the improved coolant behaviors including atomization, infiltration, and film-formation performances due to unique polar groups, bigger molecular cohesion, and viscosity.

However, this green machining method is limited to conventional process parameters according to current researches. The above conclusions can provide guidance for the extended application. The future research might focus on: (a) The extended application and in-depth analysis in high-efficiency machining, which characterized by machining with extreme processing parameters; (b) solving the issues such as insufficient infiltration performance for high efficiency deep grinding, the insufficient cooling performance for material removal with high strain rate, and difficultto-machine materials machining. The hybridization between NEBL and cryogenic air, ultrasonic vibration, electrostatic atomization, atmospheric pressure plasma jet, and textured tool might be the possible solutions. (iii) Diverse plant oil types, nano-enhancer types, and different oil-particle combination and concentration would lead to varied machining performances. Special polar groups, saturated levels of fatty acids and molecular chain length for plant oils, and microscopic shape and heat conductivity coefficient for nano-enhancers would influence machining performances as well.

However, the quick optimisation of the above elements is still based on the trial and error principle, and therefore is limited by (a) the data volume is not enough to form a robust database, (b) the current mechanism analysis is qualitative, and (c) there is no economic analysis. The establishment of the cloud case library by intelligent technology might be the future solution.

(iv) Although various kinds of nano-enhancer and plant oils were attempted in preparation of NEBL, it seems difficult to find the best one which can well balance between good cooling and superior lubrication. In this paper, this bottleneck has been analyzed in-depth, which could be used as guidance for further research in sustainable manufacturing. The future solutions/research directions might include biolubricant from animal fats (come from a wide range of sources and present good thermal stability), mixed plant oils (different kinds of plant oil were mixed together to prepare new oil), and chemical-modified of plant oil (chemical-modified of $\mathrm{C}=\mathrm{C}$ bond to improve thermostability and oxidation resistance).

\section{Acknowledgements}

This study was financially supported by the National Natural Science Foundation of China (Grant Nos. 51905289 and 51975305), National Key Research and Development Plan (2020YFB2010500), Key Projects of Shandong Natural Science Foundation of China (Grant Nos. ZR2020KE027, ZR2020ME158, and ZR2019PEE008), and Major Science and Technology Innovation Engineering Projects of Shandong Province (Grant No. 2019JZZY020111).

Open Access This article is licensed under a Creative Commons Attribution 4.0 International License, which permits use, sharing, adaptation, distribution and 
reproduction in any medium or format, as long as you give appropriate credit to the original author(s) and the source, provide a link to the Creative Commons licence, and indicate if changes were made.

The images or other third party material in this article are included in the article's Creative Commons licence, unless indicated otherwise in a credit line to the material. If material is not included in the article's Creative Commons licence and your intended use is not permitted by statutory regulation or exceeds the permitted use, you will need to obtain permission directly from the copyright holder.

To view a copy of this licence, visit http://creativecommons.org/licenses/ by/4.0/.

\section{References}

[1] Luo Z W, Dubey R, Gunasekaran A, Childe S J, Papadopoulos T, Hazen B, Roubaud D. Sustainable production framework for cement manufacturing firms: A behavioural perspective. Renew Sust Energ Rev 78: 495-502 (2017)

[2] Najiha M S, Rahman M M, Yusoff A R. Environmental impacts and hazards associated with metal working fluids and recent advances in the sustainable systems: A review. Renew Sust Energ Rev 60: 1008-1031 (2016)

[3] Shokrani A, Dhokia V, Newman S T. Environmentally conscious machining of difficult-to-machine materials with regard to cutting fluids. Int J Mach Tools Manuf 57: 83-101 (2012)

[4] Jia D Z, Li C H, Wang S, Zhang Q. Investigation into distributing characteristic of suspend particulate in MQL grinding. Manufacturing Technology \& Machine Tool 02(2): $58-61$

[5] Zainal N A, Zulkifli N W M, Gulzar M, Masjuki H H. A review on the chemistry, production, and technological potential of bio-based lubricants. Renew Sust Energ Rev 82: 80-102 (2018)

[6] Xiong J, Mao J J, Wang T L, Feng W L, Wang W G, Yang C, Miao X F, Wang C W. Refiningand sulfurization of oil from black soldier fly and its application as biodegradable lubricant additive. J Am Oil Chem Soc 97(11): 1243-1251 (2020)

[7] Krolczyk G M, Maruda R W, Krolczyk J B, Nieslony P, Wojciechowski S, Legutko S. Parametric and nonparametric description of the surface topography in the dry and MQCL cutting conditions. Measurement 121: 225-239 (2018)

[8] Okafor A C, Nwoguh T O. Comparative evaluation of soybean oil-based MQL flow rates and emulsion flood cooling strategy in high-speed face milling of Inconel 718. Int J Adv Manuf Technol 107: 3779-3793 (2020)

[9] Yang M, Li C H, Zhang Y B, Wang Y G, Li B K, Jia D Z, Hou Y L, Li R Z. Research on microscale skull grinding temperature field under different cooling conditions. Appl Therm Eng 126: 525-537 (2017)

[10] Ebbrell S, Woolley N H, Tridimas Y D, Allanson D R, Rowe W B. The effects of cuttingfluid application methods on the grinding process. Int J Mach Tools Manuf 40(2): 209-223 (2000)

[11] Morgan M N, Jackson A R, Wu H, Baines-Jones V, Batako A, Rowe W B. Optimisation of fluid applicationin grinding. CIRP-Ann 57(1): 363-366 (2008)

[12] Iskandar Y, Tendolkar A, Attia M H, Hendrick P, Damir A, Diakodimitris C. Flow visualization and characterization for optimized MQL machining of composites. CIRP AnnManuf Technol 63(1): 77-80 (2014)

[13] Said Z, Gupta M, Hegab H, Arora N, Khan A M, Jamil M, Bellos E. A comprehensive review on minimum quantity lubrication (MQL) in machining processes using nano-cutting fluids. Int J Adv Manuf Technol 105(5-6): 2057-2086 (2019)

[14] Lv T, Huang S Q, Hu X D, Ma Y L, Xu X F. Tribological and machining characteristics of a minimum quantity lubrication (MQL) technology using $\mathrm{GO} / \mathrm{SiO}_{2}$ hybrid nanoparticle water-based lubricants as cutting fluids. Int J Adv Manuf Technol 96(5-8): 2931-2942 (2018)

[15] Zhang Y B, Li C H, Jia D Z, Zhang D K, Zhang X W. Experimental evaluation of the lubrication performance of $\mathrm{MoS}_{2} / \mathrm{CNT}$ nanofluid for minimal quantity lubrication in Ni-based alloy grinding. Int J Mach Tools Manuf 99: 19-33 (2015)

[16] Hemmat Esfe M, Bahiraei M, Mir A. Application of conventional and hybrid nanofluids in different machining processes: A critical review. Adv Colloid Interface Sci 282: 102199 (2020)

[17] Khan A M, Jamil M, Mia M, He N, Zhao W, Gong L. Sustainability-based performance evaluation of hybrid nanofluid assisted machining. J Clean Prod 257: 120541 (2020)

[18] He J Q, Sun J L, Meng Y N, Pei Y. Superior lubrication performance of $\mathrm{MoS}_{2}-\mathrm{Al}_{2} \mathrm{O}_{3}$ composite nanofluid in strips hot rolling. J Manuf Process 57: 312-323 (2020)

[19] Du S N, Sun J L, Wu P. Preparation, characterization and lubrication performances of graphene oxide- $\mathrm{TiO}_{2}$ nanofluid in rolling strips. Carbon 140: 338-351 (2018)

[20] Sadeghi M H, Hadad M J, Tawakoli T, Vesali A, Emami M. An investigation on surface grinding of AISI 4140 hardened steel using minimum quantity lubrication-MQL technique. Int J Mater Form 3(4): 241-251 (2010) 
[21] Jia D Z, Li C H, Zhang D K, Zhang Y B, Zhang X W. Experimental verification of nanoparticle jet minimum quantity lubrication effectiveness in grinding. J Nanopart Res 16(12): 1-15 (2014)

[22] Zhang Y B, Li C H, Jia D Z, Zhang D K, Zhang X W. Experimental evaluation of $\mathrm{MoS}_{2}$ nanoparticles in jet MQL grinding with different types of vegetable oil as base oil. J Clean Prod 87: 930-940 (2015)

[23] Zhang D K, Li C H, Jia D Z, Zhang Y B, Zhang X W. Specific grinding energy and surface roughness of nanoparticle jet minimum quantity lubrication in grinding. Chin J Aeronaut 28(2): 570-581 (2015)

[24] Mao C, Zhang J, Huang Y, Zou H F, Huang X M, Zhou Z X. Investigation on the effect of nanofluid parameters on $\mathrm{MQL}$ grinding. Mater Manuf Process 28(4): 436-442 (2013)

[25] Itoigawa F, Childs T H C, Nakamura T, Belluco W. Effects and mechanisms in minimal quantity lubrication machining of an aluminum alloy. Wear 260(3): 339-344 (2006)

[26] Sultana S, Zaman P B, Dhar N R. Performance Evaluation of different types of cutting fluid in MQL machining of alloy steel by coated carbide insert. In Proceedings of 2009 Proceedings of the International Conference on Mechanical Engineering, Dhaka, Bangladesh, 2009: 1-6.

[27] Kelly J F, Cotterell M G. Minimal lubrication machining of aluminium alloys. J Mater Process Tech 120(1): 327-334 (2002)

[28] Ramana S V, Ramji K, Satyanarayana B. Influence of nanolevel variation of solid lubricant particle size in the machining of AISI 1040 steel. Int J Mater Eng Inno 2(1): 16 (2011)

[29] Khan M M A, Mithu M A H, Dhar N R. Effects of minimum quantity lubrication on turning AISI 9310 alloy steel using vegetable oil-based cutting fluid. J Mater Process Tech 209(15): 5573-5583 (2009)

[30] Park K H, Suhaimi M A, Yang G D, Lee D Y, Lee S W, Kwon P. Milling of titanium alloy with cryogenic cooling and minimum quantity lubrication (MQL). Int J Precis Eng Manuf 18(1): 5-14 (2017)

[31] Yin Q A, Li C H, Zhang Y B, Yang M, Jia D Z, Hou Y L, Li R Z, Dong L. Spectral analysis and power spectral density evaluation in $\mathrm{Al}_{2} \mathrm{O}_{3}$ nanofluid minimum quantity lubrication milling of 45 steel. Int $J$ Adv Manuf Technol 97(1-4): 129-145 (2018)

[32] Shabgard M, Seyedzavvar M, Mohammadpourfard M. Experimental investigation into lubrication properties and mechanism of vegetable-based $\mathrm{CuO}$ nanofluid in MQL grinding. Int J Adv Manuf Technol 92: 3807-3823 (2017)

[33] Khan M M A, Dhar N R. Performance evaluation of minimum quantity lubrication by vegetable oil in terms of cutting force, cutting zone temperature, tool wear, job dimension and surface finish in turning AISI-1060 steel. $J$ Zhejiang Univ-Sc A 7(11): 1790-1799 (2006)

[34] Bruni C, Forcellese A, Gabrielli F, Simoncini M. Hard turning of an alloy steel on a machine tool with a polymer concrete bed. J Mater Process Tech 202(1-3): 493-499 (2008)

[35] Bruni C, Forcellese A, Gabrielli F, Simoncini M. Effect of the lubrication-cooling technique, insert technology and machine bed material on the workpart surface finish and tool wear in finish turning of AISI 420B. Int J Mach Tools Manuf 46(12): 1547-1554 (2006)

[36] Bonfa M M, Costa E S, Sales W F, Amorim F L, Maia L H A, Machado A R. Evaluation of tool life and workpiece surface roughness in turning of AISI D6 hardened steel using PCBN tools and minimum quantity of lubricant (MQL) applied at different directions. Int J Adv Manuf Technol 103(1-4): 971-984 (2019)

[37] Park K H, Ewald B, Kwon P Y. Effect of nano-enhanced lubricant in minimum quantity lubrication balling milling. $J$ Tribol-Trans ASME 133(3): 8 (2015)

[38] Gutnichenko O, Bushlya V, Bihagen S, Ståhl J E. Influence of $\mathrm{GnP}$ additive to vegetable oil on machining performance when MQL-assisted turning Alloy 718. Procedia Manufacturing 25: 330-337 (2018)

[39] Zhang Y B, Li C H, Yang M, Jia D Z, Wang Y G, Li B K, Hou Y L, Zhang N Q, Wu Q D. Experimental evaluation of cooling performance by friction coefficient and specific friction energy in nanofluid minimum quantity lubrication grinding with different types of vegetable oil. J Clean Prod 139: 685-705 (2016)

[40] Jia D Z, Li C H, Zhang Y B, Zhang D K, Zhang X W. Experimental research on the influence of the jet parameters of minimum quantity lubrication on the lubricating property of Ni-based alloy grinding. Int J Adv Manuf Technol 82(1-4): 617-630 (2016)

[41] Kalita P, Malshe A P, Kumar S A, Yoganath V G, Gurumurthy T. Study of specific energy and friction coefficient in minimum quantity lubrication grinding using oil-based nanolubricants. J Manuf Process 14(2): 160-166 (2012)

[42] Zhang D K, Li C H, Zhang Y B, Jia D Z, Zhang X W. Experimental research on the energy ratio coefficient and specific grinding energy in nanoparticle jet MQL grinding. Int J Adv Manuf Technol 78(5-8): 1275-1288 (2015)

[43] Zhang Y B, Li C H, Jia D Z, Li B K, Wang Y G, Yang M, Hou Y L, Zhang X W. Experimental study on the effect of nanoparticle concentration on the lubricating property of nanofluids for MQL grinding of Ni-based alloy. $J$ Mater Process Tech 232: 100-115 (2016) 
[44] Shen B, Shih A J, Xiao G X. A heat transfer model based on finite difference method for grinding. J Manuf Sci and E-T ASME 133(3): 031001 (2011)

[45] Bai X F, Dong L, Li C H, Zhang Y L. The experimental research of lubrication performance in nanofluid minimum quantity lubrication (MQL) milling. Modular Mach Tool Autom Manuf Tech 530(4): 15-18 (2018)

[46] Ueda T, Hosokawa A, Yamada K. Effect of oil mist on tool temperature in cutting. J Manuf Sci Eng 1(128): 130-135 (2006)

[47] Yang M, Li C H, Zhang Y B, Wang Y G, Li B K, Hou Y L. Experimental research on microscale grinding temperature under different nanoparticle jet minimum quantity cooling. Mater Manuf Process 32(6): 589-597 (2017)

[48] Shen B, Shih A J. Minimum quantity lubrication (MQL) grinding using vitrified CBN wheels. Trans Namri/Sme 37: 131-136 (2009)

[49] Li C H, Zhang D K, Jia D Z, Wang S, Hou Y L. Experimental evaluation on tribological properties of nano-particle jet MQL grinding. Int J Surf Sci Eng 9(2-3): 159-175 (2015)

[50] Shen B, Shih A J, Tung S C. Application of nanofluids in minimum quantity lubrication grinding. Tribol Trans 51(6): 730-737 (2008)

[51] Yang M. Medical thermodynamic mechanism and temperature field dynamic model of bio-bone micro-grinding with nanoparticle jet sparay cooling. Ph.D Thesis. Qingdao (China): Qingdao Universityof Technology, 2019.

[52] Cui W Z, Bai M L, Lv J Z, Zhang L, Li G J, Xu M. On the flow characteristics of nanofluids by experimental approach and molecular dynamics simulation. Exp Therm Fluid Sci 39: 148-157 (2012)

[53] Liu G T, Li C H, Zhang Y B, Yang M, Jia D Z, Zhang X P, Guo S M, Li R Z, Zhai H. Process parameter optimization and experimental evaluation for nanofluid MQL in grinding Ti-6Al-4V based on grey relational analysis. Mater Manuf Process 33(9): 950-963 (2018)

[54] Joshi K K, Behera R K, Anurag. Effect of minimum quantity lubrication with $\mathrm{Al}_{2} \mathrm{O}_{3}$ nanofluid on surface roughness and its prediction using hybrid fuzzy controller in turning operation of Inconel 600. Mater Today: Proceedings 5(9): 20660-20668 (2018)

[55] Anand K N, Mathew J. Evaluation of size effect and improvement in surface characteristics using sunflower oil-based MQL for sustainable micro-endmilling of Inconel 718. J Braz Soc Mech Sci Eng 42(4): 13 (2020)

[56] Rao C M, Rao S S, Herbert M A. Influence of modified cutting inserts in machining of Ti-6Al-4V alloy using PCD insert. Mater Today: Proceedings 5(9): 18426-18432 (2018)
[57] Rahim E A, Sasahara H. A study of the effect of palm oil as MQL lubricant on high speed drilling of titanium alloys. Tribol Int 44(3): 309-317 (2011)

[58] Obikawa T, Kamata Y, Shinozuka J. High-speed grooving with applying MQL. Int J Mach Tools Manuf 46(14): 18541861 (2006)

[59] Singh T, Dureja J S, Dogra M, Bhatti M S. Environment friendly machining of inconel 625 under nano-fluid minimum quantity lubrication (NMQL). Int J Precis Eng Manuf 19(11): 1689-1697 (2018)

[60] Wu W T, Li C H, Yang M, Zhang Y B, Jia D Z, Hou Y L, Li R Z, Cao H J, Han Z G. Specific energy and G ratio of grinding cemented carbide under different cooling and lubrication conditions. Int J Adv Manuf Technol 105(1-4): 67-82 (2019)

[61] Wang Y G, Li C G, Zhang Y B, Li B K, Yang M, Zhang X P, Guo S M, Liu G T, Zhai M G. Comparative evaluation of the lubricating properties of vegetable-oil-based nanofluids between frictional test and grinding experiment. J Manuf Process 26: 94-104 (2017)

[62] Hu Z M. Study on Tribology of Hydroxy and Sulfurized Vegetable Oil fatty acids. Ph.D Thesis. Shanghai (China): Shanghai University, 1999.

[63] Sani A S A, Abd Rahim E, Sharif S, Sasahara H. Machining performance of vegetable oil with phosphonium- and ammonium-based ionic liquids via MQL technique. J Clean Prod 209: 947-964 (2019)

[64] Zhou Z. Tool wear in titanium alloy turning under nanofluids minimum quantity lubrication, M.S Thesis. Harbin (China): Harbin Institute of Technology, 2018.

[65] Belgharza M, Ihihi A, Najih Y, M. Alaoui El Belghiti M A E B. Comparative study of chemical physical properties of vegetable oils (surface tension and viscosity). Der Pharma Chemica 10(7): 50-54 (2015)

[66] Krahenbuhl U. Vegetable oil-based coolants improve cutting performance. Tooling \& Production 68(12): 34-35 (2002)

[67] Lovell M, Higgs C F, Deshmukh P, Mobley A. Increasing formability in sheet metal stamping operations using environmentally friendly lubricants. J Mater Process Tech 177(1-3): 87-90 (2006)

[68] Kalita P, Malshe A P, Jiang W, Nanomech A J S. Tribological study of nano lubricant integrated soybean oil for minimum quantity lubrication (MQL) grinding. Trans Namri/Sme 38: 137-144 (2010)

[69] Talib N, Sasahara H, Rahim E A. Evaluation of modified jatropha-based oil with hexagonal boron nitride particle as a biolubricant in orthogonal cutting process. Int J Adv Manuf Technol 92(1-4): 371-391 (2017) 
[70] Fox N J, Tyrer B, Stachowiak G W. Boundary lubrication performance of free fatty acids in sunflower oil. Tribol Lett 16(4): 275-281 (2004)

[71] Jia D Z, Li C H, Zhang Y B, Yang M, Wang Y G, Guo S M, Cao H J. Specific energy and surface roughness of minimum quantity lubrication grinding Ni-based alloy with mixed vegetable oil-based nanofluids. Precis Eng 50: 248-262 (2017)

[72] Wang Y G, Li C H, Zhang Y B, Yang M, Li B K, Jia D Z, Hou Y L, Mao C. Experimental evaluation of the lubrication properties of the wheel/workpiece interface in minimum quantity lubrication (MQL) grinding using different types of vegetable oils. J Clean Prod 127: 487-499 (2016)

[73] Talib N, Rahim E A. Performance evaluation of chemically modified crude jatropha oil as a bio-based metalworking fluids for machining process. Procedia Cirp 26: 346-350 (2015)

[74] Rahim E A, Sasahara H. An analysis of surface integrity when drilling inconel 718 using palm oil and synthetic ester under MQL condition. Mach Sci Technol 15(1): 76-90 (2011)

[75] Yuan S M, Hou X B, Wang L, Chen B C. Experimental investigation on the compatibility of nanoparticles with vegetable oils for nanofluid minimum quantity lubrication machining. Tribol Lett 66(3): 106-115 (2018)

[76] Dong L, Li C H, Bai X F, Yin Q A, Sun P. Cooling performance analysis based on minimum quantity lubrication milling with $\mathrm{Al}_{2} \mathrm{O}_{3}$ nanoparticle. Manuf Technol Mach Tool 675(9): 137-141 (2018)

[77] Mao C, Zhang M J, Zhang J, Tang K, Gan H Y, Zhang G F. The effect of processing parameters on the performance of spark plasma sintered cBN-WC-Co composites. J Mater Eng Perform 24(12): 4612-4619 (2015)

[78] Zhang Y B, Li C H, Zhang Q, Jia D Z, Wang S, Zhang D K, Mao C. Improvement of useful flow rate of grinding fluid with simulation schemes. Int J Adv Manuf Technol 84(9-12): 2113-2126 (2016)

[79] Gajrani K K, Suvin P S, Kailas S V, Sankar M R. Thermal, rheological, wettability and hard machining performance of $\mathrm{MoS}_{2}$ and $\mathrm{CaF}_{2}$ based minimum quantity hybrid nanogreen cutting fluids. J Mater Process Tech 266: 125-139 (2019)

[80] Rahim E A, Dorairaju H. Evaluation of mist flow characteristic and performance in minimum quantity lubrication (MQL) machining. Measurement 123: 213-225 (2018)

[81] Tawakoli T, Hadad M J, Sadeghi M H, Daneshi A, Stockert S, Rasifard A. An experimental investigation of the effects of workpiece and grinding parameters on minimum quantity
lubrication-MQL grinding. Int J Mach Tools Manuf 49(12-13): 924-932 (2009)

[82] Virdi R L, Chatha S S, Singh H. Experiment evaluation of grinding properties under $\mathrm{Al}_{2} \mathrm{O}_{3}$ nanofluids in minimum quantity lubrication. Mater Res Express 6(9): 8 (2019)

[83] Agrawal S M, Patil N G. Experimental study of non edible vegetable oil as a cutting fluid in machining of M2 Steel using MQL. J Procedia Manufacturing 20: 207-212 (2018)

[84] Bai X F, Zhou F M, Li C H, Dong L, Lv X J, Yin Q G. Physicochemical properties of degradable vegetable-based oils on minimum quantity lubrication milling. Int $J A d v$ Manuf Technol 106(9-10): 4143-4155 (2020)

[85] Araujo A S, Sales W F, da Silva R B, Costa E S, Machado A R. Lubri-cooling and tribological behavior of vegetable oils during milling of AISI 1045 steel focusing on sustainable manufacturing. J Clean Prod 156: 635-647 (2017)

[86] Sivaraman V, Prakash S. Performance and evaluation of $\mathrm{MoS}_{2}$ based machining using PVD-TiAlN coated tool. J Mech Sci Technol 33(9): 4383-4388 (2019)

[87] Guo S M, Li C H, Zhang Y B, Wang Y G, Li B K, Yang M, Zhang X P, Liu G T. Experimental evaluation of the lubrication performance of mixtures of castor oil with other vegetable oils in MQL grinding of nickel-based alloy. $J$ Clean Prod 140: 1060-1076 (2017)

[88] Sharma B K, Adhvaryu A, Erhan S Z. Friction and wear behavior of thioether hydroxy vegetable oil. Tribol Int 42(2): 353-358 (2009)

[89] Nguyen T, Nguyen D, Howes P, Kwon P, Park K H, Minimum quantity lubrication (MQL) using vegetable oil with nano-platelet solid lubricant in milling titanium alloy. In International Manufacturing Science and Engineering Conference, Charlotte, USA, 2015: 1-10.

[90] P. A G. Oil-soluble friction reducers-theory and application. Lubr Eng 39(7): 419-426 (1983)

[91] Allawzi M, Abu-Arabi M K, Al-zoubi H S, Tamimi A. Physicochemical characteristics and thermal stability of Jordanian jojoba oil. J Am Oil Chem Soc 75(1): 57-62 (1998)

[92] Babu M N, Anandan V, Muthukrishnan N, Santhanakumar M. End milling of AISI 304 steel using minimum quantity lubrication. Measurement 138: 681-689 (2019)

[93] Li B K, Li C H, Zhang Y B, Wang Y G, Jia D Z, Min Y. Grinding temperature and energy ratio coefficient in $\mathrm{MQL}$ grinding of high-temperature nickel-base alloy by using different vegetable oils as base oil. Chin J Aeronaut 29(4): 1084-1095 (2016)

[94] Okafor A C, Nwoguh T O. A study of viscosity and thermal conductivity of vegetable oils as base cutting fluids for minimum quantity lubrication machining of difficult-to-cut 
metals. Int $J$ Adv Manuf Technol 106(3-4): 1121-1131 (2020)

[95] Zhong W W. Little quantity lubricant cooling mechanisms under condition of liquid forced convection based on prandtl boundary layer theory. Lubr Eng 39(9): 79-82 (2014)

[96] Su Y, Gong L, Li B, Liu Z Q, Chen D D. Performance evaluation of nanofluid MQL with vegetable-based oil and ester oil as base fluids in turning. Int $J$ Adv Manuf Technol 83(9-12): 2083-2089 (2016)

[97] Sai S S, ManojKumar K, Ghosh A. Assessment of spray quality from an external mix nozzle and its impact on SQL grinding performance. Int J Mach Tools Manuf 89: 132-141 (2015)

[98] Li B K, Li C H, Zhang Y B, Wang Y G, Yang M, Jia D Z, Zhang N Q, Wu Q D, Ding W F. Numerical and experimental research on the grinding temperature of minimum quantity lubrication cooling of different workpiece materials using vegetable oil-based nanofluids. Int $J$ Adv Manuf Technol 93(5-8): 1971-1988 (2017)

[99] Vasu V, Pradeep Kumar Reddy G. Effect of minimum quantity lubrication with $\mathrm{Al}_{2} \mathrm{O}_{3}$ nanoparticles on surface roughness, tool wear and temperature dissipation in machining Inconel 600 alloy. Proc I Mech Eng Part N-J Nano 225(1): 3-16 (2017)

[100] Nguyen T K, Kwon P Y, Park K H. A critical factor in enhancement of MQL lubricants: Platelet thickness. In ASME 2013 International Manufacturing Science and Engineering Conference collocated with the 41st North American Manufacturing Research Conference, Madison, USA, 2013: 1-9.

[101] Awale A S, Srivastava A, Vashista M, Yusufzai M Z K. Influence of minimum quantity lubrication on surface integrity of ground hardened $\mathrm{H} 13$ hot die steel. Int $J A d v$ Manuf Technol 100(1-4): 983-997 (2019)

[102] Li M, Yu T B, Zhang R C, Yang L, Li H Y, Wang W S. MQL milling of TC4 alloy by dispersing graphene into vegetable oil-based cutting fluid. Int J Adv Manuf Technol 99(5-8): 1735-1753 (2018)

[103] Nurul Adlina M J, Kamaleshwaran T, Ahamd Fairuz M, Azwan I A. A study of surface roughness \& surface integrity in drilling process using various vegetable-oil Based lubricants In minimum quantity lubrication. $A J B A S$ 8(15): 191-197 (2014)

[104] Wang Y G, Li C H, Zhang Y B, Li B K, Yang M, Zhang X P, Guo S M, Liu G T. Experimental evaluation of the lubrication properties of the wheel/workpiece interface in MQL grinding with different nanofluids. Tribol Int 99: 198-210 (2016)
[105] Zhang X P, Li C H, Zhang Y B, Jia D Z, Li B K, Wang Y G, Yang M, Hou Y L, Zhang X W. Performances of $\mathrm{Al}_{2} \mathrm{O}_{3} / \mathrm{SiC}$ hybrid nanofluids in minimum-quantity lubrication grinding. Int J Adv Manuf Technol 86(9-12): 3427-3441 (2016)

[106] Zhang X P, Li C H, Zhang Y B, Wang Y G, Li B K, Yang M, Guo S M, Liu G T, Zhang N Q. Lubricating property of MQL grinding of $\mathrm{Al}_{2} \mathrm{O}_{3} / \mathrm{SiC}$ mixed nanofluid with different particle sizes and microtopography analysis by cross-correlation. Precis Eng 47: 532-545 (2017)

[107] Yin Q A, Li C H, Dong L, Bai X F, Zhang Y B, Yang M, Jia D Z, Hou Y L, Liu Y H, Li R Z. Effects of the physicochemical properties of different nanoparticles on lubrication performance and experimental evaluation in the NMQL milling of Ti-6Al-4V. Int J Adv Manuf Technol 99(9-12): 3091-3109 (2018)

[108] Das A, Patel S K, Das S R. Performance comparison of vegetable oil based nanofluids towards machinability improvement in hard turning of HSLA steel using minimum quantity lubrication. Mech Ind 20(5): 20 (2019)

[109] Das A, Patel S K, Biswal B B, Sahoo N, Pradhan A. Performance evaluation of various cutting fluids using MQL technique in hard turning of AISI 4340 alloy steel. Measurement 150: 28 (2020)

[110] Talib N, Rahim E A. Performance of modified jatropha oil in combination with hexagonal boron nitride particles as a bio-based lubricant for green machining. Tribol Int 118: 89-104 (2018)

[111] Sharma A K, Katiyar J K, Bhaumik S, Roy S. Influence of alumina/MWCNT hybrid nanoparticle additives on tribological properties of lubricants in turning operations. Friction 7(2): 153-168 (2019)

[112] Lv T, Huang S Q, Hu X D, Ma Y L, Xu X F. Tribological and machining characteristics of a minimum quantity lubrication (MQL) technology using $\mathrm{GO} / \mathrm{SiO}_{2}$ hybrid nanoparticle water-based lubricants as cutting fluids. Int $J$ Adv Manuf Technol 96(5-8): 2931-2942 (2018)

[113] Ali M, Khalil A, Azmi A I, Salleh H M, Ali M, Khalil A, Azmi A I, Salleh H M. The effects of the size of $\mathrm{Al}_{2} \mathrm{O}_{3}$ particles in nanolubricant with added SDBS on surface roughness and tool wear during turning of mild steel. In AIP Conference Series-3rd Electronic and Green Materials International Conference, Krabi, Thailand, 2017: 020101.

[114] Lee K, Hwang Y, Cheong S, Choi Y, Kwon L, Lee J, Kim $\mathrm{S} \mathrm{H}$. Understanding the role of nanoparticles in nano-oil lubrication. Tribol Lett 35(2): 127-131 (2009)

[115] Duan Z J, Yin Q G, Li C H, Dong L, Bai X F, Zhang Y B, Yang M, Jia D Z, Li R Z, Liu Z Q. Milling force and 
surface morphology of 45 steel under different $\mathrm{Al}_{2} \mathrm{O}_{3}$ nanofluid concentrations. Int J Adv Manuf Technol 107(3-4): 1277-1296 (2020)

[116] Cui X, Li C H, Zhang Y B, Jia D Z, Zhao Y J, Li R Z, Cao H J. Tribological properties under the grinding wheel and workpiece interface by using graphene nanofluid lubricant. Int J Adv Manuf Technol 104(9-12): 3943-3958 (2019)

[117] Xie H M, Jiang B, Liu B, Wang Q H, Xu J Y, Pan F S. An Investigation on the tribological performances of the $\mathrm{SiO}_{2} /$ $\mathrm{MoS}_{2}$ hybrid nanofluids for magnesium alloy-steel contacts. Nanoscale Res Lett 11(1): 329 (2016)

[118] Gupta M K, Jamil M, Wang X J, Song Q H, Liu Z Q, Mia M, Hegab H, Khan A M, Collado A G, Pruncu C I, Imran G M S. Performance evaluation of vegetable oil-based nano-cutting fluids in environmentally friendly machining of inconel-800 alloy. Materials 12(17): 20 (2019)

[119] Xiong S, Liang D, Wu H, Lin W, Chen J S, Zhang B S. Preparation, characterization, tribological and lubrication performances of Eu doped $\mathrm{CaWO}_{4}$ nanoparticle as antiwear additive in water-soluble fluid for steel strip during hot rolling. Appl Surf Sci 539: 148090 (2021)

[120] Li B K, Li C H, Zhang Y B, Wang Y G, Jia D Z, Yang M, Zhang N Q, Wu Q D, Han Z G, Sun K. Heat transfer performance of MQL grinding with different nanofluids for Ni-based alloys using vegetable oil. J Clean Prod 154: 1-11 (2017)

[121] Thakur A, Manna A, Samir S. Experimental investigation of nanofluids in minimum quantity lubrication during turning of EN-24 steel. Proc Inst Mech Eng Part J-J Eng Tribol 234(5): 712-729 (2020)

[122] Sharma A K, Singh R K, Dixit A R, Tiwari A K. Novel uses of alumina- $\mathrm{MoS}_{2}$ hybrid nanoparticle enriched cutting fluid in hard turning of AISI 304 steel. J Manuf Process 30: 467-482 (2017)

[123] Sharma A K, Tiwari A K, Dixit A R. Prediction of temperature distribution over cutting tool with aluminaMWCNT hybrid nanofluid using computational fluid dynamics (CFD) analysis. Int J Adv Manuf Technol 97(1-4): 427-439 (2018)

[124] Singh R K, Sharma A K, Dixit A R, Tiwari A K, Pramanik A, Mandal A. Performance evaluation of aluminagraphene hybrid nano-cutting fluid in hard turning. $J$ Clean Prod 162: 830-845 (2017)

[125] Khan A M, Anwar S, Jamil M, Nasr M M, Gupta M K, Saleh M, Ahmad S, Mia M. Energy, environmental, economic, and technological analysis of Al-GnP nanofluidand cryogenic LN2-assisted sustainable machining of Ti-6Al-4V alloy. Metals 11(1): 88 (2021)
[126] Khan A M, Gupta M K, Hegab H, Jamil M, Mia M, He N, Song Q H, Liu Z Q, Pruncu C I. Energy-based cost integrated modelling and sustainability assessment of Al-GnP hybrid nanofluid assisted turning of AISI52100 steel. J Clean Prod 257: 120502 (2020)

[127] Yang M, Li C H, Zhang Y B, Jia D Z, Li R Z, Hou Y L, Cao H J, Wang J. Predictive model for minimum chip thickness and size effect in single diamond grain grinding of zirconia ceramics under different lubricating conditions. Ceram Int 45(12): 14908-14920 (2019)

[128] Maheshwary P B, Handa C C, Nernade K R. A comprehensive study of effect of concentration, particle size and particle shape on thermal conductivity of titania/water based nanofluid. Appl Therm Eng 119: 79-88 (2017)

[129] Kumar A, Ghosh S, Aravindan S. Experimental investigations on surface grinding of silicon nitride subjected to mono and hybrid nanofluids. Ceram Int 45(14): 17447-17466 (2019)

[130] Shen B, Kalita P, Malshe A P, Shih A J. Performance of novel $\mathrm{MoS}_{2}$ nanoparticles based grinding fluids in minimum quantity lubrication grinding. Trans NAMRI/SME 36: 357-364 (2008)

[131] Krishna P V, Srikant R R, Rao D N. Experimental investigation on the performance of nanoboric acid suspensions in SAE-40 and coconut oil during turning of AISI 1040 steel. Int J Mach Tools Manuf 50(10): 911-916 (2010)

[132] Choi C, Jung M, Choi Y, Lee J, Oh J. Tribological properties of lubricating oil-based nanofluids with metal/carbon nanoparticles. J Nanosci Nanotechnol 11(1): 368-371 (2011)

[133] Wang Y G, Li C H, Zhang Y B, Yang M, Zhang X P, Zhang N Q, Dai J J. Experimental evaluation on tribological performance of the wheel/workpiece interface in minimum quantity lubrication grinding with different concentrations of $\mathrm{Al}_{2} \mathrm{O}_{3}$ nanofluids. J Clean Prod 142: 3571-3583 (2017)

[134] Singh H, Sharma V S, Dogra M. Exploration of graphene assisted vegetables oil based minimum quantity lubrication for surface grinding of Ti-6AL-4V-ELI. Tribol Int 144: 13 (2020)

[135] Li M, Yu T B, Zhang R C, Yang L, Ma Z L, Li B C, Wang $\mathrm{X}$ Z, Wang W S, Zhao J. Experimental evaluation of an eco-friendly grinding process combining minimum quantity lubrication and graphene-enhanced plant-oil-based cutting fluid. J Clean Prod 244: 13 (2020)

[136] Sen B, Mia M, Gupta M K, Rahman M A, Mandal U K, Mondal S P. Influence of $\mathrm{Al}_{2} \mathrm{O}_{3}$ and palm oil-mixed nanofluid on machining performances of Inconel-690: IF-THEN rules-based FIS model in eco-benign milling. Int $J A d v$ Manuf Technol 103(9-12): 3389-3403 (2019) 
[137] Padmini R, Krishna P V, Rao G K M. Effectiveness of vegetable oil based nanofluids as potential cutting fluids in turning AISI 1040 steel. Tribol Int 94: 490-501 (2016)

[138] Li B K, Li C H, Zhang Y B, Wang Y G, Yang M, Jia D Z, Zhang N Q, Wu Q D. Effect of the physical properties of different vegetable oil-based nanofluids on MQLC grinding temperature of Ni-based alloy. Int J Adv Manuf Technol 89(9-12): 3459-3474 (2017)

[139] Padmini R, Krishna P V, Rao G K M. Experimental evaluation of nano-molybdenum disulphide and nano-boric acid suspensions in vegetable oils as prospective cutting fluids during turning of AISI 1040 steel. Proc Inst Mech Eng Part J-J Eng Tribol 230(5): 493-505 (2016)

[140] Wang X Q, Mujumdar A S. A review on nanofluids-Part I: Theoretical and numerical investigations. Braz J Chem Eng 25(4): 613-630 (2008)

[141] Chieruzzi M, Cerritelli G F, Miliozzi A, Kenny J M. Effect of nanoparticles on heat capacity of nanofluids based on molten salts as PCM for thermal energy storage. Nanoscale Res Lett 8: 9 (2013)

[142] Demas N G, Timofeeva E V, Routbort J L, Fenske G R. Tribological effects of $\mathrm{BN}$ and $\mathrm{MoS}_{2}$ nanoparticles added to polyalphaolefin oil in piston skirt/cylinder liner tests. Tribol Lett 47(1): 91-102 (2012)

[143] Haddad Z, Abid C, Rahli O, Margeat O, Dachraoui W, Mataoui A. Is it important to measure the volumetric mass density of nanofluids? IJET 8(2): 310-313 (2014)

[144] Das S K, Putra N, Roetzel W. Pool boiling characteristics of nano-fluids. Int J Heat Mass Transf 46(5): 851-862 (2003)

[145] Nguyen T K, Do I, Kwon P. A tribological study of vegetable oil enhanced by nano-platelets and implication in MQL machining. Int J Precis Eng Manuf 13(7): 1077-1083 (2012)

[146] Chinnam J, Das D, Vajjha R, Satti J. Measurements of the contact angle of nanofluids and development of a new correlation. Int Commun Heat Mass Transf 62: 1-12 (2015)

[147] Guo S M, Li C H, Zhang Y B, Yang M, Jia D Z, Zhang X P, Liu G T, Li R Z, Bing Z R, Ji H J. Analysis of volume ratio of castor/soybean oil mixture on minimum quantity lubrication grinding performance and microstructure

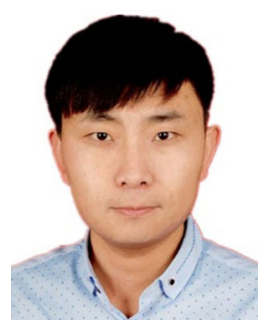

Yanbin ZHANG. He is a professor of Qingdao University of Technology (QUT). He received his Ph.D. degree from QUT in 2018. His current research interests focus on evaluation by fractal dimension. Ind Crop Prod 111: 494-505 (2018)

[148] Katna R, Suhaib M, Agrawal N. Nonedible vegetable oil-based cutting fluids for machining processes-A review. Mater Manuf Process 35(1): 1-32 (2020)

[149] Talib N, Rahim E A. The effect of tribology behavior on machining performances when using bio-based lubricant as a sustainable metalworking fluid. Procedia CIRP 40: 504-508 (2016)

[150] Politi J R D, de Matos P R R, Sales M J A. Comparative study of the oxidative and thermal stability of vegetable oils to be used as lubricant bases. $J$ Therm Anal Calorim 111(2): 1437-1442 (2013)

[151] Liu Z S, Sharma B K, Erhan S Z, Biswas A, Wang R P, Schuman T P. Oxidation and low temperature stability of polymerized soybean oil-based lubricants. Thermochim Acta 601: 9-16 (2015)

[152] Singh H, Sharma V S, Singh S, Dogra M. Nanofluids assisted environmental friendly lubricating strategies for the surface grinding of titanium alloy: Ti6Al4V-ELI. $J$ Manuf Process 39: 241-249 (2019)

[153] Hosseini S F, Emami M, Sadeghi M H. An experimental investigation on the effects of minimum quantity nano lubricant application in grinding process of Tungsten carbide. J Manuf Process 35: 244-253 (2018)

[154] Jamil M, Khan A M, Hegab H, Gong L, Mia M, Gupta M $\mathrm{K}, \mathrm{He} \mathrm{N}$. Effects of hybrid $\mathrm{Al}_{2} \mathrm{O}_{3}-\mathrm{CNT}$ nanofluids and cryogenic cooling on machining of Ti-6Al-4V. Int J Adv Manuf Technol 102(9-12): 3895-3909 (2019)

[155] Gao T, Li C H, Zhang Y B, Yang M, Jia D Z, Jin T, Hou Y L, Li R Z. Dispersing mechanism and tribological performance of vegetable oil-based CNT nanofluids with different surfactants. Tribol Int 131: 51-63 (2019)

[156] Duan W H, Wang Q, Collins F. Dispersion of carbon nanotubes with SDS surfactants: A study from a binding energy perspective. Chem Sci 2(7): 1407-1413 (2011)

[157] Guo J X, Barber G C, Schall D J, Zou Q, Jacob S B. Tribological properties of $\mathrm{ZnO}$ and $\mathrm{WS}_{2}$ nanofluids using different surfactants. Wear 382: 8-14 (2017)

intelligent and clean precision manufacturing. He has published 35 papers, including in International Journal of Machine Tools and Manufacture and Journal of Materials Processing Technology. Among them, one is ESI hot paper and three are ESI highly cited papers. 


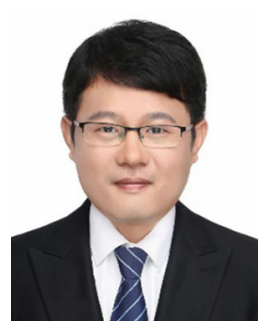

Hao Nan LI. He is an associate professor at University of Nottingham Ningbo China. He is a research affiliate of the International Academy for Production Engineering (CIRP). He received his Ph.D. degree from Northeastern University (China).

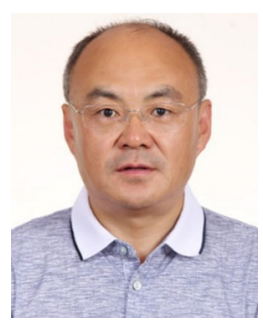

Changhe LI. He is a professor of QUT. He is a Special Expert of Taishan Scholars in Shandong Province, China. He received his Ph.D. degree from Northeastern University in 2006. His current

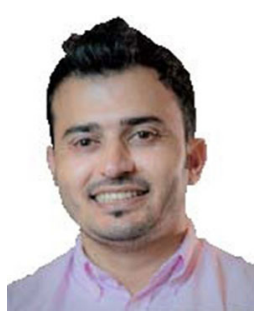

Zafar SAID. He is an assistant professor of Department of Sustainable and Renewable Energy Engineering (SREE) at University of Sharjah. He received his Ph.D. degree from
His current research interests focus on advanced and intelligent manufacturing and automation. Until June 2021, he has published 52 SCI-indexed articles on top journals in manufacturing engineering (42 out of 52 in Journal Citation Report Q1 journals) with the total citations of 1,050 including 6 ESI highly-cited papers and 2 ESI hot papers.

research interests focus on intelligent and clean precision manufacturing. He has published $153 \mathrm{SCI} / \mathrm{EI}$ papers and won the China Patent Excellence Award (2 items), Shandong Province Technical Invention 1st Prize.

University of Malaya in 2014. He works in the field of renewable energy, energy and exergy analysis, solar energy, heat transfer, nanofluids, underhood thermal management and active thermography, and $3 \mathrm{D}$ printing. 